Florida International University FIU Digital Commons

FIU Electronic Theses and Dissertations

University Graduate School

$12-3-2014$

\title{
Understanding Ten-Eleven Translocation-2 in Hematological and Nervous Systems
}

Feng Pan

fpan001@fiu.edu

DOI: $10.25148 /$ etd.FI15032103

Follow this and additional works at: https://digitalcommons.fiu.edu/etd

Part of the Biochemistry Commons, Bioinformatics Commons, Cancer Biology Commons, $\underline{\text { Cell }}$ Biology Commons, Genetics Commons, Hemic and Lymphatic Diseases Commons, Molecular and Cellular Neuroscience Commons, Molecular Biology Commons, and the Nervous System Diseases Commons

\section{Recommended Citation}

Pan, Feng, "Understanding Ten-Eleven Translocation-2 in Hematological and Nervous Systems" (2014). FIU Electronic Theses and Dissertations. 1925.

https://digitalcommons.fiu.edu/etd/1925

This work is brought to you for free and open access by the University Graduate School at FIU Digital Commons. It has been accepted for inclusion in FIU Electronic Theses and Dissertations by an authorized administrator of FIU Digital Commons. For more information, please contact dcc@fiu.edu. 


\section{FLORIDA INTERNATIONAL UNIVERSITY}

Miami, Florida

UNDERSTANDING TEN-ELEVEN TRANSLOCATION-2 IN HEMATOLOGICAL AND NERVOUS SYSTEMS

A dissertation submitted in partial fulfillment of the requirements for the degree of

DOCTOR OF PHILOSOPHY

in

BIOLOGY

by

Feng Pan

2015 
To: Dean Michael R. Heithaus

College of Arts and Sciences

This dissertation, written by Feng Pan, and entitled Understanding Ten-Eleven Translocation-2 in Hematological and Nervous Systems, having been approved in respect to style and intellectual content, is referred to you for judgment.

We have read this dissertation and recommend that it be approved.

Mingjiang Xu

John Makemson

Dietrich Lorke

Lidia Kos, Co-Major Professor

Ophelia Weeks, Co-Major Professor

Date of Defense: December 3, 2014

The dissertation of Feng Pan is approved.

\begin{tabular}{r}
\hline $\begin{array}{r}\text { Dean Michael R. Heithaus } \\
\text { College of Arts and Sciences }\end{array}$ \\
\hline Dean Lakshmi N. Reddi \\
University Graduate School
\end{tabular}

Florida International University, 2015 
(C) Copyright 2015 by Feng Pan

All rights reserved. 


\section{DEDICATION}

This dissertation is lovingly dedicated to my parents, for their heartfelt support and encouragement throughout my life.

This dissertation is also dedicated to my beloved brilliant wife, Sophie Che and our little angel Ada Pan. 


\section{ACKNOWLEDGMENTS}

First and foremost, I would like to thank my major professor Dr. Ophelia I. Weeks, for helping me receive the Ph.D. and for helping to make my academic dream come true. Dr. Mingjiang Xu for providing me such a wonderful opportunity to work as a research assistant in his lab. I would also like to thank the following people who helped me to develop and execute my projects Drs. Feng-Chun Yang, Peng Jin, Xuekun Li. Next, I would like to thank all my committee members: Drs. Lidia Kos, John Makemson and Dietrich Lorke, for all their professional help and support throughout my Ph.D. years. I appreciate all the past and current lab members of Dr. Weeks' and Dr. Xu's labs. Without your patience, kindness and understanding, I won't have grown and matured to accomplish my aims in a timely manner. 


\title{
ABSTRACT OF THE DISSERTATION \\ UNDERSTANDING TEN-ELEVEN TRANSLOCATION-2 IN HEMATOLOGICAL AND NERVOUS SYSTEMS
}

\author{
by
}

Feng Pan

Florida International University, 2015

\author{
Miami, Florida \\ Professor Ophelia Weeks, Co-Major Professor \\ Associate Professor Lidia Kos, Co-Major Professor
}

I proposed the study of two distinct aspects of Ten-Eleven Translocation 2 (TET2)

protein for understanding specific functions in different body systems.

In Part I, I characterized the molecular mechanisms of Tet2 in the hematological system. As the second member of Ten-Eleven Translocation protein family, TET2 is frequently mutated in leukemic patients. Previous studies have shown that the TET2 mutations frequently occur in $20 \%$ myelodysplastic syndrome/myeloproliferative neoplasm (MDS/MPN), 10\% T-cell lymphoma leukemia and 2\% B-cell lymphoma leukemia. Genetic mouse models also display distinct phenotypes of various types of hematological malignancies. I performed 5-hydroxymethylcytosine $(5 \mathrm{hmC})$ chromatin immunoprecipitation sequencing (ChIP-Seq) and RNA sequencing (RNA-Seq) of hematopoietic stem/progenitor cells to determine whether the deletion of Tet2 can affect the abundance of $5 \mathrm{hmC}$ at myeloid, T-cell and B-cell specific gene transcription start sites, which ultimately result in various hematological malignancies. Subsequent Exome 
sequencing (Exome-Seq) showed that disease-specific genes are mutated in different types of tumors, which suggests that TET2 may protect the genome from being mutated. The direct interaction between TET2 and Mutator S Homolog 6 (MSH6) protein suggests TET2 is involved in DNA mismatch repair. Finally, in vivo mismatch repair studies show that the loss of Tet2 causes a mutator phenotype. Taken together, my data indicate that TET2 binds to MSH6 to protect genome integrity.

In Part II, I intended to better understand the role of Tet2 in the nervous system. 5hydroxymethylcytosine regulates epigenetic modification during neurodevelopment and aging. Thus, Tet2 may play a critical role in regulating adult neurogenesis. To examine the physiological significance of Tet2 in the nervous system, I first showed that the deletion of Tet2 reduces the $5 \mathrm{hmC}$ levels in neural stem cells. Mice lacking Tet2 show abnormal hippocampal neurogenesis along with $5 \mathrm{hmC}$ alternations at different gene promoters and corresponding gene expression downregulation. Through the luciferase reporter assay, two neural factors Neurogenic differentiation 1 (NeuroD1) and Glial fibrillary acidic protein (Gfap) were down-regulated in Tet2 knockout cells. My results suggest that Tet2 regulates neural stem/progenitor cell proliferation and differentiation in adult brain. 


\section{TABLE OF CONTENTS}

CHAPTER

PAGE

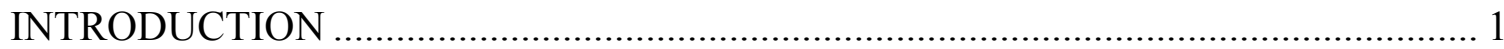

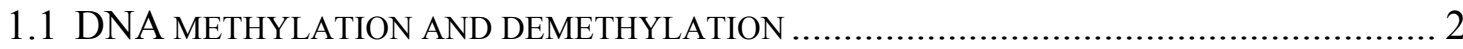

1.25 -HYDROXYMETHYLCYTOSINE AND TET FAMILY PROTEINS...................................... 7

1.3 TET2 GENE IN HEMATOPOIESIS AND HEMATOLOGICAL DISORDERS …..................... 12

1.4 TETS AND 5-HYDROXYMETHYLCYTOSINE IN NEUROGENESIS AND

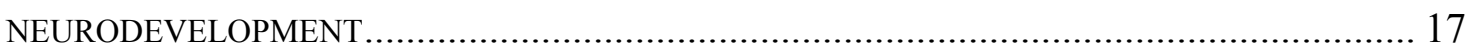

TET2 PROTECTS GENOMIC STABILITY THROUGH INTERACTING WITH

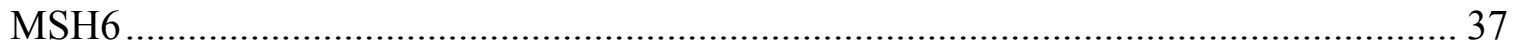

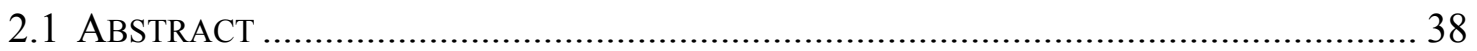

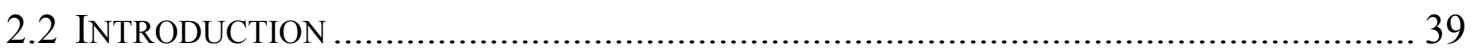

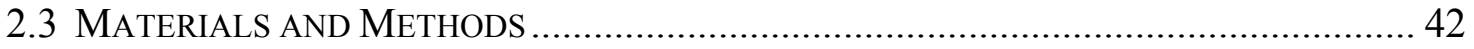

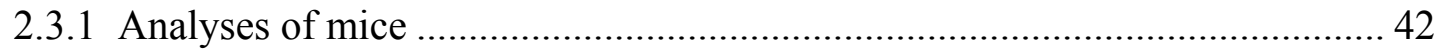

2.3.2 Tumor transfer assay ............................................................................... 43

2.3.3 Generation of FLAG-V5 Tag knock-in ES cells ............................................. 43

2.3.4 Purification of TET2-associated proteins ..................................................... 45

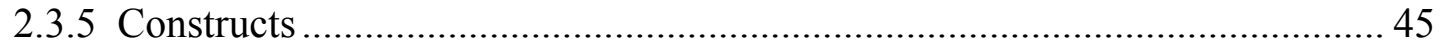

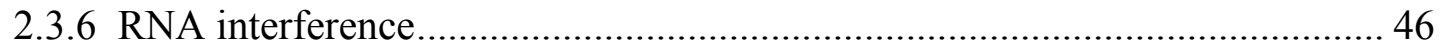

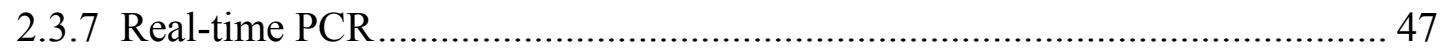

2.3.8 Western blot and co-immunoprecipitation assays .......................................... 48

2.3.9 Exome sequencing and mutational confirmation ........................................... 49

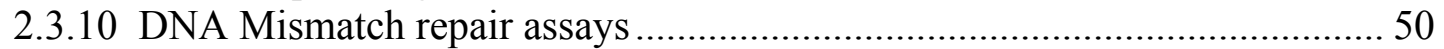

2.3.11 Microsatellite instability and HPRT mutability analyses .............................. 50

2.3.12 Confocal Microscopy and immunofluorescence analysis ............................... 51

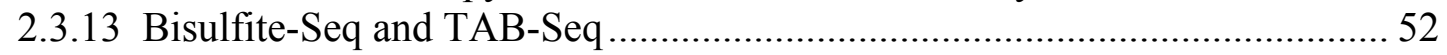

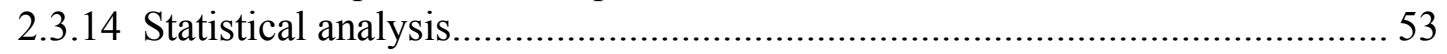

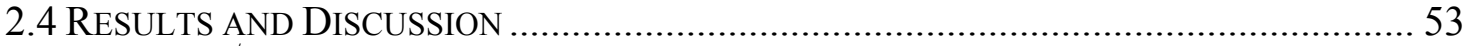

2.4.1 $\mathrm{Tet}^{-/-}$mice develop lymphoid malignancies. ............................................... 53

2.4.2 Acquisition of mutations in Tet ${ }^{-/}$tumors and increased mutational

frequency in loci marked by Tet2-dependent $5 \mathrm{hmC}$.................................................56

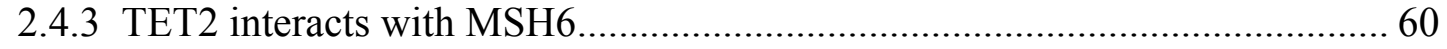

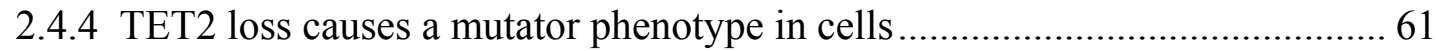

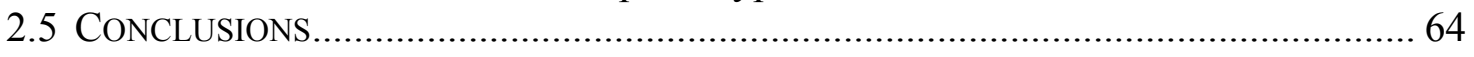

TET2 REGULATES ADULT BRAIN NEUROGENESIS......................................... 98

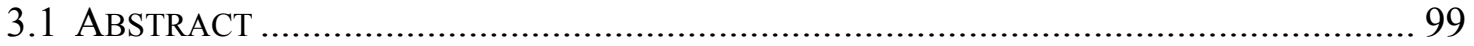

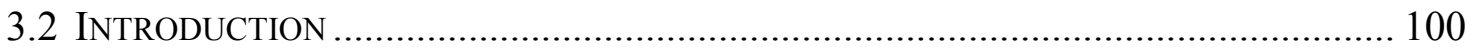

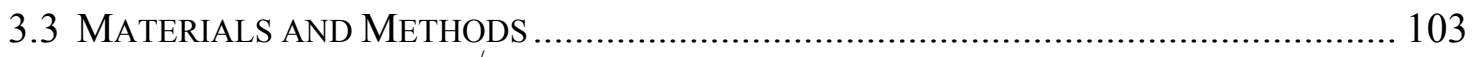

3.3.1 Generation of Tet ${ }^{-/}$mice and LacZ staining ............................................... 103

3.3.2 Adult NPCs isolation and culture ................................................................ 104

3.3.3 Proliferation and differentiation analyses of cultured adult NPCs ................. 104 


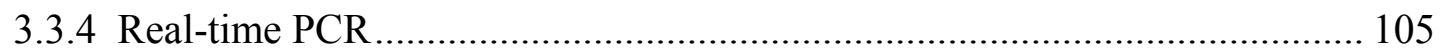

3.3.5 Confocal Microscopy and immunofluorescence analysis ............................. 105

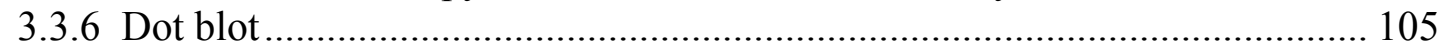

3.3.7 DNA plasmids and luciferase assay ......................................................... 106

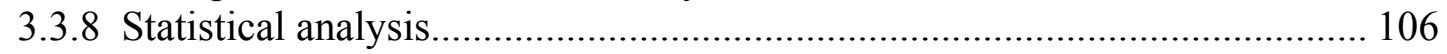

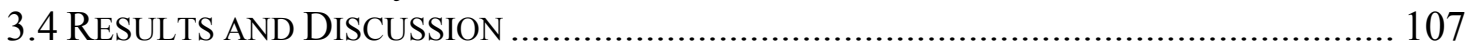

3.4.1 TET2 is highly expressed in the central nervous system............................... 107

3.4.2 Hydroxylation of 5-methylcytosine affects stem cell proliferation and differentiation in dentate gyrus of the hippocampus ............................................. 108

3.4.3 TET2 regulates the expression of NeuroD and GFAP transcriptionally ....... 109

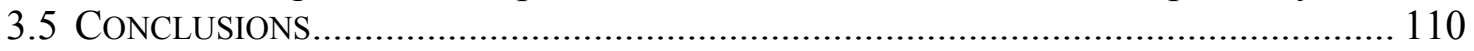

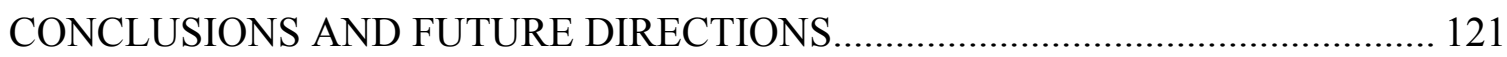

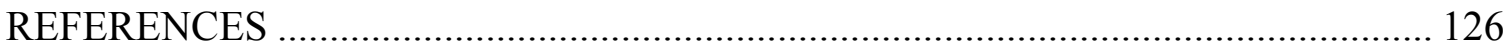

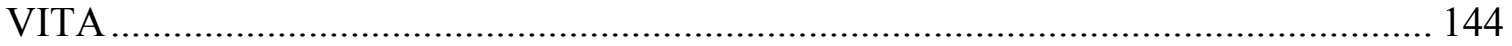




\section{LIST OF FIGURES}

FIGURE

PAGE

Figure 1 DNA methylation and demethylation pathways......................................... 22

Figure 2 The dynamic methylome landscapes of different genomic elements............... 23

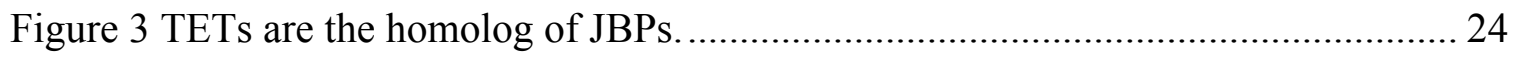

Figure 4 Quantification of $\mathrm{x}$ in Purkinje cells and granule cells.................................. 25

Figure 5 The protein structures of TET family..................................................... 26

Figure 6 Assays for mapping $5 \mathrm{mC}$ and $5 \mathrm{hmC}$ at single-base resolution....................... 27

Figure 7 TET2 mutations detected in individuals with different tumors....................... 28

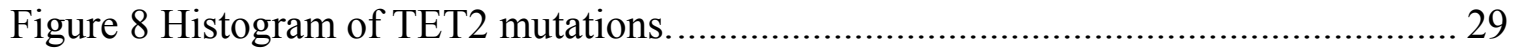

Figure 9 Circos plots demonstrating 12 coexisting genes in a cohort of patients with

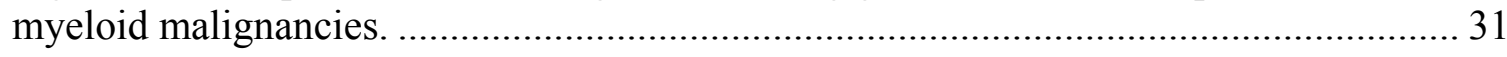

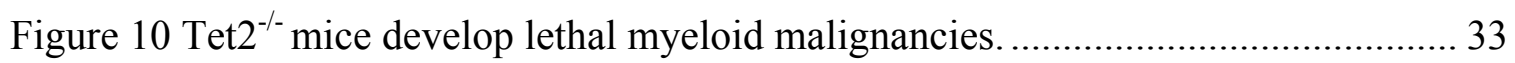

Figure 11 TET2 background mutations cause various hematological malignancies....... 34

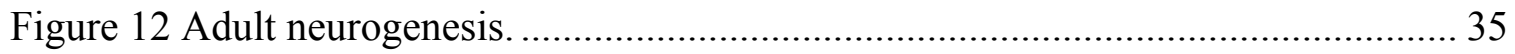

Figure 13 Transcriptional epigenetic regulators in adult neurogenesis. ......................... 36

Figure $14 \mathrm{Tet}^{-/-}$mice develop lethal lymphoid malignancies involving both $\mathrm{T}$ - and

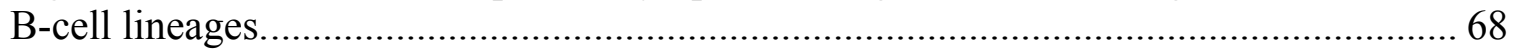

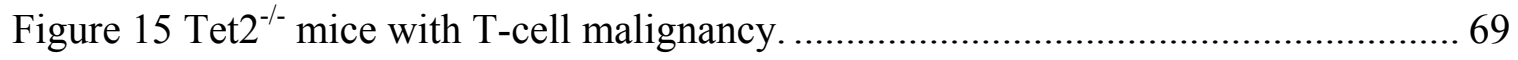

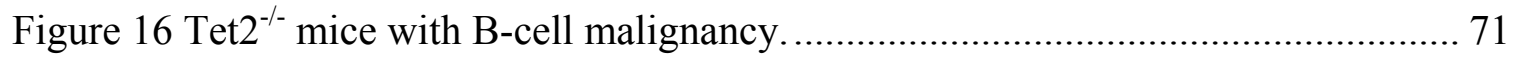

Figure 17 Lymphoid malignancies in Tet $2^{-/-}$mice are transplantable to secondary

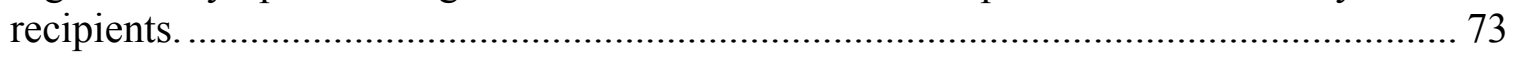

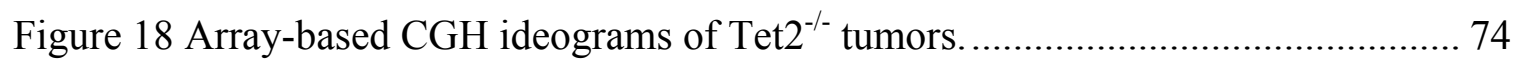

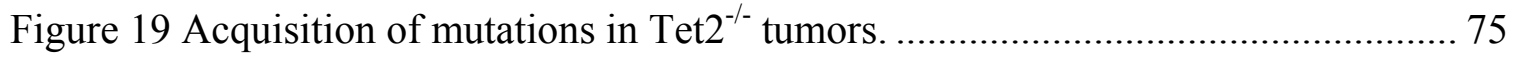


Figure 20 Notch 1 mutations were identified from Tet2 ${ }^{-/}$mice with T-cell malignancy.. 76

Figure $215 \mathrm{hmC}$ distribution and enriched regions with genomic features. 77

Figure 22 Changes of $5 \mathrm{hmC}$ among the genes with different expression levels............. 78

Figure 23 Increased mutational frequency in loci marked by Tet2-dependent $5 \mathrm{hmC} \ldots . . .79$

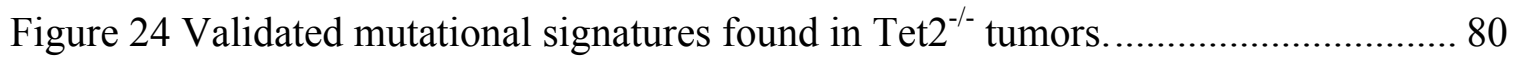

Figure 25 Dynamic changes of $5 \mathrm{mC}$ and $5 \mathrm{hmC}$ surrounding the mutation sites........... 81

Figure 26 Generation of Flag-V5 tag knock-in ES cells......................................... 82

Figure 27 Flag-TET2 is expressed as a $240 \mathrm{kD}$ protein and localized in the nucleus. ...... 84

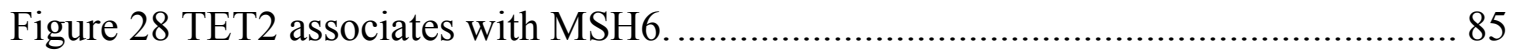

Figure 29 MSH6 co-immunoprecipitates with TET2 N-terminal................................. 86

Figure 30 Immunostaining identified TET2 and MSH6 co-localization........................ 87

Figure 31 TET2 and MSH6 co-localization at different cell cycle............................... 88

Figure 32 Tet2 is not physically involved in MMR activity in vitro............................ 89

Figure 33 Knockdown of TET2 in HeLa cells using human TET2-specific shRNA...... 90

Figure 34 Increased mutational frequency in TET2 knockdown HeLa cells. ................ 91

Figure 35 Increased mutational frequency in shTet2-NIH3T3 cells. .......................... 92

Figure 36 MSH6 foci formation and localization in control- and shTET2- HeLa cells ... 93

Figure 37 Analysis of PCR product patterns of microsatellite markers in bone marrow

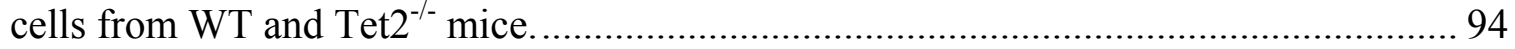

Figure 38 Analysis of PCR product patterns of two microsatellite markers in control-

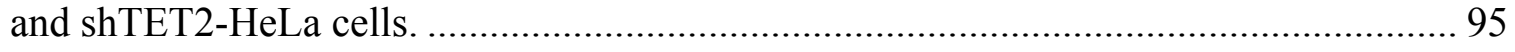

Figure 39 Mutation numbers in MDS patients with or without TET2 mutations............ 96

Figure 40 Proposed model for loss of Tet2 induced hematological malignancies. ......... 97

Figure 41 Immunostaining of $5 \mathrm{hmC}$ in two brain regions in mice............................. 112 
Figure 42 Tet1, Tet2 and Tet3 expression levels in P7 and 6-week old cerebellum..... 113

Figure 43 Tet 2 is expressed in the nervous system.................................................. 114

Figure 44 Detection of Tet 2 in WT and Tet $2^{-/}$hippocampi. .................................... 115

Figure 45 Quantification of 5hmC in P7 and adult cerebellum................................. 116

Figure 46 Cultured adult neural progenitor cells expressed representative cell markers 117

Figure 47 Quantification of $5 \mathrm{hmC}$ in proliferating and differentiating cells from WT

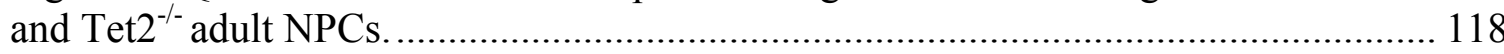

Figure 48 Loss of Tet2 leads to increased adult NPCs proliferation and decreased

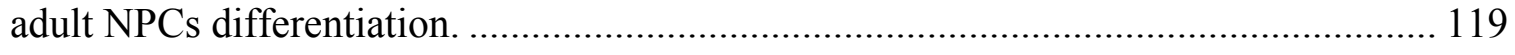

Figure 49 The NeuroD1 and Gfap promoter regions are altered by Tet $2 \ldots \ldots \ldots \ldots \ldots \ldots \ldots . . . . . . . .120$ 


\section{LIST OF ABBREVIATIONS AND ACRONYMS}

2-OG

$5 \mathrm{caC}$

$5 \mathrm{fC}$

$5 \mathrm{hmC}$

$5 \mathrm{mC}$

6-TG

$\mathrm{aCGH}$

AID

AITL

AML

APOBEC

ASXL1

BDNF

BER

$\mathrm{BM}$

CFU

CGI

ChIP-Seq

CMML

$\mathrm{CpG}$ 2-oxoglutarate

5-carboxylcytosine

5-formylcytosine

5-hydroxymethylcytosine

5-methylcytosine

6-thioguanine

Array comparative genomic hybridization

Activation-induced deaminase

Angioimmunoblastic T-cell lymphoma

Acute myeloid leukemia

Apolipoprotein B mRNA editing enzyme, catalytic polypeptide-like

Additional sex combs like transcriptional regulator 1 Brain-derived neurotrophic factor

Base excision repair Bone marrow Colony-forming unit

CpG islands Chromatin immunoprecipitation sequencing Chronic myelomonocytic leukemia

Cytosine linked with a phosphodiester bond to guanine 
DLD-1

DMEM

DMR

DNA

DNMT

DSBH

EBF1

ESC

EZH2

FBS

FGF

FLT3

GCL

GFAP

GFP

$\mathrm{H} \& \mathrm{E}$

HEK293T

HNPCC

HPC

HPRT

HSC
DL Dexter, Dukes' type C, colorectal adenocarcinoma

Dulbecco's Modified Eagle's Medium

Differentially methylated regions

Deoxyribonucleic acid

DNA methyltransferase

Double stranded beta helix

Early B-cell factor 1

Embryonic stem cell

Enhancer Of Zeste Homolog 2

Fetal bovine serum

Fibroblast growth factors

Fms-like tyrosine kinase 3

Granule cell layer

Glial fibrillary acidic protein

Green fluorescent protein

Hematoxylin and eosin

Human Embryonic Kidney 293 cells with Tantigen of SV40

Hereditary nonpolyposis colorectal cancer

Hematopoietic progenitor cell

Hypoxanthine-guanine phosphoribosyltransferase

Hematopoietic stem cell 
IDAX

JBP

KD

KI

LC-MS

LK

LSK

MBD2

MDS

MMR

MPN

MS

$\mathrm{MSH} 2$

MSH6

MSI

NeuroD1

NIH3T3

NOTCH1

NPC

NSC

OGT

PB
Inhibition Of The Dvl And Axin Complex

J-binding-protein

Knock-down

Knock-in

Liquid chromatography-mass spectrometry Lineage negative, c-kit positive Lineage negative, Scal positive, c-kit positive Methyl-CpG binding domain protein 2 Myelodysplastic syndromes Mismatch repair Myeloproliferative neoplasm Mass spectrometry MutS homolog 2 MutS homolog 6 Microsatellite instability Neurogenic differentiation 1 NIH Swiss mouse embryo; adherent fibroblastoid cells Neurogenic locus notch homolog protein 1 Neural progenitor cell Neural stem cell O-linked $\mathrm{N}$-acetylglucosamine transferase Peripheral blood 
TujI

UTR

$\mathrm{VZ}$

WT

$\beta \mathrm{GT}$
Neuron-specific class III beta-tubulin

Untranslated region

Ventricular zone

Wild type

$\beta$-glucosyltransferase 


\section{CHAPTER}

INTRODUCTION 


\subsection{DNA METHYLATION AND DEMETHYLATION}

Epigenetics, proposed by Waddington in 1942, is broadly defined and attributed to heritable cellular changes without altering the deoxyribonucleic acid (DNA) sequence ${ }^{1,2}$. Molecular mechanisms of epigenetic regulation include: DNA methylation, histone modifications and noncoding regulatory ribonucleic acids (RNAs). DNA methylation on cytosine-phosphate-guanine $(\mathrm{CpG})$ islands at promoter regions is considered as one stable epigenetic mark ${ }^{3}$ and such DNA alternation is sufficient to maintain genome imprinting and X-chromosome inactivation ${ }^{4}$. Deoxyribonucleic acid methylation also occurs in other genomic elements such as gene body, enhancer and untranslated regions (UTR). It may contribute to transcription elongation or gene activation/inactivation ${ }^{5}$. Histone modifications widely exist posttranslationally, and include lysine and arginine methylation, lysine acetylation, ubiquitination and sumoylation, as well as serine and threonine phosphorylation ${ }^{6}$. These modifications regulate gene expression and are responsible for the presence of enhancers or repressors ${ }^{6,7}$. In mammalian cells, microRNAs regulate gene expression by posttranslational repression of target sequences. Since the expression of microRNAs is also affected by their promoter status, the transcriptional regulation by microRNAs is relatively mild ${ }^{8}$. In recent years, studies on hematological malignancies have revealed a subset of epigenetic regulators as cancerrelevant genes. The corresponding epigenetic alterations lead to changes in specific gene transcriptions, which finally result in abnormal hematopoietic stem cells (HSC) and/or hematopoietic progenitor cells (HPC) self-renewal, proliferation and differentiation.

Methylation of DNA normally indicates modification of cytosine. In mammals, the DNA methyltransferase (DNMT) family comprises five members: DNMT1, DNMT2, 
DNMT3A, DNMT3B and DNMT3L. The enzyme DNA methyltransferase 1 (DNMT1) maintains cytosine hemimethylated during DNA replication ${ }^{9}$ (Figure 1). DNA methyltransferase 2 (DNMT2), also termed TRDMT1, is the smallest DNMT whose function is still poorly understood, but the specific protein structure of DNMT2 suggests the possibility of involvement in DNA recombination and DNA damage repair ${ }^{10}$. Deoxyribonucleic acid methyltransferase 3 has two family members: DNMT3A and DNMT3B which control de novo cytosine methylation of unmethylated DNA substrates ${ }^{11}$ (Figure 1). However, their enzymatic activities can be negatively regulated by DNMT3L, which functions mainly during early embryogenesis ${ }^{12,13}$.

The human genome contains around 28 million CpGs while the mouse genome has approximately 22 million CpGs. These CpGs reside in different genomic elements such as CpG islands (CGIs), gene bodies and enhancers. Only around 20\% of CpGs are dynamic, most of the $\mathrm{CpGs}$ are relatively stable ${ }^{14,15}$. Genome-wide methylation studies have revealed detailed architectural profiles for DNA methylation at gene bodies, CGIs, CGI shore, enhancers, canyons, repeats and large differentially methylated regions $(\mathrm{DMR})^{16}$ (Figure 2). Cytosine-phosphate-guanine islands are defined as short and CpGrich regions within the genome, and more than $70 \%$ of genes have CGIs ${ }^{17}$. When CGIs are unmethylated at the promoter region, that usually signifies transcription initiation in nucleosome-free style, in which the transcriptional levels are regulated by Histone $\mathrm{H} 3$ lysine4 tri-methylation and transcription factors association. Whereas, methylation at CGIs may signify long-term gene silencing, as occurs in imprinted genes ${ }^{18,19}$.

Recently, genome-wide methylome studies have allowed scientists to examine DNA methylation status outside promoter CGIs in both stem and differentiated cells. It has 
been reported that tissue- or cancer-specific differentially methylated regions within CGI shores are more dynamic than those regions within CGIs ${ }^{16}$. Thus, it is plausible to propose that the methylation status at CGI shores may be involved in epigenetic reprogramming and cancer $^{20}$. Actually, many genes in lymphoid- or myeloid-specific lineages show frequent methylation changes in CGI shores during cell differentiation ${ }^{21}$.

DNA methylation also occurs in intergenic regions, but little is known about its physiological function. As a critical genetic element, most enhancers reside in such regions. Studies suggest that cell-specific transcription is closely associated with enhancer methylation levels even if the relevant promoter stays unmethylated. Through binding to chromatin modulating factors, these enhancers are able to interact with distal promoters, which result in specific DNA methylation patterns in different cell types ${ }^{22}$. Genome-wide methylome studies also identify a bunch of differential methylated regions that are enriched at different cellular stages during hematopoiesis and these regions are demonstrated as transcription factor binding sites. Interestingly, in lymphoid stem/progenitor cells, myeloid transcription factor binding sites are hypomethylated. Whereas during lymphoid differentiation, myeloid-specific factors binding sites are hypermethylated ${ }^{23}$.

In addition, large hypomethylated regions have been identified serendipitously, during the process of comparing $5 \mathrm{mC}$ abundance in differentiated fibroblasts and human embryonic stem cells ${ }^{24}$. These large canyon regions usually spin at $1 \mathrm{Mb}$, and include certain oncogenes and cancer biomarker genes ${ }^{25}$. The loss of DNA methylation in these regions leads to repressive histone mark acquisition and gene downregulation ${ }^{26}$. Moreover, methylation canyons are found in regions with very low levels of methylation 
in hematopoietic stem cells ${ }^{27}$. The loss of DNMT3A causes DNA methylation alterations at the edge of canyons ${ }^{28}$. The methylation changes in canyons may result in transcription alteration and genomic instability that contribute to the progression of cancer.

In addition to being in promoter regions, CGIs are also found within gene bodies ${ }^{16}$. Even though there is a small amount of evidence that gene body methylation correlates with gene transcription repression, the opposite, gene transcription activation has been proposed $^{29}$. Indeed, actively transcribed genes have been identified as hypermethylated in the gene bodies ${ }^{16}$. Several studies infer that gene body methylation regions are the enhancer sites or regulate tissue-specific gene transcription from promoters. Besides, DNA methylation at gene bodies may also facilitate the recruitment of $\mathrm{CpG}$ binding proteins and prevent CCCTC-binding factor mediated RNA polymerase II stalling and spliceosome assembly ${ }^{30-33}$. Obviously, gene body methylation and promoter methylation play distinct roles in transcription regulation. But, the underlying mechanism of gene body methylation still needs to be elucidated in the future ${ }^{16}$.

There are also specific genomic regions called repetitive elements with multiple copies in the genome. Methylation of repetitive elements may repress the expression of transposable elements in order to maintain genome integrity ${ }^{34}$. Bisulfite sequencing from DNMT3B mutant patients exhibit significant changes of DNA methylation in inactive heterochromatic regions, satellite repeats and transposons. And, aberrant expression levels of key genes may result from hypomethylation of repetitive elements, even though ribosomal RNA repeats are free from global hypomethylation ${ }^{35}$. As the most abundant genes in the genome, ribosomal DNA stays in tandem repetitive clusters. The hematopoietic progenitor cells from MDS patients harbor increased ribosomal DNA 
(rDNA) methylation levels with decreased ribosomal RNA (rRNA) expression compared to healthy controls ${ }^{35}$. When myeloid cells are treated with 5-Aza-2'-deoxycytidine, significant methylation decrease at rDNA promoter regions is observed along with increased rRNA levels ${ }^{36}$.

It has been reported that about $80 \%$ of CpGs are methylated in mammalian genome, which suggest a relatively stable pattern of DNA methylation in the genome. However, DNA methylation can be erased passively or actively through different demethylation pathways. Passive demethylation initiates through the inactivation of DNMT1/3 (downregulation of gene expression, genetic mutations or inhibitors). The methylation of a newly synthesized DNA strand is blocked during DNA replication. Other studies have demonstrated that DNA methylation patterns can be further modified by active demethylation. Active demethylation is mediated by TET family enzymes, which catalyze the conversion of 5-methylcytosine $(5 \mathrm{mC})$ to 5 -hydroxymethylcytosine $(5 \mathrm{hmC})$ and further 5-formylcytosine $(5 \mathrm{fC})$ and 5-carboxylcytosine $(5 \mathrm{caC})$ in this pathway ${ }^{37-39}$ (Figure 1).

On the basis of DNA semiconservative replication mechanism, the relative amount of DNA methylation is half diluted when new DNA strands are synthesized. Thus, the methylation status at specific gene loci will disappear in daughter cells upon cell divisions. The above phenotype is the so-called "passive DNA demethylation" ${ }^{, 40}$ (Figure 1). However, how "active DNA demethylation" initiates is still less understood. Yet, the identification of $5 \mathrm{mC}$ glycosylases in plants has thrown some light on the process, since there is a similar occurrence in mammalian cells during zygote fertilization ${ }^{40,41}$. In primordial germ cells (PGCs), genome-wide erasure of DNA methylation occurs 
naturally $^{42}$. It is believed that active DNA demethylation preferentially happens at the specific loci in differentiated somatic cells ${ }^{43}$. Studies on identification of DNA demethylases have greatly increased in recent years. Methyl-CpG binding domain protein 2 (MBD2) binds the promoter region enriched in $\mathrm{CpG}$ and functions as a mediator of methylation signals to activate gene transcription ${ }^{44}$. Additional studies have shown that mammalian thymine DNA glycosylase (TDG) catalyzes the glycosylation of $5 \mathrm{mC}$, eventhough no in vivo data have verified the exact role of TDG in DNA demethylation ${ }^{45}$. But, several potential mechanisms have also been proposed to better explain DNA demethylation. These include deamination by activation-induced deaminases (AID), and apolipoprotein B mRNA-editing enzyme, catalytic polypeptide-like (APOBEC) protein deaminases or DNMTs. Briefly, generated T:G mismatch leads to the initiation of base excision repair (BER) and a series of enzymes facilitate the refill of unmodified mononucleotides ${ }^{46}$. Indeed, several reports provide evidence to support BER mechanisms, such as the requirement of BER-related enzymes and low methylation levels in AID deficient PGCs ${ }^{47,48}$. Even if AID is completely eliminated, demethylation of PGCs still occurs, suggesting the existence of other possible DNA demethylation mechanisms.

\subsection{5-HYDROXYMETHYLCYTOSINE AND TET FAMILY PROTEINS}

The first discovery of $5 \mathrm{hmC}$ was reported in frog and rodent brain DNA in 1971, but this amazing finding did not draw too much attention ${ }^{49}$. In 2009, two labs shed light on the mystery nucleotide in mammalian DNA (Figure 3\&4). Kriaucionis and Heintz (2009) detected an unusual nucleotide when comparing the abundance of $5 \mathrm{mC}$ in cerebellar Purkinje neurons and granule cells ${ }^{38}$. Subsequent experiments determined the nucleotide 
as $5 \mathrm{hmC}$, but the abundance of $5 \mathrm{hmC}$ is quite low with less than $1 \%$ of total nucleotides in cerebellar Purkinje neurons and granule cells ${ }^{38}$ (Figure 4). In another study, Rao and colleagues (2009) showed that the Ten Eleven Translocation (TET) family proteins catalyze the conversion of $5 \mathrm{mC}$ to $5 \mathrm{hmC}$ (Figure 5), suggesting a novel epigenetic regulation of $5 \mathrm{hmC}^{37}$. In addition, $5 \mathrm{hmC}$ expression level was found to be higher in mouse embryonic stem cells (mESC) than other cell types. Both Tet1 and 5hmC levels are downregulated upon the differentiation of $\mathrm{mESC}$, suggesting a potential role of Tet1 and $5 \mathrm{hmC}$ in epigenetic reprogramming ${ }^{37}$. The recurrence of $5 \mathrm{hmC}$ has caught the interest of many towards providing detailed characterization of its biological functions. Ten Eleven Translocation 1 protects the promoter region of Nanog in an unmethylated state, which regulates ESC self-renewal and lineage commitment. Once Tet1 is knocked down, the promoter of Nanog returns to a methylated state and finally contributes to gene silencing. In contrast, the overexpression of Tet1 triggers the demethylation of methylated plasmid DNA ${ }^{50}$.

In various human and mouse cells, $5 \mathrm{hmC}$ displays differential profiles, suggesting a critical balance between $5 \mathrm{mC}$ and $5 \mathrm{hmC}$, which may subsequently maintain the cell in its normal state ${ }^{37,38,51}$. Except for serving as an intermediate during active DNA demethylation, 5hmC may have other functions in biological systems. The baseresolution level of $5 \mathrm{hmC}$ helps to uncover its biological roles. Several techniques have been developed to map $5 \mathrm{hmC}$ architecture in the genome. These techniques include cytosine-5-methylenesulfonate sequencing, oxidative bisulfate sequencing, hydroxymethyl DNA immunoprecipitation sequencing and Tet2-assisted bisulfite sequencing $^{52-56}$ (Figure 6). Studies using these techniques have characterized $5 \mathrm{hmC}$ 
profiles in different cells and tissues. For example, $5 \mathrm{hmC}$ accounts for $1 \%$ of total $5 \mathrm{mC}$ in immune cells, $5-10 \%$ of total $5 \mathrm{mC}$ in ES cells and $40 \%$ of total $5 \mathrm{mC}$ in neural cell $\mathrm{s}^{37,38,57}$. Whereas, $5 \mathrm{fC}$ and $5 \mathrm{ca}$ represent only $0.03 \%$ and $0.01 \%$ of total $5 \mathrm{mC}$ in mouse ES cells ${ }^{39}$. Analysis of genome-wide Tet1-dependent $5 \mathrm{hmC}$ distribution, has shown that Tet1 and Tet1-dependent 5hmC are enriched at transcription start sites (TSS) along with repressive histone modifications ${ }^{58,59}$. However, other labs have obtained opposite results, in which $5 \mathrm{hmC}$ and histone modifications are enriched at enhancers, promoters and exons in order to regulate active transcription ${ }^{60-62}$. These differences are plausible for independent mechanisms, different techniques and the variation of $5 \mathrm{hmC}$ dynamics from cell to cell during $5 \mathrm{hmC}$ signal capture. In addition, $5 \mathrm{hmC}$ abundance changes dynamically during human $\mathrm{CD} 34+$ cell and erythroid development such that $5 \mathrm{hmC}$ increases at erythroid-specific transcription factor binding sites and decreases at repressive genes. Also, rapid DNA demethylation is observed during erythropoiesis ${ }^{63,64}$. Therefore, it is reasonable to assert that $5 \mathrm{hmC}$ regulates transcription activation or repression during cell differentiation. The later discovery of TET family proteins has helped to better understand the importance of $5 \mathrm{hmC}$ and $5 \mathrm{hmC}$ dynamics in gene expression and cell-fate decision.

Ten-eleven translocation (TET) family proteins contain two key components: Fe (II) and 2-oxoglutarate (2-OG) to catalyze oxidation of the methyl group of $5 \mathrm{mC}$ to hydroxymethyl, formyl and carboxyl groups, which generate 5-hydroxymethylcytosine, 5 -formylcytosine and 5-carboxylcytosine step-by-step in an enzymatic activity-dependent manner ${ }^{39,65}$. Presently, the biological functions of $5 \mathrm{hmC}, 5 \mathrm{fC}$ and $5 \mathrm{caC}$ are not wellstudied, but most of recent studies have pointed potential roles to DNA demethylation, 
which regulates gene expression by a series of enzyme catalysis and DNA repair mechanisms $^{3}$. All three family members of TET: TET1, TET2 and TET3 are present in different mammalian tissues ${ }^{57}$. They participate in diverse biological processes, i.e., gene transcription, embryonic development and cancer initiation/progression.

The discovery of TET proteins originate from analysis of J-binding-protein 1 (JBP1) and JBP2 in the parasite Trypanosoma brucei that causes African sleeping sickness ${ }^{66}$. Such species contain base $\mathrm{J}$, a modified thymine in which $\beta$-D-glucosyl-hydroxymethyl group is added up to uracil, which enzymatic process is catalyzed by JBP1 and JBP2 which are capable of oxidizing methylthymine to 5-hydroxymethyluracil, and the intermediate is then further glucosylated by an unknown glucosyltransferase ${ }^{67,68}$ (Figure 3). The J-binding-proteins belong to $\mathrm{Fe}(\mathrm{II})$ and 2-oxoglutarate dependent dioxygenases. In $T$. brucei, most of base $\mathrm{J}$ resides in silent copies of variant surface glycoproteins that help parasites evade host immune defense ${ }^{69}$. When computational screening of JBP homologues were used to predict nucleic acid modifying dioxygenases, TET family proteins were identified in eukaryotic cells and bacteriophages (Figure 3). Ten-eleven translocations are present in all metazoans but not in Caenorhabditis elegans because of a loss of methylation function ${ }^{70}$. On the basis of the chemical similarity between thymine and $5 \mathrm{mC}$ and the protein structure of TET, it is possible that TET proteins may oxidize $5 \mathrm{mC}$ in mammalian genome.

All three TET proteins contain a Cys-rich domain and a carboxy-terminal catalytic domain that forms a double-stranded $\beta$ helix (DSBH). Evolutionary studies indicate that the ancestor TET gene triplicated to TET1, TET2 and TET3 ${ }^{71}$ (Figure 5). Furthermore, TET2 underwent chromosomal inversion, which resulted in the detachment of CXXC 
domain, thereby encoding a separate gene called IDAX $^{72}$. Many chromatin-binding proteins contain CXXC domains. The CXXC domain of IDAX preferentially binds to unmethylated $\mathrm{CpG}$ in CGIs. Strangely, TET1 CXXC domain does not bind DNA regardless of whether $\mathrm{CpG}$ is methylated or not $^{73}$. On the other hand, TET3 CXXC domain binds to unmethylated cytosine even if the resulting nucleotide is not a guanine (supported by X-ray crystallography) ${ }^{74}$. Ten-eleven translocation 2 no longer has a CXXC domain, but instead IDAX (Figure 5). The loss of IDAX in ES cells prevents TET2 from being degraded in a caspase-dependent destruction mechanism during ES cells differentiation while the depletion of TET2 in human myeloid cell line upregulates TET2 and 5hmC levels. If CXXC domain of IDAX was mutated, IDAX lost the control of TET2 and $5 \mathrm{hmC}$ suggesting IDAX recruits TET2 to chromatin and TET2 binds to DNA through a Cys-rich domain ${ }^{72}$ (Table 1.2).

The C-terminal of TET2 catalytic domain is composed of a Cys-rich domain and DSBH domain ${ }^{75}$. The crystallized TET2 catalytic domain made it possible to uncover a detailed inspection of TET2 DSBH bound to methylated DNA. According to the crystal structure of TET2, two Zinc fingers stick Cys-rich and DSBH domains together to form a catalytic domain. The Cys-rich domain stabilizes DNA substrate with proximity to DSBH. $5 \mathrm{mC}$ stays in the catalytic cavity in which a methyl group is pointed to $\mathrm{Fe}(\mathrm{II})$ for further oxidation $^{76}$. The structural features of TET2 catalytic domain helps to better understand the mechanisms of TET-mediated DNA interaction and oxidation. 


\subsection{TET2 GENE IN HEMATOPOIESIS AND HEMATOLOGICAL DISORDERS}

All the DNMTs contribute to hematopoiesis ${ }^{16}$. The deletion of Dnmt1 in hematopoietic stem cells (HSC) and progenitor cells (HPC) leads to defects in hematopoiesis at early stages, characterized by an insufficient myeloid cell population and a decreased myeloid progenitor pool ${ }^{77,78}$. The loss of Dnmt3a and/or Dnmt3b in mouse HSC shows a deficiency in HSCs self-renewal, with no lineage commitment of HSC shift. However, serial transplantation studies have shown that Dnmt3a is required to maintain HSC differentiation potential ${ }^{79,80}$. In addition, exome sequencing of patients with acute monocytic leukemia (AML-M5) indicate that DNMT3A mutations occur in $20.5 \%$ of cases $^{81}$ (Table 1.1). All of these studies demonstrate that DNMT3 are critical for maintaining normal hematopoiesis.

In addition to identified biological roles in epigenetic reprogramming, stem cell selfrenewal and embryonic development, several studies have reported the genetic alterations of TET2 in myeloid malignancies, including in myelodysplastic syndrome (MDS), myeloproliferative neoplasms (MPN), acute myeloid leukemia (AML) and chronic myelomonocytic leukemia (CMML), while TET1 and TET3 are rarely mutated in hematological malignancies ${ }^{82}$. A large number of single/double -copy defects, nonsense and frameshift mutations of TET2 throughout the gene are commonly found in clinical patients $^{83}$ (Figure $7 \& 8$ ). The above high genetic alteration frequency of loss-of-function mutations indicates a critical role for TET2 in the cause and/or progression of leukemia. And if it is true, at least biological functions of TET2 could be determined by genetic tools. Previously, $\mathrm{Xu}$ and other groups showed that Tet2, a potential tumor suppressor gene, has multiple biological effects on the development of myeloid malignancies ${ }^{84-87}$. 
Although the targeting strategies were different, all of the Tet $2^{-/}$mice developed similar phenotypes including an elevated hematopoietic progenitor cell population, and HPC differentiation skewed toward myelomonocytic lineage.

To fully unearth and characterize the nature of Tet2 in myeloid malignancies, four research groups generated Tet2 knockout murine models by different strategies. For example, Li et al (2011) inserted nLacZ/nGFP instead of partial exon 3 of Tet2 gene since exon 3 is the first and largest coding exon in Tet2 and is also highly mutated in myeloid malignancies ${ }^{84}$. Through a specific interbreed crossing, a global knockout mouse model $\left(\right.$ Tet2 $^{-/}$) was obtained (Figure 10). On the other hand, Moran-Crusio and colleagues (2011) generated a conditional knockout mouse model in hematopoietic compartment (vav-cre; $\left.\mathrm{Tet}^{\mathrm{f} / \mathrm{f}}\right)^{87}$. However, the other two groups' disruption approaches were slightly different. Quivoron and colleagues (2011) generated two models, including a gene-trap targeting intron 9 (Tet2 $\left.{ }^{\mathrm{LacZ} / \mathrm{LacZ}}\right)$ and a conditional knockout targeting exon 11 $\left(\text { Mx1-cre; Tet } 2^{\text {Lox/Lox }}\right)^{86}$. Both of these two models lost the DSBH domain, which eliminated dioxygenase activity in vivo. In addition, Ko and colleagues (2011) deleted Tet2 exon 8-10 globally to fully remove enzymatic activity ${ }^{85}$. Together, these global or conditional Tet2 knockout murine models were viable and fertile and their progeny was in accordance with Mendelian ratio.

Accordingly, detailed phenotypic analyses were performed on these knockout mice. We have examined hematologic parameters of WT, Tet $2^{+/-}$and Tet $2^{-/-}$as early as 2 to 5 months of age ${ }^{84}$. Notably, increased WBC counts and abnormal numbers of monocytes and neutrophils were observed in $T e t 2^{-/}$peripheral blood. Besides the appearance of significant hepatosplenomegaly in most of the studies, we also found pale footpads in 
Tet $2^{-/-}$that may indicate anemia and this was consistent with the decrease in erythrocytes and platelets counts in Tet2 ${ }^{-1-84}$, suggesting a possible occurrence of monocytosis and/or neutrophilia in Tet $2^{-/}$mice. In addition to these mentioned findings in Tet $2^{-/-}$mice, other changes include increased bone marrow (BM) cellularity, splenomegaly and hepatomegaly, as well as increased numbers of colony forming unit granulocyte, monocyte (CFU-GM) in BM and spleen. A resulting diagnosis of these Tet $2^{-/-}$mice is CMML.

The Tet $2^{+/}$and $\mathrm{Tet}^{2 /-}$ mice died from 3 to 18 month as a result of spontaneous lethal hematological malignancies. Compared with age-matched WT mice, postmortem examination of $\mathrm{Tet}^{-/-}$mice show remarkable splenomegaly and hepatomegaly, which are 8-15 times and 2-5 times larger, respectively (Figure 10). Histologic studies reveal massive erythroid and/or myeloid infiltration in spleen and liver. Histopathology and cytospin studies identify specific cell types as myeloblasts, monocytes/macrophages and neutrophils ${ }^{84}$.

Flow cytometric analyses of $\mathrm{BM}$ and spleen cell from Tet $2^{-/-}$mice is consistent with the results from the histologic analyses. Located in the infiltrated BM and spleen are large numbers of erythroblasts at different stages and various myeloid cell populations. Also, a large peritoneal mass and a few white nodules in the liver are observed, which contains Gr- $1^{+} \mathrm{CD} 11 \mathrm{~b}^{+}$cells, suggesting the existence of myeloid sarcoma ${ }^{84}$.

To determine whether Tet2 alterations contribute to HSC compartment, previous studies have used a range of cells. These included analyzing BM from 6-7 weeks old $\mathrm{Tet}^{-/-}$mice, with the emphasis on lineage-negative (Lin-), ScaI-positive (Sca+), c-kit positive (c-kit+) (LSK) and LK cell populations. But even though results showed 
increased numbers of LSK cells, no obvious myeloid malignancies were observed. Single-cell clonogenic assays were also performed to determine the effect of Tet2 alterations on proliferation and differentiation of LSK cells. Here, the results showed that $\mathrm{Tet}^{2 /-}$ LSK exhibited higher cloning efficiency than Tet ${ }^{+/-}$and WT LSK cells along with CFU-GM in the colonies ${ }^{84}$. Taken together, it is reasonable to believe that the deletion of Tet2 stimulated the differentiation and proliferation of $\mathrm{HSC} / \mathrm{HPC}$ and facilitated the development of myeloid malignancies.

Genome-wide whole exome sequencing from different groups have revealed that TET2 is one of the most frequently mutated epigenetic regulators in CMML $(\sim 50 \%)^{88-90}$, AML $(\sim 20 \%)^{83,91-93}$ and MDS $(\sim 20 \%)^{94-96}$ (Table 1.1$)$. In many patients, deletion of TET2 on one allele at $4 \mathrm{q} 24$ region occurs with mutations of TET2 on a second allele ${ }^{94}$ suggesting that haploinsufficiency of TET2 may lead to genome instability through DNA damage/repair pathways. More than 700 TET2 mutations have been identified in about 2000 leukemic patients ${ }^{97}$. These harmful mutations impair the enzymatic activity of TET2, which ultimately result in aberrant DNA methylation profiling and decreased $5 \mathrm{hmC}$ levels. The majority of TET2 missense mutations are clustered in two highly conserved regions (AA 1104-1478 and 1845-2002) that are considered as the catalytic domain of TET2 protein $^{76}$. The mutations within these regions may influence proteinDNA association, protein-protein interaction or post-translational modifications. The TET2 mutations have also been found in lymphoma including angioimmunoblastic T-cell lymphomas $(\sim 76 \%)^{98}$ and peripheral T-cell lymphoma not otherwise specified $(\sim 38 \%)$ along with Ras homolog gene family, member A (RHOA) mutations ${ }^{99,100}$. 
Analyses of clonal architecture and mutation frequency of MDS and CMML indicate that TET2 mutations occur at an early stage of cell differentiation, which leads to clonal expansion of leukemic stem cells ${ }^{101,102}$. However, the loss of Tet2 itself in mouse models is not able to initiate hematological disorders. In addition, most of TET2 alone mutations have been observed in older individuals with clonal hematopoiesis but without hematological malignancies ${ }^{103}$. Therefore, it is possible to propose that there should be more gene mutations that serve as "driver mutations" which occur during hematological malignancies initiation and/or progression. Through meta-analysis of mutational sites of hematological malignant patients, TET2 mutations co-exist with other gene mutations such as serine/arginine-rich splicing factor 2 (SRSF2), enhancer of zeste 2 polycomb repressive complex 2 subunit $(\mathrm{EZH} 2)$ and additional sex combs like transcriptional regulator 1 (ASXL1) in MDS and CMML ${ }^{102,104,105}$ (Figure 9). The SRSF2 belongs to splicing factors that recognize 3' splice-site and mediate ATP-dependent interactions between U1/U2 snRNPs and pre-mRNA. Like TET2, SRSF2 is frequently mutated in myeloid cancers. EZH2 is an $\mathrm{H} 3 \mathrm{~K} 27 \mathrm{me} 3$ reader and it is the key component of polycomb repressive complex 2 (PRC2) while ASXL1 differentially recruits methylated $\mathrm{H} 3$ to promoters and it also mediates deubiquitination of H2AK119ub1 $1^{104,106,107}$. In AITL patients, TET2 mutations accompany a recurrent mutation in RHOA (G17V) which is a small GTPase that regulates cell morphology and migration ${ }^{99}$. The DNMT3A mutations also co-exist with TET2 mutations in T-cell lymphomas ${ }^{99}$. Therefore, TET2 mutations happen in the early stages of hematopoietic stem/progenitor cells, but the mutation alone does not lead to malignant transformations. Additional gene mutations must occur, along 
with TET2 mutations for oncogenesis to take place, as in the case of various types of hematological malignancies (Figure 11).

In addition to the hematological system, TET genes mutations also exist in solid tumors at quite low frequencies, according to The Cancer Genome Atlas (TCGA) database. For example, all TET genes mutations are found in colorectal cancer, clear-cell renal cell carcinoma and metastatic castration-resistant prostate cancer ${ }^{108-110}$. It is still unknown if TET mutations contribute to initiation/progression in these solid cancers. Additional studies will help to clarify the "driver mutations" in TET mutant background which trigger cell proliferation and survival during oncogenesis. Crossing TET knockout mice with current cancer-specific mouse models may help increase our understanding of TET functions.

\subsection{TETS AND 5-HYDROXYMETHYLCYTOSINE IN NEUROGENESIS AND NEURODEVELOPMENT}

Neurogenesis produces various types of functional neural cells from neural stem cells (NSC). Neurogenesis occurs not only at the embryonic stage but also adult stage throughout the life span of the individual. Such could be considered as an essential neural activity/mechanism for regulating learning and memory ${ }^{111}$.

Embryonic neurogenesis in mice usually starts from embryonic day 8 (E8) to E14 ${ }^{112}$. During E8-E10, neuroepithelial cells undergo transformation in the ventricular zone (VZ) and subventricular zone (SVZ), thereby allowing the cells to acquire astroglial properties $^{113}$. These radial glial cells (RGs) have "stem" features, which trigger the generation of nascent neurons or intermediate neuron progenitor cells. When RGs initiate symmetrical mitosis, neurons are generated. However, if RGs go through asymmetrical 
mitosis, other "stem" cells are produced ${ }^{114}$. Newly synthesized neurons and glial cells then migrate to the cortex during embryonic development to thicken the neocortex and build up complicated neural networks ${ }^{111}$. At the end of embryonic development, RGs detach from the ventricular zones, and move to the cortical plate and transform into astrocytes. Some RGs quietly remain in the SVZ and are responsible for adult neurogenesis ${ }^{113}$.

Adult neurogenesis occurs in two germinal zones of the brain: the subgranular zone (SGZ) in dentate gyrus and subventricular zone (SVZ) in lateral ventricles (Figure 12). Adult neurogenesis is regulated by many cellular activities including neural stem cell (NSC)/neural progenitor cell (NPC) proliferation and differentiation, fate determination, maturation and localization of newborn neurons ${ }^{115,116}$. And because neurogenesis occurs largely in these two regions, it is reasonable to postulate that neurogenesis may play a major role in regulating learning and memory. In SGZ, two types of NSC have been identified, type I and type II cells. Type I cells are radial glia-like cells, which maintain self-renewal and may differentiate to type II cells, even astrocytes. As well, the morphology and cellular markers of type I and type II cells are slightly different. Other than the common Nestin marker, type I cells are glial fibrillary acidic protein positive $\left(\right.$ GFAP $\left.^{+}\right)$while type II cells are GFAP'. Two cell types constitute the NSC/NPC in SVZ: type B cells are self-renewal radial glia-like cells that are able to differentiate to type C cells, and these transient amplifying cells can also transform into neuroblasts at a later development period ${ }^{115}$. Neurogenesis generates various types of neural cells with the same genome but with distinct properties, suggesting a role for epigenetic regulation in neurogenesis (Figure 13). Significant DNA methylation occurs in neurons and astrocytes. 
Consider GFAP which is a cellular marker for astrocytes. The promoter region of GFAP is initially hypermethylated, which blocks the differentiation of astrocytes. However, at specific stages during development, the GFAP promoter becomes hypomethylated and then initiates the differentiation of astrocytes. Two additional critical neural factors, brain-derived neurotrophic factor (BDNF) and fibroblast growth factor (FGF), are regulated by Tet 1 protein in terms of the demethylation of BDNF and FGF promoters ${ }^{117}$.

Studies that have mapped genome-wide $5 \mathrm{hmC}$, have shown that $5 \mathrm{hmC}$ distributes temporally and spatially during neurodevelopment ${ }^{61,118,119}$. For example, studies have shown an age-dependent abundance and distribution of $5 \mathrm{hmC}$ in the cerebellum and hippocampus. Interestingly, $5 \mathrm{hmC}$ acquisition in these regions is different than what would be expected. There is no strong correlation between $5 \mathrm{hmC}$ acquisition and $5 \mathrm{mC}$ loss in many important neurodevelopment-related genes, therefore one could argue that $5 \mathrm{hmC}$ role in gene regulation may be via a mechanism other than by transient oxidation in the brain ${ }^{118}$. To better understand the role of $5 \mathrm{hmC}$ in the brain, more than 6000 differentially hydroxymethylated regions (DhMRs) at different ages have been identified. These DhMRs were only found in adult brain, from 6-week-old brain, but not in postnatal day 7 (P7) cerebellum, indicating long-term modification of $5 \mathrm{hmC}$ in the brain ${ }^{118,119}$. Although the correlation of $5 \mathrm{hmC}$ abundance and gene transcription is still unclear, the enrichment of $5 \mathrm{hmC}$ and loss of $5 \mathrm{mC}$ at gene bodies coincide with gene transcription activation $^{119}$. In fact, $5 \mathrm{hmC}$ regulation of neurogenesis was reported in 2011. Tet1 overexpression in the dentate gyrus (DG) significantly downregulated the methylation levels of Bdnf and Fgflb, highlighting the role of $5 \mathrm{hmC}$ in neurogenesis ${ }^{117}$. Several types of neurodevelopment and neurodegenerative disorders have been found closely 
associated with 5hmC, such as Rett syndrome, Autism spectrum disorder and Alzheimer's disease ${ }^{120}$.

Because of the extensive roles of $5 \mathrm{hmC}$ and TETs, several studies have explored TET proteins functions in neurogenesis ${ }^{117,121}$. There is evidence that Tet $1^{-/-}$mice exhibits robust loss $(\sim 45 \%)$ of NSCs in the SGZ compared with WT mice and neurospheres from Tet1 $^{-/}$show growth defects. Microarray studies have shown that many genes (Galanin, $\mathrm{Ng} 2$ and $\mathrm{Ngb}$ ) that are down-regulated during NSC proliferation ${ }^{121}$. In addition, Tet $1^{-/-}$ mice show increased hippocampal long-term repression and memory defects ${ }^{121}$. Moreover, in Xenopus, Tet3 has been found to regulate early eye development and neurodevelopment transcriptionally. Deletion of Tet3 decreases neuronal genes in the eyes $^{74}$. The role of Tet2 in neurogenesis is still unknown.

My dissertation begins with a review of the molecular basis of DNA methylation and demethylation with a particular focus on newly identified 5hmC and TET family proteins, along with their contribution to the pathogenesis of hematological and neurological disorders. In chapter 2, I discuss the proposed work on uncovering the role of Tet2 in hematological malignancies. Section 2.3 introduces the methods and approaches being used in this chapter. I then describe the results and discussions I have achieved to date in Section 2.4. Later, in Section 2.5, I draw conclusions about what I have observed. Given the roles of $5 \mathrm{hmC}$ and Tet 2 in the nervous system, I discuss specific findings of Tet2 in adult neurogenesis in chapter 3. In Section 3.3, I describe the materials and methods being used in this chapter. Section 3.4 presents the results including Tet2 regulation in NPC proliferation and differentiation. Specific conclusions 
are drew in Section 3.5. Finally, chapter 5 summarizes all the observations of the study presented in chapter 2 and 3, as well as discusses directions for future research. 

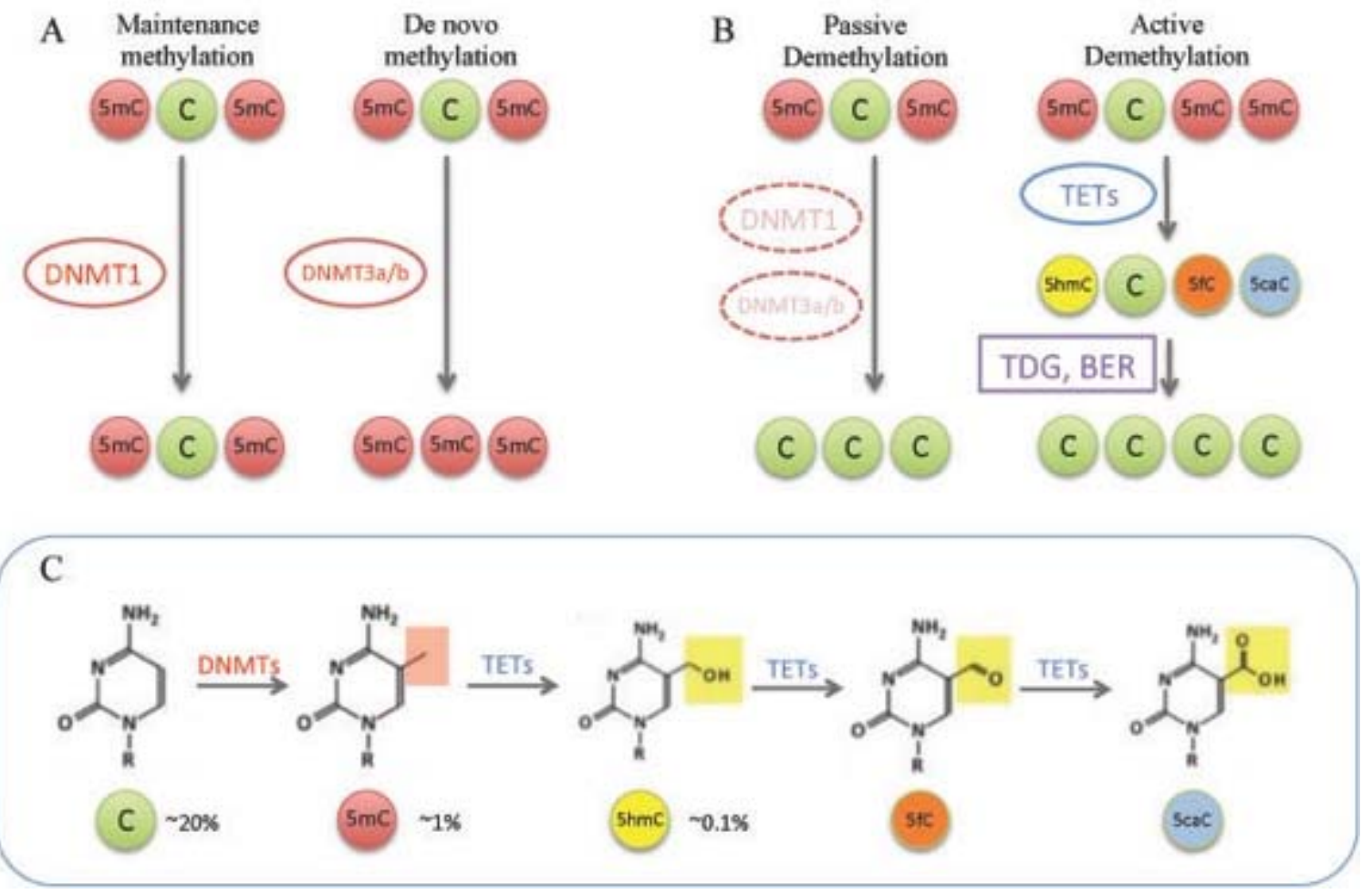

Figure 1 DNA methylation and demethylation pathways.

(A) DNMT1 adds methyl group to hemimethylated DNA. DNMT3a/b add methyl group to non-methylated DNA. (B) Passive demethylation occurs through the absence of DNMTs. TETs mediate active DNA demethylation through hydroxylation of $5 \mathrm{mC}$ to $5 \mathrm{hmC}, 5 \mathrm{fC}$ and $5 \mathrm{caC}$, which can be recognized and removed by base excision repair. (C) The molecules involved in DNA methylation and demethylation. 


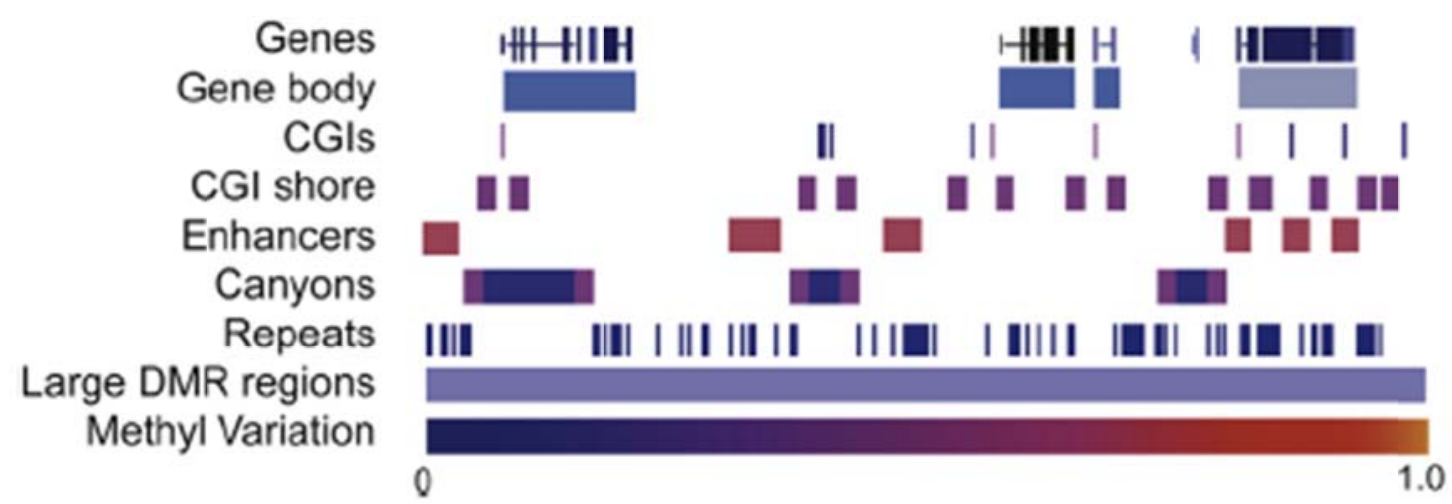

Figure 2 The dynamic methylome landscapes of different genomic elements ${ }^{16}$. DNA methylation levels vary from low (blue) to high (red). CGI shores, enhancers and canyon edges indicate the most differentially methylated regions. 

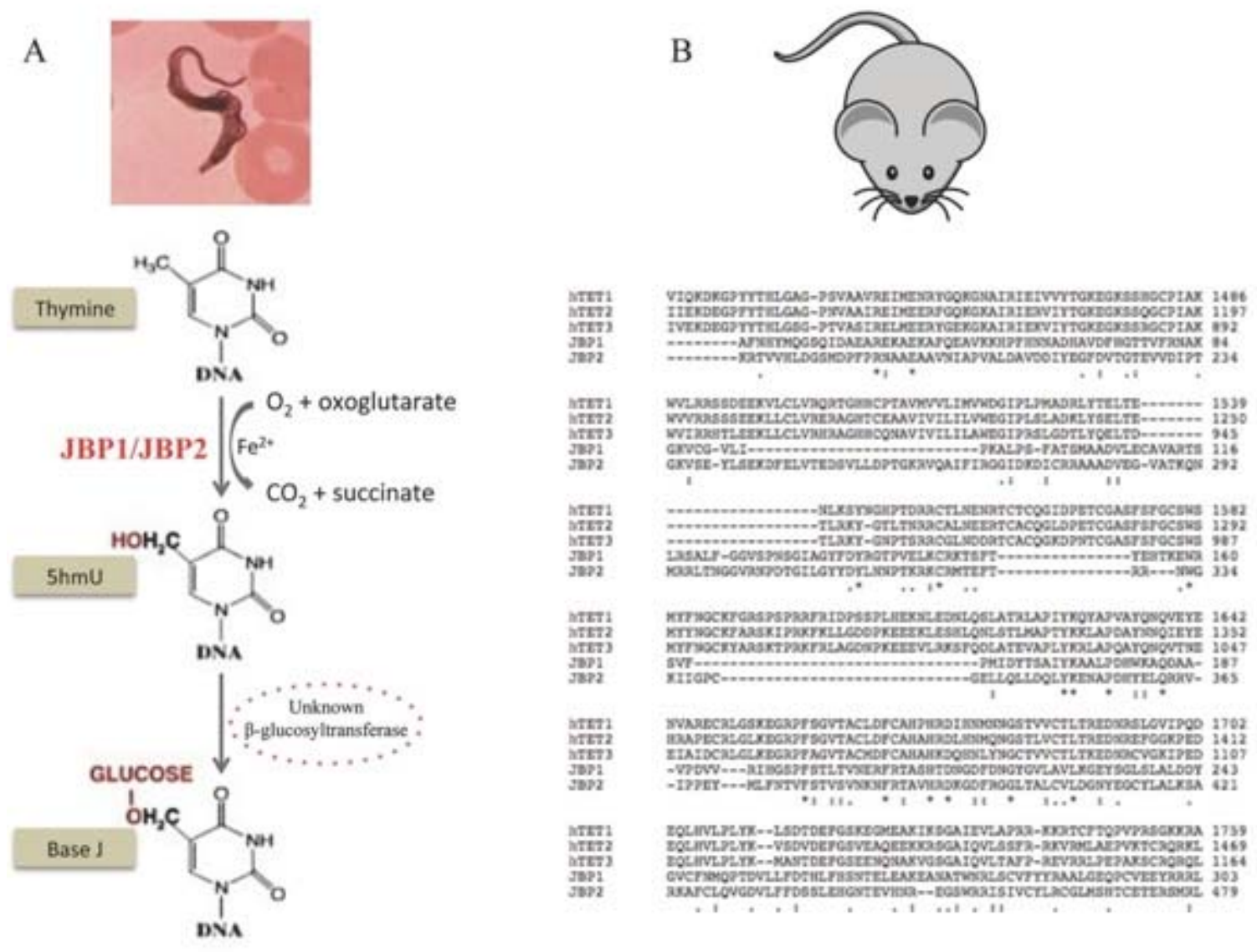

Figure 3 TETs are the homolog of JBPs.

(A) The biogenesis of base J. JBP1/2 oxidize thymidine to produce $5 \mathrm{hmU}$, which can be further catalyzed to base $\mathrm{J}$ by unknown glucosyltransferases. (B) The multiple alignments of JBP1, JBP2, TET1, TET2 and TET3 are performed using Clustal Omega. These five proteins are highly conserved in their oxygenase regions. 


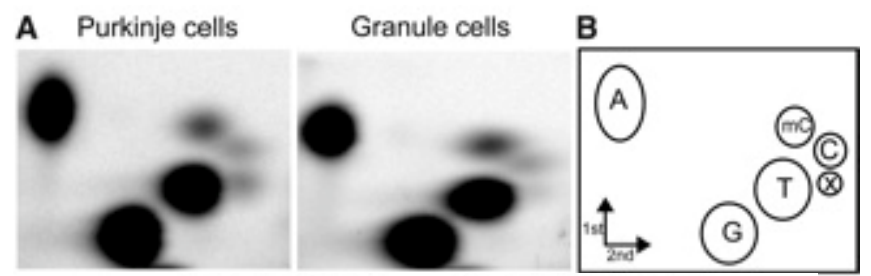

Synthetic DNA C

Synthetic DNA C+hmC
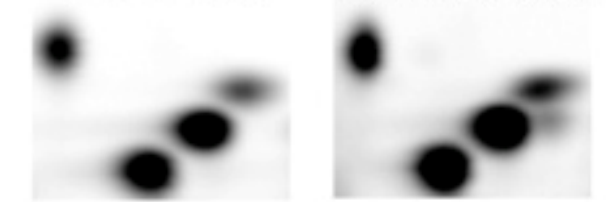

Figure 4 Quantification of $x$ in Purkinje cells and granule cells ${ }^{38}$.

(A) Nucleoside monophosphates separated from genomic DNA in Purkinje and granule cells. (B) Reference map. 


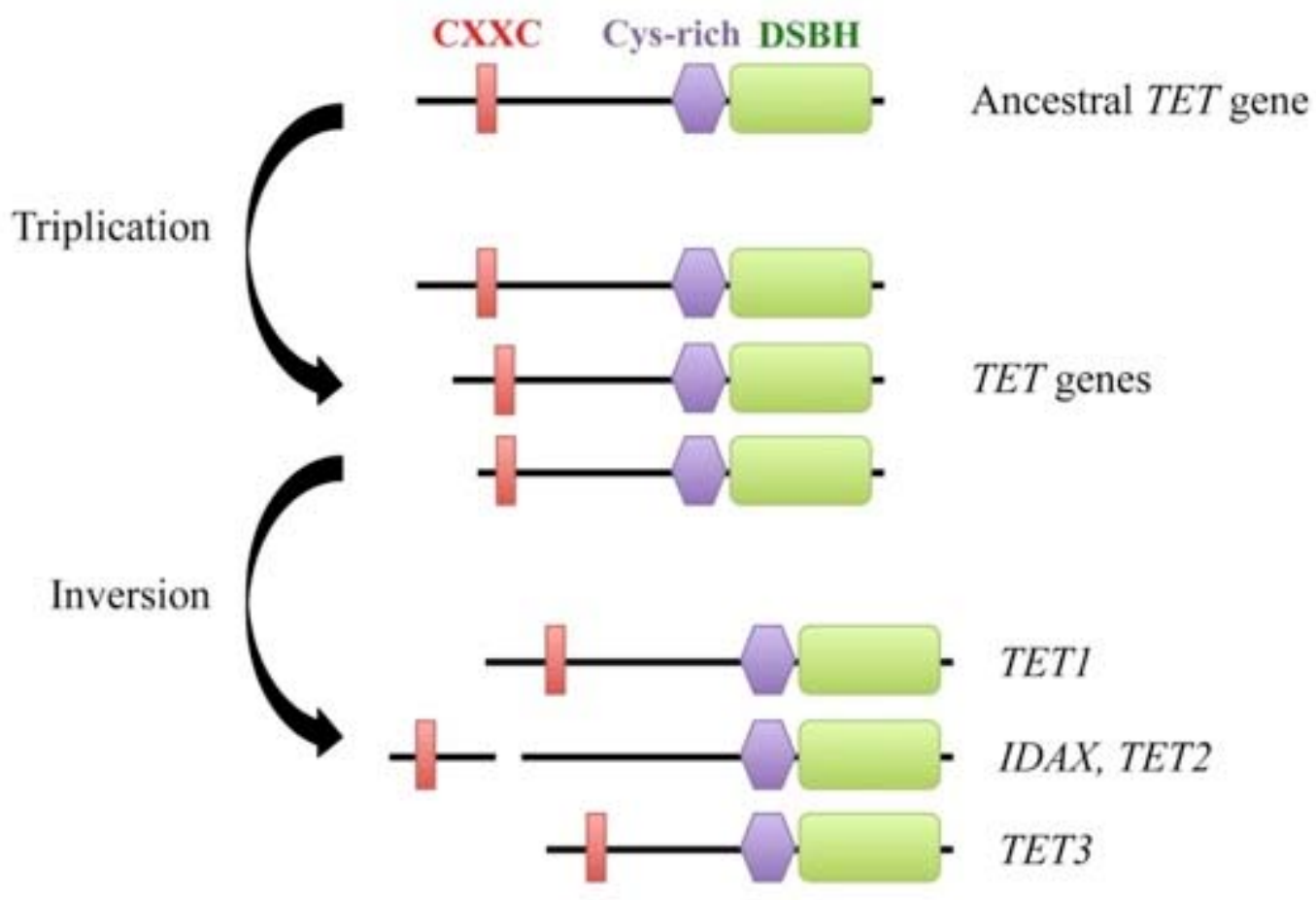

Figure 5 The protein structures of TET family.

TETs have a DNA-binding CXXC domain at N-terminal and Cys-rich domain, DSBH domain located at C-terminal. An ancestral TET gene triplicated into three TET family members. Chromosome inversion occurred and separated TET2 from its CXXC domain, which generated IDAX. 
Bisulfite sequencing

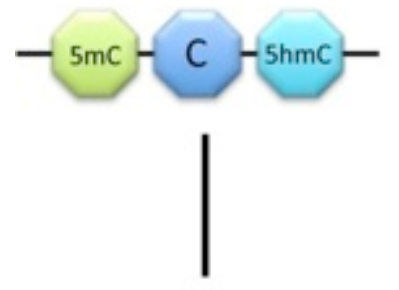

Bisulfite treatment

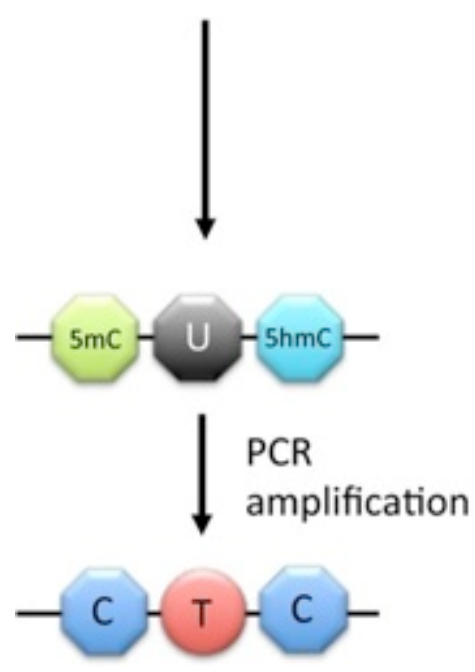

TET-Assisted Bisulfite Sequencing

(TAB-Seq)

genomic DNA
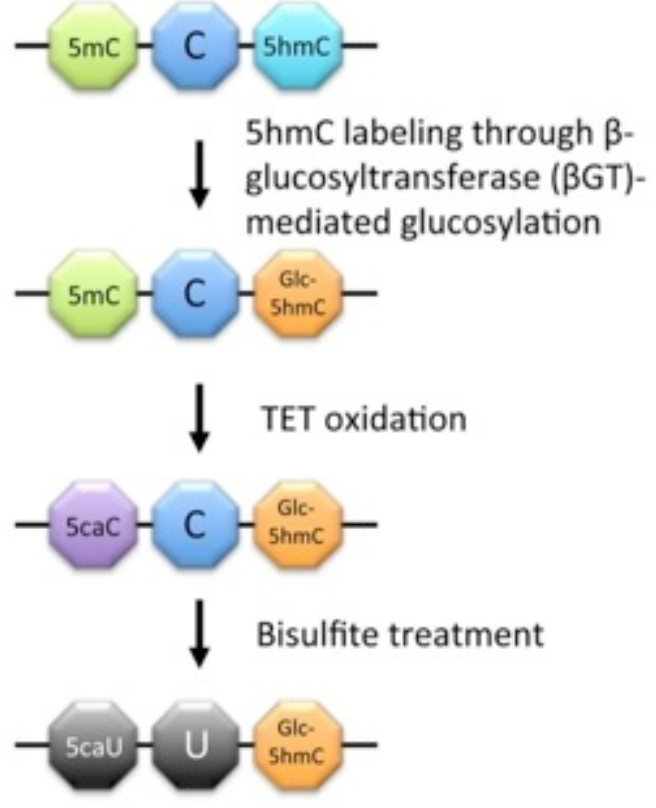

Read as

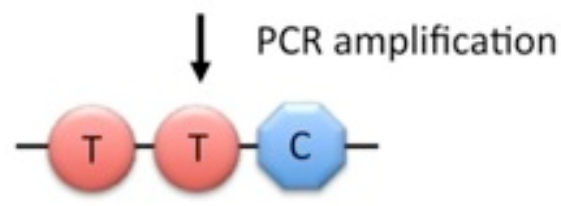

Figure 6 Assays for mapping $5 \mathrm{mC}$ and $5 \mathrm{hmC}$ at single-base resolution.

Traditional bisulfite sequencing separates $5 \mathrm{mC}$ from regular cytosine. TET-assisted bisulfite sequencing separates $5 \mathrm{hmC}$ from $5 \mathrm{mC}$. 

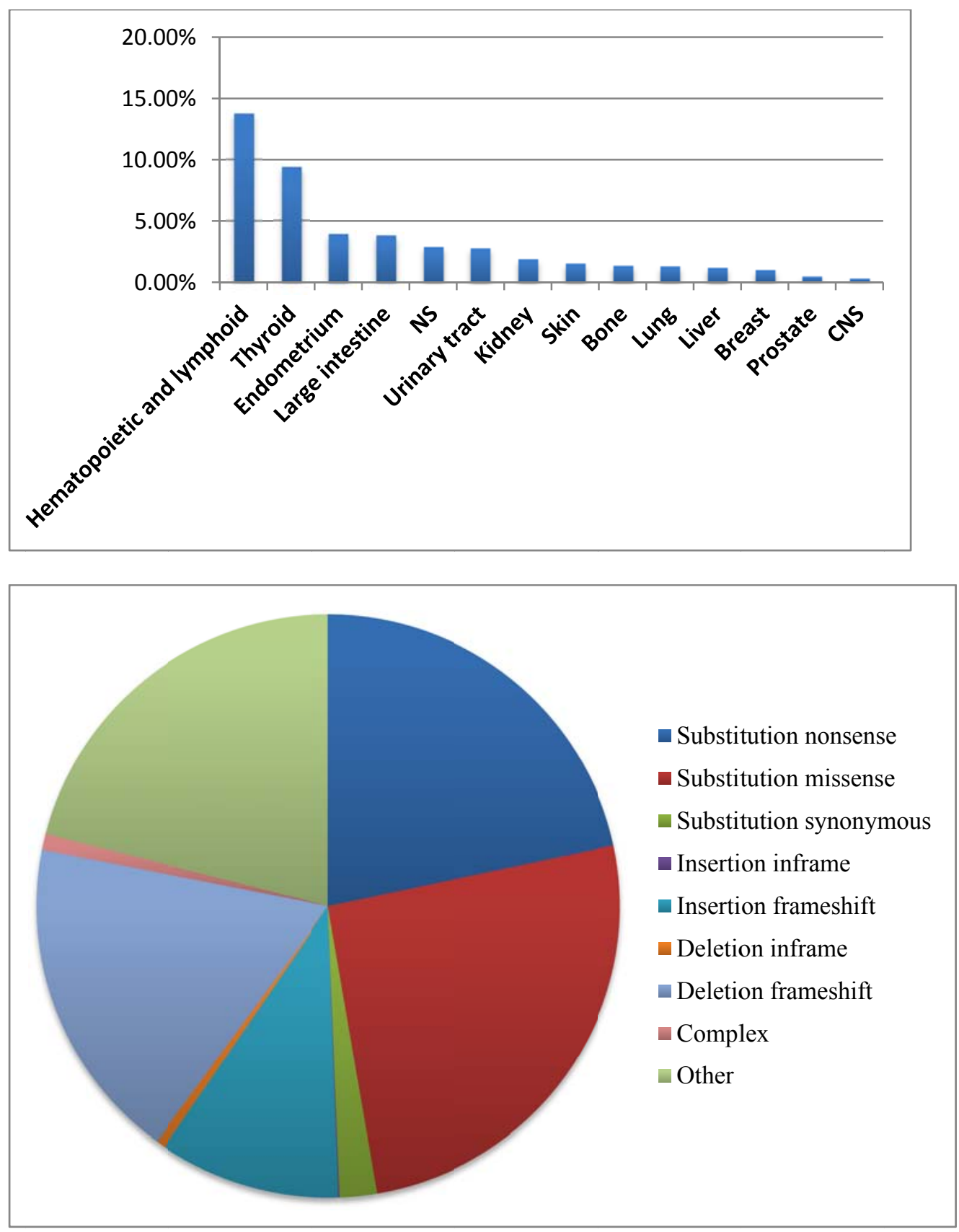

Figure 7 TET2 mutations detected in individuals with different tumors.

(A) TET2 mutations frequently occur in hematological malignancies and solid tumors. (B) Pie chart of TET2 mutations distribution. Data collected from Catalogue of somatic mutations in cancer database. 


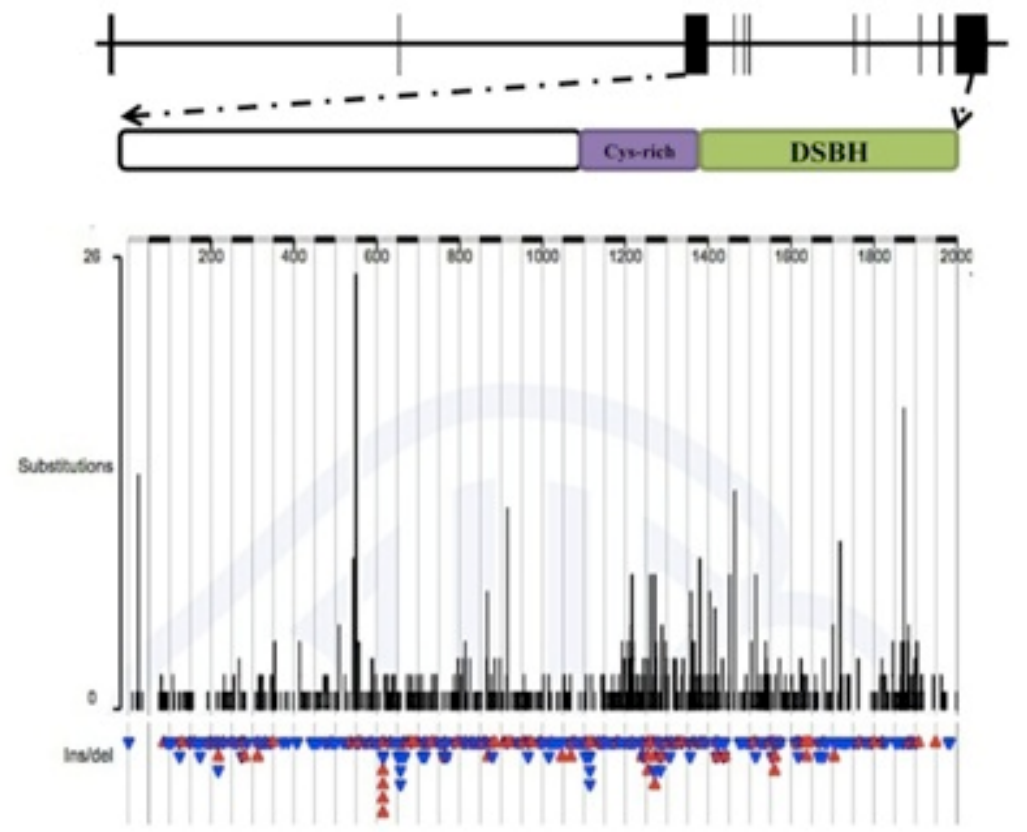

Figure 8 Histogram of TET2 mutations.

Data collected from Catalogue of somatic mutations in cancer database. 


\begin{tabular}{lll}
\hline Gene & Malignancy & Mutation $\%$ \\
\hline DNMT3A & AML & $12 \%-22 \%$ \\
MDS & $8 \%$ \\
MPN & $7 \%-15 \%$ \\
TET2 & CMML & $4 \%$ \\
& AML & $12 \%-34 \%$ \\
& MDS & $20 \%-25 \%$ \\
& MPN & $4 \%-14 \%$ \\
& CMML & $50 \%$ \\
\hline
\end{tabular}

Table1.1 Mutations of DNMT3A and TET2 in hematological malignancies ${ }^{16}$. The incidence of DNA modification related gene DNMT3A and TET2 mutations in hematological malignancies. 


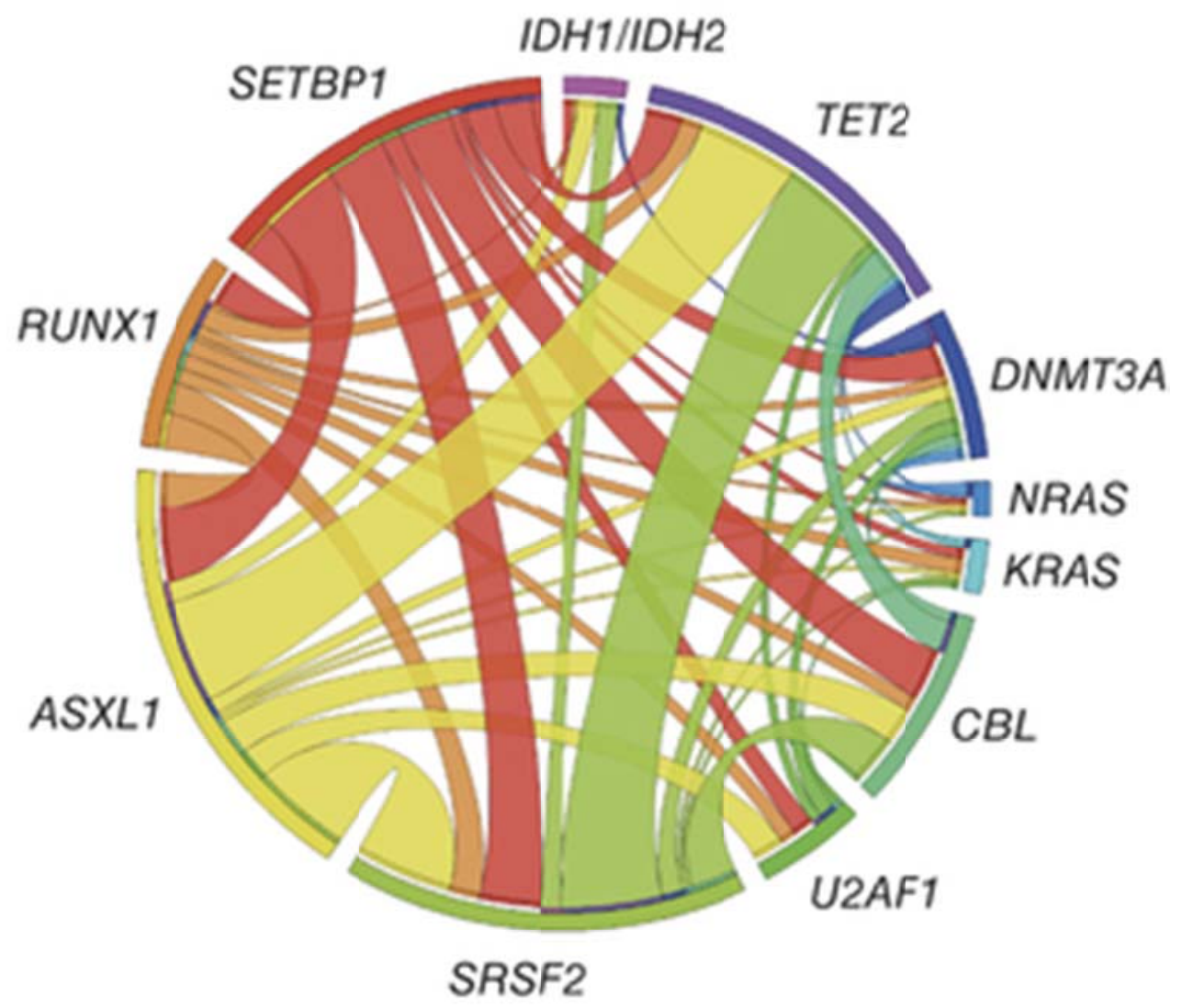

Figure 9 Circos plots demonstrating 12 coexisting genes in a cohort of patients with myeloid malignancies ${ }^{122}$.

12 genes have been have been identified fro coexisting genes that show mutual mutations. Ribbons connecting distinct gene mutations within this plot reflect the position and frequency between different gene mutations. 


\begin{tabular}{ll}
\hline Interactor & Function \\
\hline OGT & $\begin{array}{l}\text { TET2 recruits OGT to chromatin to regulate H3K4me3 } \\
\text { and gene transcription }\end{array}$ \\
IDAX & $\begin{array}{l}\text { Promotes degradation of TET2 through caspase pathway } \\
\text { EBF1 }\end{array}$ \\
Uhrf2 & Pnknown function \\
Vitamin C & Promotes Fe(II) and 2-oxoglutarate dependent dioxygenases \\
miR22 & Decreases Tet2 pre-mRNA expression level \\
\hline
\end{tabular}

Table 1.2 Identified TET2 interactor ${ }^{123}$. Several protein complexes, microRNA and small molecule have been shown to interact with TET2. 

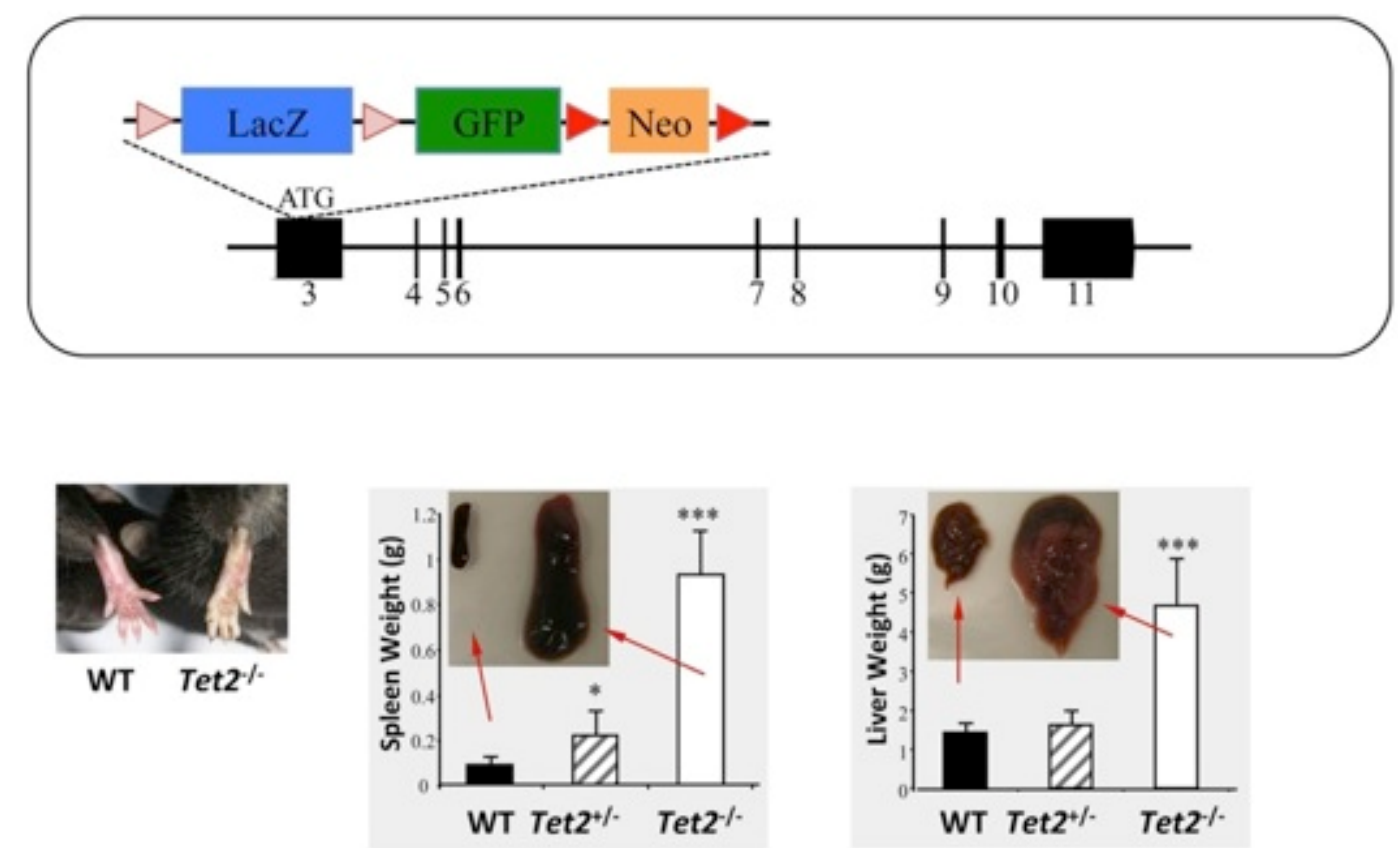

Figure 10 Tet2 $^{-/-}$mice develop lethal myeloid malignancies ${ }^{84}$.

(A) Targeting strategy of Tet2 knockout mouse model. (B) Appearance of Tet2 ${ }^{-/-}$mice with pale footpads, splenomegaly and hepatomegaly. 


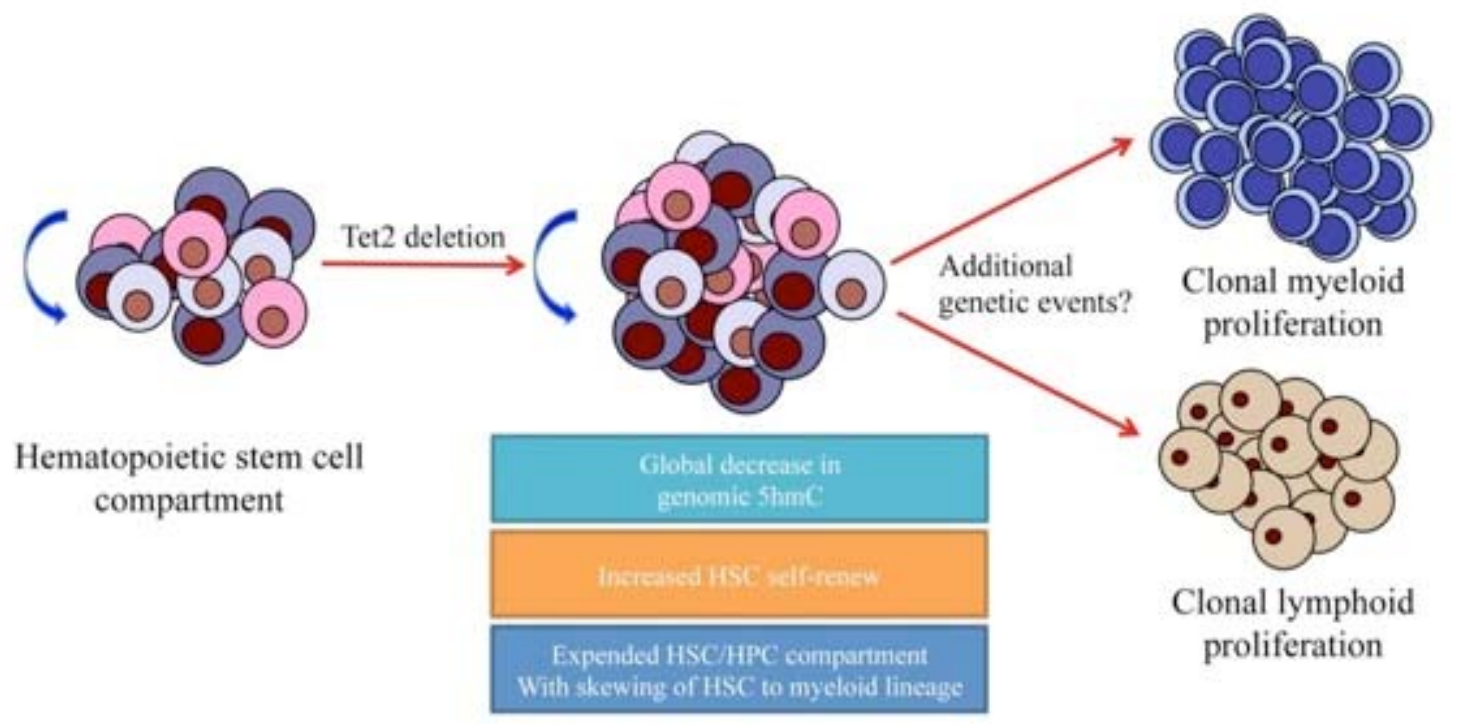

Figure 11 TET2 background mutations cause various hematological malignancies.

TET2 mutations may occur in hematopoietic stem/progenitor cells with aging suggesting that additional genetic events lead to the initiation/progression of the diseases. 


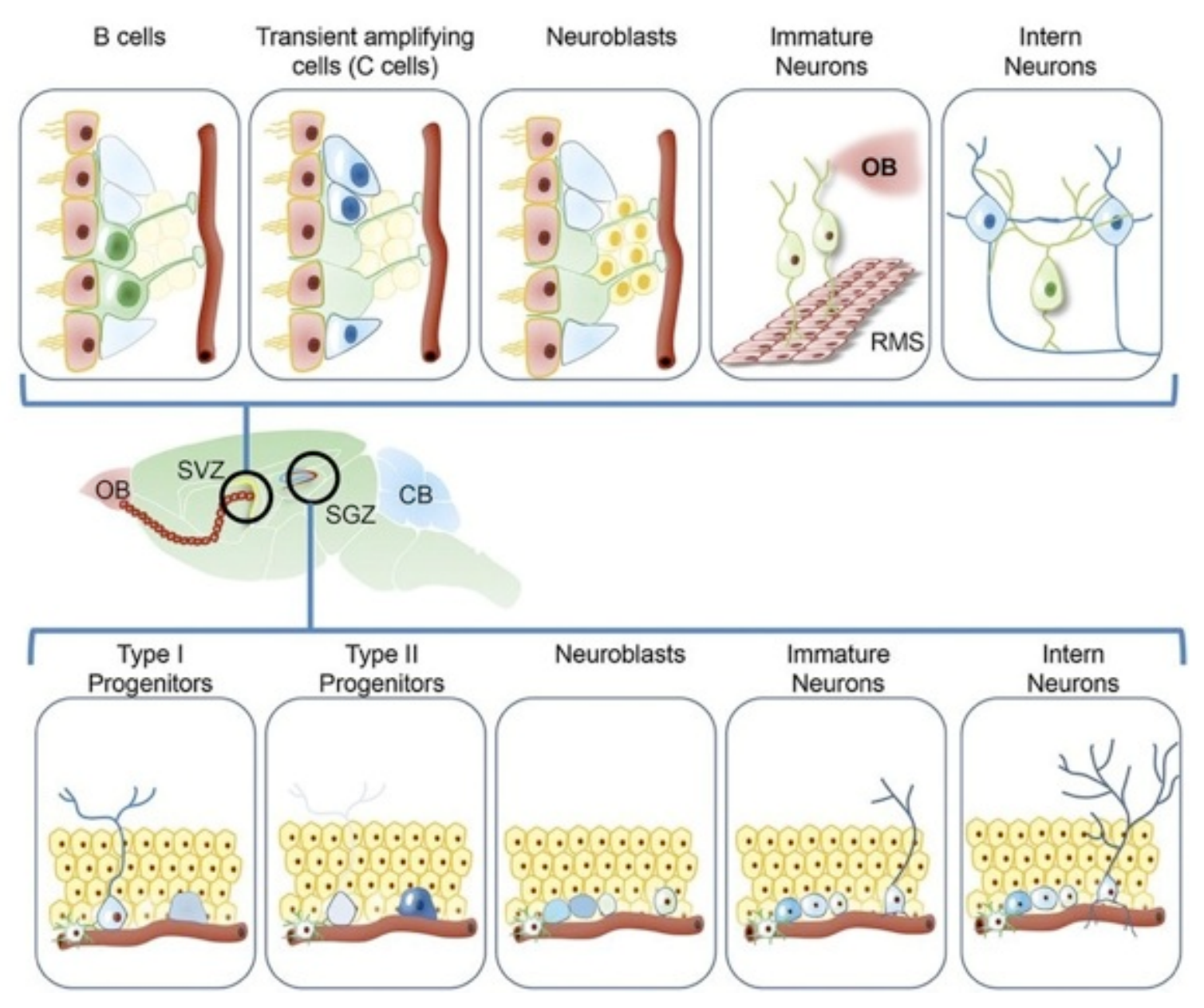

Figure 12 Adult neurogenesis ${ }^{111}$.

In subventricular zone, B-cells (Quiescent RGs) are activated and produce C-cells (transient amplifying cells). C-cells transform to neuroblasts and migrate though rostral migratory stream to olfactory bulb as interneurons. In the dentate gyrus, type I progenitors give rise to type II progenitors, which migrate to granule cell layers and transform to neuroblasts. The neuroblasts then become immature neurons and merge into neural circuit through synaptic integration. 

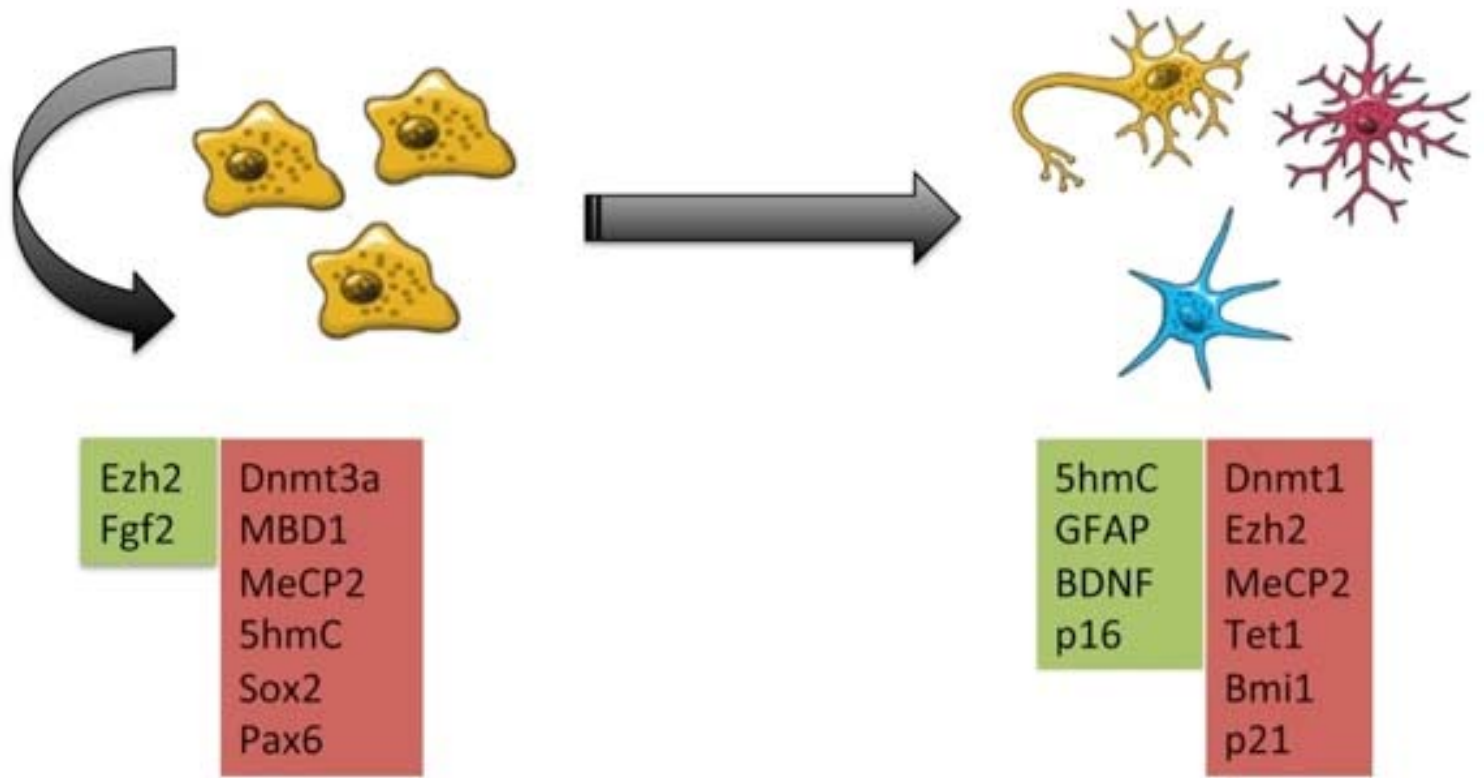

Figure 13 Transcriptional epigenetic regulators in adult neurogenesis.

Green columns highlight the positive regulators and red columns indicate the negative regulators. The left columns are the regulators that impair NSC differentiation and neurogenesis. The right columns are the regulators that promote NSC differentiation and aberrant neurogenesis. This figure was modified from (Yao et al. 2014) ${ }^{111}$. 


\section{CHAPTER}

TET2 PROTECTS GENOMIC STABILITY THROUGH INTERACTING WITH MSH6 


\subsection{Abstract}

Ten-eleven translocation 2 is a member of dioxygenases that catalyze the multi-step $5 \mathrm{mC}$ oxidation. Loss-of-function TET2 mutations are frequently associated with hematological malignancies; however, the underlying mechanism remains unknown. Here, I show that Tet $2^{-/-}$mice develop spontaneous myeloid, T- and B-cell malignancies. The mice with T-cell lymphoma/leukemia are characterized with enlargement of spleen, liver and thymus. The normal architecture of these organs are disrupted by abnormal lymphoid with cells aberrantly expressing CD4 and CD8. Mice with B-cell lymphoma/leukemia display enlarged lymph nodes and atypical lymphoid infiltrates are observed in the small intestines. Cells with B-cell lineage are altered in different tissues, particularly, B220+/low IgM/low CD43/CD19+ with high forward scatter. To obtain a more detailed view of the role of Tet2 in hematopoiesis, sublethally irradiated F1 mice were transferred with $\mathrm{Tet}^{-/-} \mathrm{T}$-cell and B-cell tumor cells. Both T-cell and B-cell malignancies were transplantable, suggesting the malignant and neoplastic nature of the infiltrating $\mathrm{T}$ - or $\mathrm{B}$ - lymphocytes in $\mathrm{Tet} 2^{-/}$mice. To explore genome-wide genetic alterations and multiple lineage involvement in Tet $2^{-/}$mice, additional exome sequencing of $\mathrm{Tet}^{-/}$tumors were performed, which revealed acquisition of numerous mutations, including genes frequently mutated in human hematological malignancies such as Neurogenic locus notch homolog protein 1 (NOTCH1) and fms-related tyrosine kinase 3 (FLT3). The mutation frequency in Tet $2^{-/-}$tumors is significantly greater at loci containing Tet2-dependent active demethylation. To investigate the underlying mechanism by which Tet2 loss may result in genomic instability, I found that TET2 associates with MutS homolog 6 (MSH6), a key component of DNA mismatch repair 
(MMR) using both Tet2-tag knock-in ES clones and human TET2 overexpressing cell line. The association between TET2 and MSH6 was substantiated by immunostaining. The latter study showed that these two proteins bind closely to each other at S-phase. To examine if TET2 loss impairs DNA mismatch repair, I depleted TET2 in HeLa cells. TET2-deficient cells displayed elevated spontaneous mutational frequencies and increased microsatellite instability, characteristic of MMR-deficient cells. Consistently, myelodysplastic syndrome patients with TET2 mutations exhibit significantly higher mutational events than patients without TET2 mutations. Together, these results suggest that TET2 protects genomic stability through interacting with MSH6, unveiling a novel means by which TET2 loss leads to diverse hematological malignancies.

\subsection{INTRODUCTION}

Ten-eleven translocation (TET) family of methylcytosine dioxygenases (Tet1/2/3) catalyze the conversion of 5-methylcytosine $(5 \mathrm{mC})$ to 5 -hydroxymethylcytosine $(5 \mathrm{hmC})$, which could be further oxidized to 5-formylcytosine (5fC) and 5-carboxylcytosine (5caC), resulting in active DNA demethylation ${ }^{39}$. The dynamic methylation/demethylation cycle has been shown to occur at a large number of genomic loci across the genome ${ }^{124}$. Several studies suggest that $5 \mathrm{hmC}$ may also have DNA demethylation-independent functions and serve as stable epigenetic marks that recruit specific readers, DNA repair proteins and transcription factors, with limited overlap between these TET proteins ${ }^{119,125}$. TET2 inactivation through mutations is a common event in myeloid and lymphoid malignancies, and has been detected also in solid tumors ${ }^{123}$. Several TET2 binding proteins have been identified, including O-linked $\mathrm{N}$-acetylglucosamine transferase (OGT), inhibition of the 
Dvl and Axin complex (IDAX) and early B-cell factor 1 (EBF1) ${ }^{72,126,127}$ (Table 1.2). Identification of critical novel partners of TET2 and unveiling functional significance of these interactions may provide valuable insights into the mechanism underlying the critical roles of TET2 in tumorigenesis of many cancers.

To fully unearth and characterize the nature of Tet2 in myeloid malignancies, four research groups generated Tet2 knockout murine models by different strategies. For example, Li et al (2011) inserted nLacZ/nGFP instead of partial exon 3 of Tet2 gene since exon 3 is the first and largest coding exon in Tet 2 and is also highly mutated in myeloid malignancies ${ }^{84}$. Through a specific interbreed crossing, a global knockout mouse model $\left(\mathrm{Tet}^{-/-}\right)$was obtained. We, and others examined hematologic parameters of WT, $\mathrm{Tet}^{+/-}$and Tet2 $2^{-/}$as early as 2 to 5 months of age. Notably, increased WBC counts and abnormal numbers of monocytes and neutrophils were observed in $T e t 2^{-/-}$peripheral blood. Besides the appearance of significant hepatosplenomegaly in most of the studies, we also found pale footpads in $\mathrm{Tet}^{-/}$that may indicate anemia and this was consistent with the decrease in erythrocytes and platelets counts in Tet2 $2^{-1-84}$, suggesting a possible occurrence of monocytosis and/or neutrophilia in Tet $2^{-/-}$mice. In addition to these mentioned findings in $\mathrm{Tet}^{-/}$mice, other changes include increased bone marrow (BM) cellularity, splenomegaly and hepatomegaly, as well as increased numbers of colony forming unit granulocyte, monocyte (CFU-GM) in BM and spleen. A resulting phenotype of these Tet $2^{-/}$mice is potentially CMML. Histologic studies reveal massive erythroid and/or myeloid infiltration in spleen and liver. Histopathology and cytospin studies identify specific cell types as myeloblasts, monocytes/macrophages and neutrophils ${ }^{84}$. Flow cytometric analyses of BM and spleen cells from Tet $2^{-/}$mice are consistent with 
the results from histologic analyses. Moreover, a large peritoneal mass and a few white nodules with $\mathrm{Gr}-1^{+} \mathrm{CD} 11 \mathrm{~b}^{+}$cells were observed in the liver, suggesting the existence of myeloid sarcoma ${ }^{84}$. Taken together, it is reasonable to believe that the deletion of Tet2 stimulated the differentiation and proliferation of $\mathrm{HSC} / \mathrm{HPC}$ and facilitated the development of myeloid malignancies.

Here, my consideration is to uncover the mechanisms of Tet2 and to discover TET2 interactors to better understand Tet2 loss induced tumorigenesis. Specifically, I proposed to: 1) characterize hematological malignancies in Tet $2^{-/-}$mice; 2) use whole genome analyzing tools to examine Tet2 ${ }^{-/-}$genomic landscape; 3) seek TET2 interactors that facilitate leukemogenesis; and 4) identify Tet2 regulatory network. Tet $2^{-/-}$mice develop spontaneous myeloid, T- and B-cell malignancies. Both T-cell and B-cell malignancies were transplantable, suggesting the malignant and neoplastic nature of the infiltrating Tor B- lymphocytes in Tet $2^{-/}$mice. To explore genome-wide genetic alterations and multiple lineage involvement in $\mathrm{Tet} 2^{-/}$mice, additional exome sequencing of $\mathrm{Tet} 2^{-/}$ tumors were performed, which revealed acquisition of numerous mutations, including genes frequently mutated in human hematological malignancies such as Neurogenic locus notch homolog protein 1 (NOTCH1) and fms-related tyrosine kinase 3 (FLT3). The mutation frequency in $\mathrm{Tet}^{-/-}$tumors were significantly greater at loci containing Tet2dependent active demethylation. To investigate the underlying mechanism by which Tet2 loss may result in genomic instability, I found that TET2 associates with MutS homolog 6 (MSH6), a key component of DNA mismatch repair (MMR) using both Tet2-tag knock-in ES clones and human TET2 overexpressing cell line. To examine if TET2 loss impairs DNA mismatch repair, I depleted TET2 in HeLa cells. TET2-deficient cells 
displayed elevated spontaneous mutational frequencies and increased microsatellite instability, characteristics of MMR-deficient cells. Consistently, myelodysplastic syndrome patients with TET2 mutations have significantly higher mutational events than patients without TET2 mutations. I therefore proposed that TET2 protects genomic stability through interacting with MSH6, unveiling a novel means by which TET2 loss leads to diverse hematological malignancies.

\subsection{MATERiALS AND METHODS}

\subsubsection{Analyses of mice}

Peripheral blood (PB) was collected by retro-orbital bleeding of mice and was smeared for May-Grunwald-Giemsa staining, and/or subjected to an automated blood count (Hemavet System 950FS). Morphological analysis and cell differential of BM and spleen samples were performed via cytospins $\left(5 \times 10^{5}\right.$ cells/sample) followed by MayGrunwald-Giemsa staining. For histopathology analyses, femurs were fixed in formaldehyde, decalcified, and paraffin embedded.

Spleens, livers, lymph nodes, thymus and intestine were treated similarly except for the step of decalcification. Sections $(4.5 \mu \mathrm{m})$ were stained with hematoxylin/eosin (H\&E). Flow cytometric analysis was performed as previously described ${ }^{84}$. Total PB white blood cells were obtained after lysis of red blood cells. Single-cell suspensions from BM, spleen, liver, lymph node, thymus and PB were stained with panels of fluorochromeconjugated antibodies. Briefly, cells were divided into $40 \mu \mathrm{l}$ aliquots containing $2 \%$ FBS in PBS in 96-well plates. One microliter of antibodies was added into each well and incubated for $45 \mathrm{~min}$ at $4{ }^{\circ} \mathrm{C}$. Then, the stained cells were re-suspended in $150 \mu 12 \%$ FBS 
in PBS and processed for flow cytometric analysis. Dead cells were excluded by DAPI staining. The analyses were performed using a BD FACS CantoII or LSRII flow cytometer. All data were analyzed by FlowJo7.6 software.

\subsubsection{Tumor transfer assay}

Tumor transfer experiments were performed to evaluate the malignant nature of the abnormally infiltrated $\mathrm{T}$ - or B-lymphocytes in the moribund/deceased $\mathrm{Tet}^{-/-}$mice. Briefly, $1 \times 10^{6}$ spleen cells from primary Tet $2^{-/-}$or WT mice were transplanted into sublethally irradiated (600 cGy) F1 recipient mice $(\mathrm{CD} 45.1 / \mathrm{CD} 45.2, \mathrm{n}=5)$ through tail veins. Recipient mice were sacrificed when they became moribund or 6 months after injection. Donor cell chimerism in the $\mathrm{PB}$, spleen and $\mathrm{BM}$ were examined at the end of the observation period. The mice were also phenotypically analyzed to determine their hematological phenotype and development of T- or B-cell malignancies. None of the recipients receiving WT spleen cells developed pathology or gross evidence of disease within 6 months of transplantation. By contrast, all of the animals receiving spleen cells from $\mathrm{Tet}^{-/-}$mice with T- or B-cell leukemia/lymphoma developed diseases with similar characteristics as those observed in their respective primary donor animals including elevated WBC counts, lymphocytosis, splenomegaly, enlarged lymph nodes and death.

\subsubsection{Generation of FLAG-V5 Tag knock-in ES cells}

The targeting vector contained a neomycin (Neo) cassette flanked by two FRT sites, followed by a $0.5 \mathrm{~kb}$ genomic fragment upstream of the Tet 2 start codon and an ATG/3xFlag/V5 sequence. A $2.2 \mathrm{~kb} 5^{\prime}$ and a $4.8 \mathrm{~kb} \mathrm{3'}$ arm genomic fragments were 
subcloned into the vector for gene targeting. All the fragments were amplified using KOD Xtreme ${ }^{\mathrm{TM}}$ Hot Start DNA Polymerase and ES cell genomic DNA as template. KOD Xtreme standard reaction:

\begin{tabular}{lc}
\hline 2X Xtreme Buffer & $25 \mu \mathrm{l}$ \\
\hline dNTPs (2mM) & $10 \mu \mathrm{l}$ \\
PCR grade water & $10 \mu \mathrm{l}$ \\
Primer mix & $3 \mu \mathrm{l}$ \\
Template DNA & $1 \mu \mathrm{l}$ \\
KOD Xtreme Polymerase & $1 \mu \mathrm{l}$ \\
Total volume & $50 \mu \mathrm{l}$ \\
\hline
\end{tabular}

The three-step cycling was used to amplify the targets: $94^{\circ} \mathrm{C}$ for $2 \mathrm{~min}, 98^{\circ} \mathrm{C}$ for $10 \mathrm{~s}$, $60^{\circ} \mathrm{C}$ for $30 \mathrm{~s}$ and $68^{\circ} \mathrm{C}$ for $5 \mathrm{~min}$. Steps $2-4$ were performed for 35 cycles. The targeting vector was linearized by EcoRI or ScaI and electroporated into 129/sv mouse ES cells and screened by southern blot. I then examined the levels of WT- and Tagged-Tet2 transcripts in the Tet2:Tag ES cells by allele specific qPCR (ß-actin as internal calibrator). Using Tet2 primers for both WT-Tet2 and Tagged-Tet2, the expression of WT-Tet2 plus Tagged-Tet2 mRNA in Tet2:Tag ES cells was comparable to that in the WT ES cells. While, using the Tagged-Tet2 specific primers, the Tagged-Tet2 mRNA expression was not detected in control ES cells, suggesting the primers are Tagged-Tet2 mRNA specific. These data suggest that Tagged-Tet2 mRNA expression was comparable to WT-Tet2 mRNA expression in the Tet2:Tag ES cells. 


\subsubsection{Purification of TET2-associated proteins}

To search for binding partners of Tet2, I collected 30 plates $(10 \mathrm{~cm})$ of Tet2:Tag ES cells. Briefly, cells were washed with PBS and scraped off from the plates. Then, cells were fully re-suspended in Buffer A (10mM HEPES pH7.6, 420nM NaCl, $1.5 \mathrm{mM} \mathrm{MgCl}_{2}$, $0.2 \mathrm{nM}$ EDTA and $25 \%$ Glycerol) in order to separate cytoplasmic protein. Next, the remaining suspension was incubated with Buffer C (20mM HEPES pH7.6, 420nM NaCl, 1.5mM $\mathrm{MgCl}_{2}, 0.2 \mathrm{nM}$ EDTA and 25\% Glycerol) to obtain nuclear proteins. The nuclear extracts were incubated with $0.2 \mathrm{ml}$ anti-Flag M2 beads at $4^{\circ} \mathrm{C}$ for at least $4 \mathrm{~h}$. The beads were washed and associated proteins were eluted twice with $200 \mathrm{ng} / \mu \mathrm{l} 3 \mathrm{xFlag}$ peptide (Sigma). The eluted proteins were analyzed by 10\% SDS-PAGE and gel slices were subjected to trypsin digestion followed by liquid chromatography and tandem mass spectrometry (LC-MS/MS) as described previously ${ }^{128}$. WT ES Cells were used as purification control.

\subsubsection{Constructs}

WT TET2 was cloned into pOZ-FH-N vector. A mammalian codon optimized human TET2 cDNA was cloned into pcDNA3.1 vector. TET2-N (amino acid 1-942), TET2-M (amino acid 943-1322) and TET2-C (amino acid 1323-2002) were cloned into pcDNA3.1 vector. Briefly, the human TET2 fragments were amplified by PCR and the products were sub-cloned to pCR-Blunt II-TOPO for validating sequences. 


\begin{tabular}{lc}
\hline Fresh PCR products & $3 \mu \mathrm{l}$ \\
Salt solution & $1 \mu \mathrm{l}$ \\
Water & $1 \mu \mathrm{l}$ \\
pCR-Blunt II-TOPO & $1 \mu \mathrm{l}$ \\
Total volume & $6 \mu \mathrm{l}$
\end{tabular}

The reaction was mixed gently and incubated for $5 \mathrm{~min}$ at room temperature. Normally, 1 $\mu l$ mixture was pipetted directly into one vial of competent cells. The vial was incubated on ice for $30 \mathrm{~min}$. Then, the vial was incubated in $42^{\circ} \mathrm{C}$ for $30 \mathrm{~s}$ and on ice for $2 \mathrm{~min}$. Prewarmed S.O.C. medium was added to each vial and the vial was incubated at $37^{\circ} \mathrm{C}$ for 1 hour at $225 \mathrm{rpm}$. About $200 \mu \mathrm{l}$ mixture was spread on the LB agar plates with kanamycin for colony selection. The sequence confirmed clones were cloned into pcDNA3.1 vector using NheI and XhoI. Each of these vectors contained Flag-tag and nuclear localization signal at their N-terminal.

\subsubsection{RNA interference}

shRNA sequences targeting mouse Tet2 (5'-GCTTACAGAATGGAGGGATAA-3' or 5'-CGGGTTCATATTTGAATCCTT-3') were inserted into the pLKO.puro.IRES.mCherry vector. Generation of lentivirus was carried out as previously described. shRNA sequences targeting human TET2 (CCGGCCTTATAGTCAGACCATGAAACTCGAGTTTCATGGTCTGACTATAAGG TTTTTTG) and human MSH6 (CCGGGCCAGAAGAATACGAGTTGAACTCGAGTTCAACTCGTATTCTTCTGGC TTTTTG) were cloned into pLKO.1-puro vector. 
The tissue culture 6-well plates were treated with $0.01 \%$ poly-L-lysine for $5 \mathrm{~min}$ at RT. HEK293T cells $\left(1 \times 10^{6}\right)$ were seeded in each well for 24h using Dulbecco's Modified Eagle's Medium with 10\% fetal bovine serum (FBS) and 1\% Penicillin-Streptomycin. When cells confluence reached $90 \%$, transfection mixture was prepared. $3.75 \mu 1$ Lipofectamine ${ }^{\circledR} 3000$ was diluted by $125 \mu$ l Opti-MEM ${ }^{\circledR}$ Medium. Next, 500 ng pLKO construct, 50ng pCMV-VSVG and 450ng psPAX2 were mixed with $125 \mu 1$ Opti-MEM® Medium and $5 \mu 1 \mathrm{P} 3000^{\mathrm{TM}}$ Reagent. Diluted DNA was added to diluted Lipofectamine ${ }^{\circledR}$ 3000 reagent at RT for 5min. The DNA-lipid complex was dropped to cells. The virus containing supernatant was collected after 24 and $48 \mathrm{~h}$ for instant lentivirus titer test using Lenti-X ${ }^{\mathrm{TM}}$ GoStix ${ }^{\mathrm{TM}} .1 \times 10^{6} \mathrm{HeLa}$ or NIH3T3 cells were re-suspended in $500 \mu 1$ lentivirus supernatant and transferred to $24-w e l l$ plates. Polybrene $(8 \mu \mathrm{g} / \mathrm{ml})$ was added to each well and the plate was centrifuged at $2000 \mathrm{rpm}$ for $90 \mathrm{~min}$ at $37^{\circ} \mathrm{C}$. Another $500 \mu \mathrm{l}$ complete medium was added to each well for $48 \mathrm{~h}$. The viral-infected cells were selected by puromycin $(2 \mu \mathrm{g} / \mathrm{ml})$ for $72 \mathrm{~h}$ and then used for phenotypic and/or functional analysis.

\subsubsection{Real-time PCR}

Total RNA was isolated and put on ice. The reverse transcription reaction included: $6 \mu 1$ 7xgDNA wipeout buffer, $3 \mu \mathrm{g}$ RNA template and $33 \mu \mathrm{l}$ RNase-free water. The mixture was incubated at $42^{\circ} \mathrm{C}$ for $2 \mathrm{~min}$ and placed immediately on ice. Additional $3 \mu \mathrm{l}$ quantiscript reverse transcriptase, $12 \mu \mathrm{l} 5 \mathrm{xQuantiscript} \mathrm{RT} \mathrm{buffer,} 3 \mu \mathrm{RT}$ primer mix were added and the tube was incubated at $42^{\circ} \mathrm{C}$ for $15 \mathrm{~min}$ and $95^{\circ} \mathrm{C}$ for $3 \mathrm{~min}$. Firststrand cDNA was synthesized. Real time PCR was performed using Fast SYBR Green master mix. Briefly, each reaction contained $10 \mu$ Fast SYBR ${ }^{\circledR}$ Green Master Mix, $2 \mu 1$ 
primer mix and $2 \mu \mathrm{l}$ cDNA template. The plate was applied to Applied Biosystems 7500 fast real-time PCR system following the program: $95^{\circ} \mathrm{C}$ for $20 \mathrm{~s}, 95^{\circ} \mathrm{C}$ for $3 \mathrm{~s}$ and $60^{\circ} \mathrm{C}$ for 30s, 40 cycles. The PCR amplifications were performed in triplicate for each gene of interest along with parallel measurements of Gapdh or $\beta$-Actin cDNA(an internal control). To confirm specific amplification of the desired PCR product, melting curves were analyzed and PCR products were separated on a 3\% agarose gel. The data was analyzed by 7500 Fast SDS v1.5.1.

\subsubsection{Western blot and co-immunoprecipitation assays}

Cells or tissues were disrupted in either whole cell lysis buffer (50mM Tris, pH7.4, $250 \mathrm{mM} \mathrm{NaCl}, 5 \mathrm{mM}$ EDTA, 50mM NaF, $1 \mathrm{mM} \mathrm{Na} 3 \mathrm{VO} 4,1 \% \mathrm{NP} 40$ and complete protease inhibitor cocktail) or nuclear extraction buffer. Briefly, cells were washed twice in ice-cold PBS. For each 10 -cm dish, $0.5 \mathrm{ml}$ ice-cold cell lysis buffer was added to each cell culture dish, and incubated on ice for 30min. The cells were scraped off the dish and transferred to $1.5 \mathrm{ml}$ microcentrifuge tubes. The tubes were microcentrifuged for $10 \mathrm{~min}$ at $4^{\circ} \mathrm{C}, 13,000 \mathrm{x} \mathrm{rpm}$. The supernatant of cell lysate was saved for immunoprecipitation or SDS-PAGE.

Supernatants or nuclear extracts were incubated with $30 \mu 1$ protein A/G PLUSAgarose (Santa Cruz Biotechnology) and incubated with rotation at $4^{\circ} \mathrm{C}$ for 1 hour.

The tube was microcentrifuged for $10 \mathrm{~min}$ at $4^{\circ} \mathrm{C}$ to preclear the cell lysate. Primary antibodies FLAG, TET2, MSH6 and so on were added into $400 \mu$ cell lysate, and incubated with gentle rotation overnight at $4^{\circ} \mathrm{C}$. Next day, $30 \mu 1$ protein A/G PLUSAgarose was added to the cell lysate for an additional 3 hours at $4^{\circ} \mathrm{C}$. Precipitates were 
washed five times with cell lysis buffer, and the pellet was re-suspended with $30 \mu \mathrm{l}$ 2XSDS sample buffer. The samples were heated at $95^{\circ} \mathrm{C}$ for $6 \mathrm{~min}$ and centrifuged at $13,000 \mathrm{x}$ rpm for $5 \mathrm{~min}$. The samples were loaded on SDS-PAGE (4\%-15\%). The gel was then electro-transferred to PVDF membrane $(80 \mathrm{~V}, 120 \mathrm{~min})$. After transfer, the membrane was washed with $25 \mathrm{ml}$ TBST for $5 \mathrm{~min}$ and $25 \mathrm{ml}$ blocking buffer $(5 \%$ non-fat milk in TBST) for 1 hour at room temperature. Later, the membrane was incubated in $10 \mathrm{ml}$ primary antibody dilution buffer $(1: 1,000)$ with gentle rocking overnight at $4^{\circ} \mathrm{C}$. Next day, the membrane was washed 3 times for 5 min each with TBST. The membrane was incubated with horseradish peroxidase (HRP)-linked secondary antibody dilution buffer $(1: 10,000)$ for 1 hour at room temperature. The membrane was the washed 3 times for 5 min each with TBST, and ECL substrate was added onto the membrane in the dark and exposed to x-ray film. Proper exposure time was performed to detect signals.

\subsubsection{Exome sequencing and mutational confirmation}

Initial whole-exome sequencing was carried out in order to identify candidate mutations in the exome of genes. The genomic DNA was captured with the NimbleGen mouse exome array according to the manufacturer's protocol and 100bp paired-ended sequencing was performed on the Illumina HiSeq 2000. Raw sequencing reads were mapped to the whole mouse genome (mm10) using the PEmapper (http://pemapper.sourceforge.net/) with the default settings, and variant bases were annotated with SeqAnt (http://seqant.genetics.emory.edu/).

For the samples subjected to mutational detection, genomic DNA was amplified in selected exons by PCR, and sequenced by means of Sanger sequencing. The location and 
types of mutations were then determined by sequencing data.

The exome-Seq was performed and analyzed by Thomas Wingo from Emory University, Georgia.

\subsubsection{DNA Mismatch repair assays}

In vitro MMR assays were performed essentially as described with some modifications. A circular DNA substrate containing a G-T mismatch and a nick 3' to the mismatch was incubated with $75 \mu \mathrm{g}$ or $150 \mu \mathrm{g}$ of whole cell extracts at $37^{\circ} \mathrm{C}$ for $15 \mathrm{~min}$. DNA samples were digested with Nsil (repair scoring enzyme), followed by polyacrylamide gel electrophoresis and Southern blot analysis to identify repaired and unprepared molecules.

\subsubsection{Microsatellite instability and HPRT mutability analyses}

The MSI and HPRT mutability analyses were performed as described previously ${ }^{129}$. For the detection of MSI in mouse bone marrow cells, 5 microsatellite markers (A33, Bat26, Bat66, D6Mit59, and D1Mit62 loci) were used. The D1Mit62 CA repeat loci were used as negative control as these loci are stable. For the human cell lines tested for MSI, independent single cell colonies were isolated in 96-well microtiter plates, and genomic DNA was isolated. Four microsatellite markers (BAT25, BAT26, D2S123, and D5S346) were used for MSI analysis. The HPRT mutation assay was conducted as described previously $^{129}$. Cells $\left(5 \times 10^{5}\right)$ were seeded in triplicate $10 \mathrm{~cm}$ Petri dishes for $12 \mathrm{hr}$ and fed with complete medium containing $5 \mu \mathrm{M}$ freshly prepared 6-thioguanine (6-TG). The plating efficiency was determined by culturing 500 cells similarly in the absence of 6-TG. 
After 10 days of culturing, cell colonies were visualized by staining with $0.05 \%$ crystal violet. The mutation frequency was determined by dividing the number of 6-TG-resistant colonies by the total number of cells plated after being corrected for the colony-forming ability.

\subsubsection{Confocal Microscopy and immunofluorescence analysis}

Immunofluorescence analysis was performed as described below. Coverslips were treated by $0.01 \%$ polylysine for $5 \mathrm{~min}$ at room temperature. The remaining polylysine solution was aspirated and the coverslips air-dried for $10 \mathrm{~min} .10^{5}$ cells were seeded into 6-well plates with coated coverslips overnight. Next day, the medium was aspirated and the monolayer was washed $2 \mathrm{X}$ with PBS. Then the cells were fixed in fresh $2.5 \%$ PFA at $37^{\circ} \mathrm{C}$ for $10 \mathrm{~min}$. The coverslips were rinsed $2 \mathrm{X}$ with PBS and washed $1 \mathrm{X}$ with PBS in the dark for 10min. The cells were permeabilized and blocked with SS-PBS buffer $(10 \%$ normal goat serum and $0.3 \%$ Triton $^{\mathrm{TM}} \mathrm{X}-100$ ) at room temperature (RT) for $5 \mathrm{~min}$. After SS-PBS buffer was removed, $10 \mu 1$ primary antibody was added directly onto the coverslips for $60 \mathrm{~min}$. The well was rinsed $2 \mathrm{X}$ with PBS and $1 \mathrm{X}$ with SS-PBS in the dark for $10 \mathrm{~min} .10 \mu \mathrm{l}$ secondary antibody was added onto the coverslips directly after SS-PBS was removed from the well completely. The plate was left at RT in the dark for 30min. The coverslips were rinsed $2 \mathrm{X}$ with $\mathrm{PBS}, 2 \mathrm{X}$ with $\mathrm{PBS}+0.3 \%$ Triton $^{\mathrm{TM}} \mathrm{X}-100$ and $2 \mathrm{X}$ with PBS. After wicking the majority of buffer from the coverslips, the coverslips were

mounted using Prolong Gold anti-fade reagent. The coverslips were set overnight in the dark and used for imaging next day. Fluorescence images were obtained using Olympus FV1000 MPE or Leica SP8 MP. The images were analyzed by ImageJ 1.48 software. 


\subsubsection{Bisulfite-Seq and TAB-Seq}

Genomic DNAs (500ng) from WT and Tet $2^{-/-}$mice LK cells were mixed with $130 \mu 1$ CT conversion reagent. The tubes were placed in a thermal cycler under the following program: $98^{\circ} \mathrm{C}, 10 \mathrm{~min} ; 64^{\circ} \mathrm{C}, 150 \mathrm{~min} ; 4^{\circ} \mathrm{C}$ for up to 20 hours. The products were transferred to spin columns with $600 \mu \mathrm{l}$ binding buffer. The columns with collection tubes were centrifuged at $10,000 \mathrm{xg}$ for $30 \mathrm{~s}$. After washing the column twice with washing buffer, the columns were filled with elution buffer. The eluted DNA was ready for PCR or further analyses.

Genomic DNAs from WT and Tet $2^{-/-}$mice LK cells were sheared to average $400 \mathrm{bp}$. The $\beta$-glucosyltransferase reaction was prepared as follows: $4 \mu \mathrm{g}$ sheared gDNA, $0.4 \mu 1$ 10mM UDP-Glucose, $2 \mu 1$ 10x $\beta$ GT protection buffer, $0.5 \mu 1$ T4- $\beta$ GT and Milli-Q water to $20 \mu \mathrm{l}$. The reaction was performed at $37^{\circ} \mathrm{C}$ for $1 \mathrm{~h}$. The products were then purified using a QIAquick PCR Purification Kit. Next, 500ng gDNA from the last step was incubated with TET1 protein and Tet 2 oxidation reagent $1 \& 2$. The reaction was carried-out at $37^{\circ} \mathrm{C}$ for $1 \mathrm{~h} .1 \mu \mathrm{l}$ Proteinase $\mathrm{K}$ was added to the reaction and incubated at $50^{\circ} \mathrm{C}$ for $1 \mathrm{~h}$. The product was purified by Micro-Bio-Spin Columns and then with QIAquick PCR Purification Kit. The target sites were amplified by PfuTurbo Cx DNA polymerase

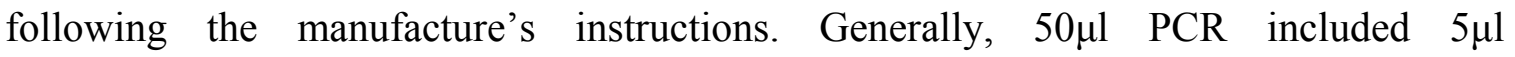
10xPfuTurboCx reaction buffer, $1 \mu \mathrm{l} 10 \mathrm{mM}$ dNTP mix, $2 \mu \mathrm{l} 5 \mathrm{mC}$ control primers, $4 \mu \mathrm{l}$ Bisulfite treated DNA, $1 \mu \mathrm{l}$ PfuTurboCx DNA polymerase and Milli-Q water to $50 \mu 1$. The verified PCR products were used for either individual clone sequencing or Genome-wide Sequencing analysis. 


\subsubsection{Statistical analysis}

To determine differences between experimental groups, I used the Student's t-test or analysis of variance (ANOVA) followed by Newman-Keuls multiple comparison tests as appropriate. $\mathrm{P}$ values $<0.05$ were considered significant. For SNV count data, chi-square tests were used as implemented in R (http://cran.r-project.org/).

\subsection{RESUlTS AND DiscUSSION}

\subsubsection{Tet2 $^{-/-}$mice develop lymphoid malignancies.}

The TET2 gene is frequently mutated in human hematopoietic malignancies. Most of these homozygous and heterozygous mutations lead to truncation of TET2 protein and subsequently decreased TET2 enzymatic activity. Several groups generated Tet2 knockout mouse models to determine the role of TET2 in hematopoiesis and hematopoietic diseases ${ }^{84-87}$. Similar phenotypes were observed from these groups that $\mathrm{Tet}^{-/-}$mice developed a wide spectrum of myeloid malignancies and the loss of Tet2 was sufficient to promote myeloid transformation. It is still unknown if the deletion of Tet2 is able to cause lymphoid transformation, as previously reported, that TET2 mutations also exist in patients with lymphoid malignancies ${ }^{100}$. A long-term investigation was performed to determine if the loss of Tet2 is sufficient to cause lymphoid transformation. I conducted a 2-year study on a cohort of Tet $2^{-/-}$and 67 wild-type (WT) mice. All the Tet2 ${ }^{-}$ I- mice were born with expected Mendelian ratios, were viable, fertile with normal organ development, suggesting Tet1 and Tet3 may have extra roles in embryonic development. No expression level changes in Tet1 and Tet3 were seen in hematopoietic cells after Tet2 
deletion, which eliminates the presumption of enzymatic compensation in TET family and endows a unique role for Tet2 in hematopoiesis.

Next, I analyzed details of the incidence, latency, and pathological features of hematological neoplasms that occur in Tet $2^{-/-}$mice and Tet ${ }^{+/+}$littermates. Strikingly, all of the $198 \mathrm{Tet}^{-/-}$animals developed spontaneous lethal hematological malignancies with a latency ranging from 3 to 18 months, while no progressive leukocytosis was characterized in the hematopoietic organs of WT animals (Figure 14).

Analyses of these Tet2-deficient mice strengthened the finding that a majority of $(>90 \%)$ these $\operatorname{Tet}^{-/-}$mice developed predominantly myeloid malignancies that include CMML-like disease, MDS and MPN with significant hematological phenotypes of leukocytosis (accompanied by neutrophilia and/or monocytosis), hepatosplenomegaly and marked expansion of well-differentiated myeloid cells or erythroid precursors in the bone marrow (BM), spleen, and liver that compromised the normal architecture of these organs. Interestingly, Tet2 loss also affects lymphoid-lineage development. The rest of Tet2 $^{-/-}$mice developed T-cell ( 7 of $198,3.5 \%$ ) or B-cell (9 of 198, 4.5\%) lymphoma/leukemia (Figure 14). With age, these mice showed lymphocytosis consisting of atypical lymphocytes, lymphadenopathy, hepatosplenomegaly, and/or enlarged thymus (in most cases of T-cell malignancies).

The mice with T-cell lymphoma/leukemia were characterized with lymphoid infiltration in BM, thymus, spleen and liver (Table 2.1). Histopathological analysis of moribund mice indicated complete effacement of the normal architecture of these organs with lymphoid elements. The morphology of atypical lymphocytes was observed (Figure 14). They were medium sized, immature appealing with irregular nuclei and small to 
moderate amount of cytoplasm. The spleen specimen exhibited a diffuse infiltrate within both red and white pulp. The predominant hepatic perivascular and sinusoidal infiltrates were also observed after histological examinations. Flow cytometric analysis confirmed a predominant proportion of T-lymphocytes expressing CD3 and aberrantly co-expressing CD4 and/or CD8 in BM, spleen and thymus (Figure 15).

Atypical lymphoid infiltrate was also identified in the small intestines with lymphoepithelial lesions and lymphoid nodules in $\mathrm{Tet}^{-/-}$mice diagnosed as B-cell lymphoma/leukemia (Table 2.2). These atypical lymphocytes were medium sized with irregular nuclei, condensed chromatin and small amount of cytoplasm. Nodular lymphoid infiltrate disrupted the normal architecture of the spleen, especially in the white pulp. Requisite perivascular and sinusoidal infiltration occurred in the liver. The B-cell lineage was also altered in different tissues, particularly, B220 ${ }^{+/ l o w} \mathrm{IgM}^{+/ \mathrm{low}} \mathrm{CD} 43^{+} \mathrm{CD} 19^{+}$with high forward scatter (FSC) (Figure 16).

To obtain a more detailed view of the role of Tet2 in hematopoiesis, I transferred $\mathrm{Tet}^{-/-}$spleen cells from $\mathrm{Tet}^{-/-}$mice with $\mathrm{T}$ - and B-cell malignancies to sub-lethally irradiated WT mice. Two weeks later, transplanted mice were analyzed. Both T- and Bcell malignancies were transplantable, suggesting the malignant and neoplastic nature of the infiltrating T- or B-lymphocytes in these Tet $2^{-/}$mice (Figure 17).

Taken together, these results show that besides myeloid malignancies, Tet $2^{-/-}$mice also develop lethal lymphoid malignancies involving both T- and B-cell lineages. These finding are consistent with the clinical observations that loss of function mutations of TET2 are frequently associated with T- and B-cell malignancies. The kinetics of disease onset suggests that additional genetic lesion events may occur along with Tet2 ablation to 
cause distinct types of hematological malignancies, either in myeloid or lymphoid lineage. It is reasonable to speculate that the deletion of Tet2 may contribute to locus specific hypermethylation. Aberrant methylation at specific myeloid, T-cell and B-cell promoters should correlate with transcription alterations and later disease development.

\subsubsection{Acquisition of mutations in $\mathrm{Tet}^{-/-}$tumors and increased mutational frequency in loci marked by Tet2-dependent $5 \mathrm{hmC}$}

To explore if the loss of Tet2 leads to genome-wide genetic alterations, I performed comparative genomic hybridization array $(\mathrm{aCGH})$ and whole-exome sequencing using tumor and/or non-tumor cell genomic DNA from Tet2 ${ }^{-/}$mice with myeloid-, T- or B-cell malignancies. In the myeloid tumor sample, CGH analysis detected a gain of 16q (Figure 18). Both myeloid- and T-cell malignant genomes showed sub-chromosomal copy number alterations. While no significant alterations were seen from B-cell malignant genome (Figure 18).

The newer and current massive parallel sequencing techniques make it feasible to characterize somatic mutations in cancers. The exome (coding regions) sequencing allows us to identify driver mutations in cancer genome. To gain new insight into Tet2 loss induced leukemogenesis and relevant molecular basis underlying the clinical finding of multiple lineage involvement, I performed whole exome sequencing and subsequent Sanger sequencing to identify somatic mutations in Tet $2^{-/}$myeloid-, T- and B-cell tumors. I captured and sequenced the exomes from paired samples of Tet2 loss induced tumors. After normalization (remove SNVs from WT and Tet2 $2^{-/}$non tumor samples), I identified potential somatic mutations including 3,309 single-nucleotide variations (SNVs) and 211 
small insertions or deletions (indels). I analyzed the alterations affecting protein-coding sequence, and 1,480 non-synonymous replacement sites and 1,829 silent sites per tumor type were found, which influence the integrity of open reading frame. Of the Tet $2^{-/}$ tumors from each cell origin, I found somatic mutations in 190 genes with recurrent SNVs that appeared to originate in the different tumors including Notch1, Ebf1, Flt3, Nf1, Rhoa and Ikzf3 (Figure 19). Integration of the above data, together with literature searching for these genes which have been frequently found in human hematological malignancies, led to the validation of exome sequencing results. I amplified the corresponding regions from original tumor samples and applied the PCR products for Sanger sequencing.

Non-synonymous mutations of Notch1 were identified in all 3 cases of Tet ${ }^{-/-} \mathrm{T}$-cell tumors. As a critical transcription factor regulating innate and adaptive immunity, NOTCH1 can direct hematopoietic stem cell differentiation toward T-cells. In addition, NOTCH1 is frequently altered in hematopoietic and solid tumors. Intriguingly, NOTCH1 genetic mutations may lead to either ligand-independent activation or delayed turnover of NOTCH1 protein, depending on the context and mutation induced conformation changes ${ }^{130}$.

In the hematological system, NOTCH1 mutations have been detected not only in $\sim 55 \%$ of human T-cell acute lymphoblastic leukemia (T-ALL) but also in a high fraction of murine precursor-T lymphoma/leukemia in which NOTCH1 is a well-characterized oncogene ${ }^{130}$. Previous studies have shown that the HD (heterodimerization) and PEST (proline-glutamic acid-serine-threonine rich) domains of NOTCH1 are mutation hotspots in T-ALL ${ }^{131}$. Indeed, the Notch1 mutations identified by exome sequencing of Tet2 $2^{-/-} \mathrm{T}$ - 
cell tumors are all within these hotspots (p.Leu1668Pro, p.Arg1673Pro) and the Notch1 mutations in these hotspots were also found in 3 additional cases of Tet $2^{-/-} \mathrm{T}$-cell tumors (p.Thr2346---, p.Ala1639Thr, p.His1598*) (Figure 20), providing novel insight into the T-cell leukemogenesis caused by the loss of Tet2.

Together, Tet2 loss-induced tumors are characterized by the acquisition of SNVs and small indel, but not large chromosomal deletions/amplifications, suggesting that the loss of Tet2 may create a genomic instability state in cells, where gene mutations accrue much more readily than normal. Indeed, hypermethylation states have been shown to be a potential mutagen in tumor cells.

Given the role of TET proteins in the oxidation process of $5 \mathrm{mC}$, I next examined the effect of the loss of Tet2 on genome-wide $5 \mathrm{hmC}$ modification. I mapped the genomic distribution of $5 \mathrm{hmC}$ in WT and $\mathrm{Tet}^{-/-} \mathrm{Lin}^{-} \mathrm{c}-\mathrm{Kit}^{+}(\mathrm{LK}) \mathrm{BM}$ cells using selective chemical labeling and affinity enrichment procedures (Figure 21). The deletion of Tet2 leads to a significant decrease of $5 \mathrm{hmC}$ at gene bodies, which is consistent with previous observations in mouse ES cells with a reduced expression of Tet2. The effects of Tet2 loss engendered a striking dependence on intermediately-expressed, but not highlyexpressed genes in LK cells (Figure 22). The majority of Tet2-dependent 5hmC modifications in LK cells are located within the genes. Genome-wide $5 \mathrm{hmC}$ profiling of WT and Tet $2^{-/}$LK cells identified the shared loci.

The shared loci represent the ones with $5 \mathrm{mC}$ oxidation catalyzed by other TET proteins, such as TET1, but not Tet2 (Tet2-independent sites). Both gain and loss of $5 \mathrm{hmC}$ loci in the absence of Tet 2 may represent loci with Tet2-dependent $5 \mathrm{mC}$ oxidation and might reflect distinct role(s) for Tet2 in the $5 \mathrm{mC}$ oxidation process. The loci with the 
loss of $5 \mathrm{hmC}$ in the absence of Tet 2 are the ones that are converted from $5 \mathrm{mC}$ to $5 \mathrm{hmC}$ by Tet2 (Tet2-dependent $5 \mathrm{mC}$ conversion to $5 \mathrm{hmC}$ ), while the loci with the gain of $5 \mathrm{hmC}$ more likely represent the regions with further $5 \mathrm{mC}$ oxidation (from $5 \mathrm{hmC}$ to 5fC/5caC) mediated by Tet2 (Tet2-dependent active DNA demethylation) (Figure 23). I then explored the overlap between the sites with SNVs/indel in Tet $2^{-/-}$tumors and the three different genomic loci. Using a chi-square test to examine the correlation between mutation sites and three different genomic loci, I observed a significantly greater frequency of SNVs/indel within the loci that require Tet2 for active demethylation, as compared to that of Tet2-independent sites and the loci that require Tet2 for the conversion of $5 \mathrm{mC}$ to $5 \mathrm{hmC}$ alone. Similar increases were observed with either overall mutations or $\mathrm{C}$ to $\mathrm{T}$ (or $\mathrm{G}$ to $\mathrm{A}$ ) mutations (Figure $23 \& 24$ ). Thus the genetic loci marked by Tet2-mediated active demethylation are likely accessible by Tet2, which could in turn play a role in the maintenance of genomic stability.

I observed a decrease in $5 \mathrm{hmC}$ abundance at mutation sites as these regions close to CpG sites, which further indicates that Tet2 loss induced genetic mutations correlate with Tet2-mediated DNA demethylation. To determine the dynamics of $5 \mathrm{hmC}$ alterations at mutation sites, I used single-base resolution Bisulfite-Seq and TAB-Seq to examine the changes of cytosine modification between WT and Tet $2^{-/}$young mice LK cells, in which I assumed that these mutation sites stay in origin. From representing gene analysis (Akap12), I found the "C" was hypermethylated in Tet2 ${ }^{-/}$cells but no expected $5 \mathrm{hmC}$ changes were observed (Figure 25), suggesting that the $\mathrm{C}$ base confers an essential function to maintain genome integrity because $5 \mathrm{mC}$ is considered as a mutagen in the genome and the accumulation of $5 \mathrm{mC}$ may alter its active enzymatic deamination. 
Although I was not able to detect $5 \mathrm{hmC}$ changes, I cannot exclude the dynamics of $5 \mathrm{hmC}$ because of 1) $5 \mathrm{hmC}$ overlapping region controlled by TETs; 2) $5 \mathrm{hmC}$ further oxidized to $5 \mathrm{fC}$ or $5 \mathrm{caC} ; 3)$ Technique limitations.

\subsubsection{TET2 interacts with MSH6}

To investigate the mechanisms by which Tet2 loss may result in genomic instability, I sought the functional Tet2-binding partners. I generated knock-in ES clones in which tandem (Flag and V5) tags were inserted after the Tet2 start codon within exon 3 through homologous recombination (Figure 26). The knock-in allele allows the expression of both Flag-tagged Tet2 and WT Tet2 at roughly 1:1 ratio in the Tet2:Tag ES cells.

I characterized endogenous TET2-interacting proteins by mass spectrometry, and identified a list of TET2-interacting proteins including the known TET2-interacting protein OGT, and unknown associates MSH6 (Table 2.3). These results are intriguing as MSH6 is specifically involved in the DNA mismatch repair (MMR) of base-base mismatches and small insertion/deletion mispairs generated during DNA replication ${ }^{129}$, consistent with the types of genetic alterations identified in the Tet $2^{-/}$tumors. To confirm interaction between TET2 and MSH6, I performed co-immunoprecipitation assays using both Tet2:Tag ES cells and Flag-TET2 overexpressing HEK293 cells (Figure 27 \& 28). TET2 was also captured in the MSH6 precipitates from mouse BM cells, confirming the endogenous TET2-MSH6 interaction in primary hematopoietic cells. To map the interacting regions between TET2 and MSH6, I generated a series of constructs including Flag-TET2 fragments and Myc-MSH6 fragments. Human TET2 gene was fragmented to four parts: hTET2-N (AA 1-942), hTET2-M (AA 916-1921) and hTET2-C (AA 1323- 
2002, DSBH) (Figure 29). On the basis of the secondary structure of human MSH6, the MSH6 gene was dissected to five fragments that are MSH6-PWWP (AA 1-200), MSH6MutSNter (AA 183-537), MSH6-MutSConnector (AA 525-735), MSH6-MutSCore (AA 700-1102) and MSH6-MutSCter (AA 1075-1360). TET2-N terminal showed interaction with full-length MSH6. To examine if MSH6 directly interacts with TET2 protein, I also co-expressed GST-MSH6 and TET2-N. These two recombinant proteins were co-purified in vitro, suggesting the direct binding between TET2 and MSH6 in vivo and in vitro. Moreover, the co-localization of the two proteins was examined using HeLa cells and immunofluorescence staining. Consistent with previous reports ${ }^{129}$, MSH6 formed distinct foci in the chromatin of HeLa cells, and the localization of MSH6 and TET2 largely overlapped in these foci (Figure 30). These data collectively demonstrate that TET2 interacts with MSH6 in vivo.

\subsubsection{TET2 loss causes a mutator phenotype in cells}

Mismatch repair (MMR) of DNA corrects base-base and small insertion/deletion generated during DNA replication. Since MMR reduces the DNA replication errors, defective MMR increases the spontaneous mutation rate, which results in the "mutator

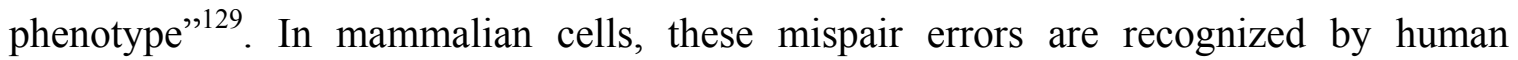
heterodimer proteins hMutS $\alpha$ and hMutS $\beta$. MSH2 and MSH6 are major components of $\mathrm{hMutS} \alpha$ and they form a heterodimer to repair the mispairs. Previous studies indicate that the alteration of MSH2 and MSH6 expression leads to susceptibility to certain types of cancer, especially hereditary non-polyposis colorectal cancer (HNPCC) ${ }^{132}$. The MMR defects cause the instability of high frequency of insertion/deletion in microsatellites at 
the cellular level. Microsatellite instability (MSI) is a hallmark characteristic in hereditary nonpolyposis colorectal cancer (HNPCC), which is associated with mutations in the MMR pathway genes including MLH1, MSH2 and MSH6 ${ }^{129}$. In addition to colorectal cancer, MSI phenomenon is also observed in certain types of leukemia such as secondary AML and $\mathrm{MDS}^{133}$.

The above TET2 and MSH6 interaction data prompted the following question. Does TET2 loss impair MMR and subsequently cause the mutator phenotype? To answer these questions, I first examined the in vitro MMR activity and MSH6 expression in the nuclear extract of WT and Tet2 ${ }^{-/}$total BM cells. A functional in vitro MMR assay was performed. Surprisingly, both WT and Tet $2^{-/}$BM cell extracts restored MMR efficiently (Figure 32), suggesting TET2 is not a critical factor for MMR in vitro and Tet2 loss does not alter the expression or function of MSH6 in vitro.

However, if the MSH6-TET2 interaction recruits hMutS $\alpha$ to chromatin, I cannot exclude the possibility that MSH6-TET2 interaction is required for MMR in vivo. If this is true, TET2 deficient cells should have impaired MMR and displayed an increased mutation frequency. To determine MSH6 chromatin localization, I depleted TET2 by shRNAs in HeLa cells (Figure 33), which is a MMR-proficient cell line. I used double thymidine block to synchronize control of HeLa (scramble shRNAs) and TET2KD HeLa cells in G1, S and G2/M phase. Then, endogenous MSH6 expression levels and chromatin localization were determined by immunofluorescence (Figure 31). Decreased MSH6 foci were observed in TET2KD HeLa cells compared to control HeLa cells (Figure 36), suggesting that MSH6 chromatin localization is facilitated by TET2. Around $10 \%$ of MSH6 foci co-localized with TET2 in WT HeLa cells indicating that not all 
TET2 recruit MSH6. Like a previous report ${ }^{129}$, decreased MSH6 foci is also seen in G2/M phase, but not because of altered MSH6 expression.

Control and TET2-depleted HeLa cells were then tested for MSI at four microsatellite loci as described previously ${ }^{129}$. No MSI was detected in control HeLa cells, whereas 9-18\% sub-clones $(\mathrm{n}=11)$ from TET2-depleted HeLa cells showed new microsatellite species at these loci (Figure 38). As a positive control, MSI was also analyzed in MSH6-deficient DLD-1 cells, which exhibited new repeat species in 27-36\% sub-clones. Despite a difference in the percent sub-clones showing new repeat species, these data indicate that like MSH6-deficient DLD-1 cells, TET2-depleted HeLa cells display MSI. I also examined the frequency of MSI in BM DNAs from aged WT or Tet2${ }^{1-}$ mice. Tet2 ${ }^{-/}$BM samples showed $43-86 \%$ novel alleles at A33, Bat26, Bat66 and D6Mit59 loci (Figure 37), while no novel alleles were detected at these loci in each of the WT BM samples, further demonstrating Tet2 loss displays MSI.

To further confirm that the deletion of TET2 leads to the mutator phenotype, I measured the spontaneous forward mutation frequency in the hypoxanthine-guanine phosphoribosyltransferase (HPRT) gene in TET2KD HeLa cells, control HeLa cells (negative control) and DLD-1 cells (positive control). Human HPRT gene encodes HPRT enzyme whose activity is important for DNA synthesis. 6-thioguanine (6-TG) is a toxic nucleoside analog and it is used for cell selection. Cells without HPRT gene mutations are poisoned by 6-TG, while HPRT gene mutations help cells survive and form colonies. As shown in Figure 34, the mutation frequency in TET2KD HeLa cells had a 24-fold increase compared to control HeLa cells and is $\sim 10$-fold lower than that in hMSH6deficient DLD-1 cells (Figure 34). The presence of HPRT mutations was confirmed in 
mutant clones of each cell type and most of the mutations were located at HPRT hot spots. This is likely due to both the efficiency of TET2 knockdown and a likely TET2independent mechanism for MSH6-mediated MMR. Similar results were obtained using control and Tet2-knock down NIH3T3 cells (Figure 35), confirming that TET2 loss causes a mutator phenotype.

Lastly, I analyzed the number and type of mutations in a cohort of human MDS cases. Interestingly, MDS patients with TET2 mutations harbor a significantly higher number of mutational events compared to patients without TET2 mutations (Figure 39). The association of the presence of TET2 mutations with higher mutational frequencies in MDS patients is consistent with the findings that Tet2 loss constitutes genetic instability. Collectively, these observations are consistent with the hypothesis that TET2 is likely involved in recruitment of MSH6 to the chromatin, and TET2 loss impairs MMR in vivo thereby enhancing susceptibility to malignant transformation by a multitude of genetic mutations.

\subsection{CONCLUSIONS}

Studies using different Tet2 knock-out animal models have revealed that Tet2 loss alters the epigenetic landscape with decreased $5 \mathrm{hmC}$ and global hypermethylation of the DNA, increases HSC self-renewal and myeloid progenitor expansion with skewed differentiation toward monocytic lineages, leading to the pathogenesis of myeloid malignancies ${ }^{84}$. Here, I show that a fraction of $\mathrm{Tet}^{-/-}$mice develop lymphoid malignancies of both T- and B-cell origin, demonstrating that TET2 plays an important role in both myeloid and lymphoid malignancies. Leukemogenesis is thought to be a 
multi-step process in which a series of genetic mutations may be acquired in a specific clonal lineage. Genome analysis of Tet $2^{-/-}$tumors allowed not only a better understanding of Tet2 loss-mediated leukemogenesis, but also the identification of candidate secondary gene mutations that lead to diverse disease phenotypes in Tet $2^{-/}$mice.

The exome sequencing identified numerous SNVs/indel in Tet $2^{-/}$tumors of each cell origin, indicating that TET2 loss constitutes a state of genetic instability. The increased susceptibility of mutational acquisition is likely further accelerated in Tet $2^{-/-}$ HSC/HPCs since TET2-loss induced intrinsic changes in these cells, with increased selfrenewal and proliferation. TET2 loss represents an obvious initiating event in the pathogenesis of hematological malignancies. The occurrence of secondary oncogenic gene mutations, presumably in an early hematopoietic progenitor, is likely capable of modifying the disease phenotype and/or promoting the transformation/progression of a specific hematological malignancy in $\mathrm{Tet}^{-/-}$mice. This is evident by the acquisition of Notch1, Flt3, Nf1, Ebf1, Rhoa, Ikzf3 and other gene mutations in the Tet2 ${ }^{-/}$ hematological malignancies, consistent with the human hematological malignancy induction and maintenance by gene alterations of these critical genes. Consistently, clinical observations also suggest an initiating role for TET2 mutations in the pathogenesis of hematological malignancies.

Analysis of the clonal architecture in CMML showed that TET2 mutations are often the first detected oncogenic event ${ }^{134}$. As well, the prevalence of TET2 mutations is higher in secondary than in de novo AMLs ${ }^{123}$. Furthermore, single-cell-derived colony genotyping identified TET2 mutation as one of the earliest events in the accumulation of genetic alterations that lead to the leukemic clone expansion. And, a recent exome 
sequencing study on angioimmunoblastic T-cell lymphoma showed that $68 \%$ of cases had both TET2 and RHOA mutations, and TET2 mutations predated RHOA mutations in most cases as RHOA mutations were specifically identified in tumor cells, whereas TET2 mutations were found in both tumor cells and non-tumor hematopoietic cells ${ }^{99}$.

The MMR maintains genome stability primarily by correcting base-base and small indel mispairs generated during DNA replication. In mammalian cells, these mispairs are recognized by MSH2-MSH6 and MSH2-MSH3 complexes, both of which are required for $\mathrm{MMR}^{135,136}$. Tet2 ${ }^{-/-}$tumors are associated with the acquisition of SNVs and small indel, and a significantly more SNVs were observed in loci containing Tet2-dependent active DNA demethylation, where Tet2 normally binds. MSH6 is a TET2, but not TET1, binding partner and Tet2 loss causes a mutator phenotype--hallmark of MMR defects, as evidenced by increased MSI and mutational frequencies at the cellular level. The data strongly suggest that TET2 is required for MMR in vivo by regulating MSH6 distribution on the chromatin. Therefore, the loss of TET2 could promote the local mutation rate in these Tet2-dependent active DNA demethylation loci by losing MSH recruitment. However, it is also possible that besides altering gene expression, the active DNA demethylation process itself could protect genomic stability. Indeed, $5 \mathrm{mC}$ has been shown to be a mutagen in tumor cells ${ }^{137}$.

Interestingly, $\mathrm{Li}$ et al (2013) recently showed that H3K36me3 and SETD2 are required for MMR in vivo, since H3K36me3 recruits hMutS onto chromatin through direct interaction with MSH6. Further studies are warranted to determine if H3K36me3 and/or SETD2 play a role in the TET2-mediated recruitment of MSH6. Of note, Tet2deficient cells that become MMR defective are not malignant per se, but since they 
display a consistent increase in mutational rate, they could accumulate driver mutations in target genes leading to malignancies.

My results unveil a novel role for TET2 in the maintenance of genome integrity, and provide significant insight into the mechanisms by which loss-of-function TET2 mutations causes diverse human hematological malignancies (Figure 40). These important findings might aid the generation of new therapeutic approaches for these hematological malignancies. 

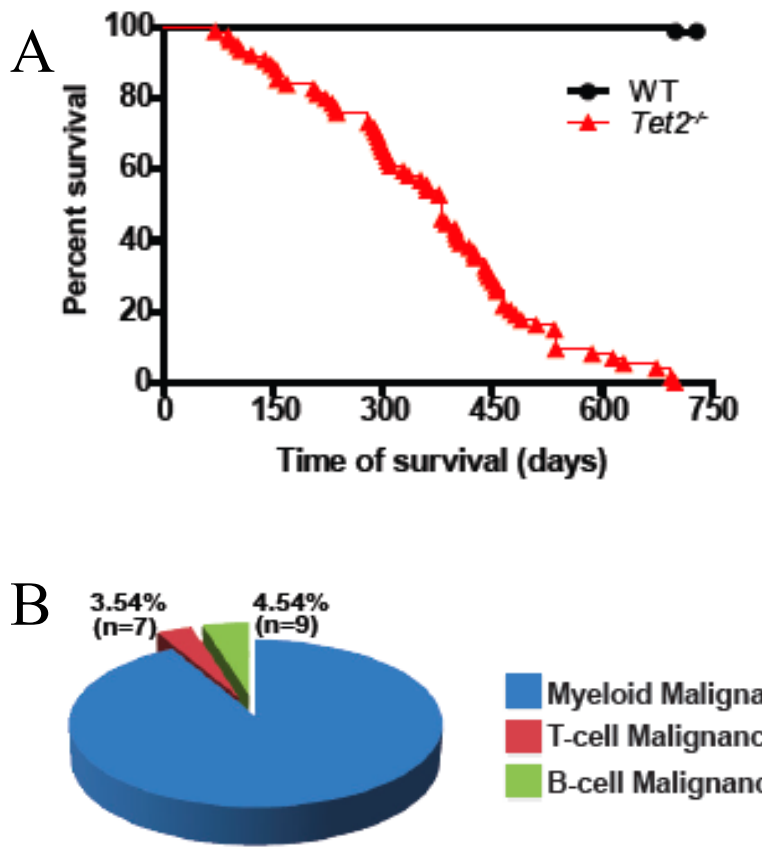

Myeloid Malignancy

T-cell Malignancy

B-cell Malignancy

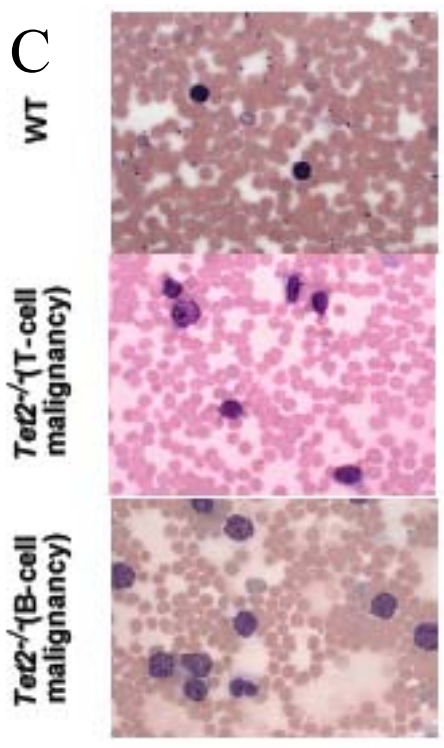

Figure 14 Tet2 $^{-/-}$mice develop lethal lymphoid malignancies involving both $\mathrm{T}$ - and B-cell lineages.

(A) Kaplan-Meier survival curve of WT $(n=67)$ and Tet2 ${ }^{-/}(n=198)$ mice. (B) Pie charts show the percentage of hematological malignancies of myeloid-, Tor B-cell origin in Tet $2^{-/-}$mice $(n=198)$. (C) May-Grunwald Giemsa stained PB smears prepared from a representative WT mouse and Tet $2^{-/-}$mouse with T- or B-cell malignancy. 

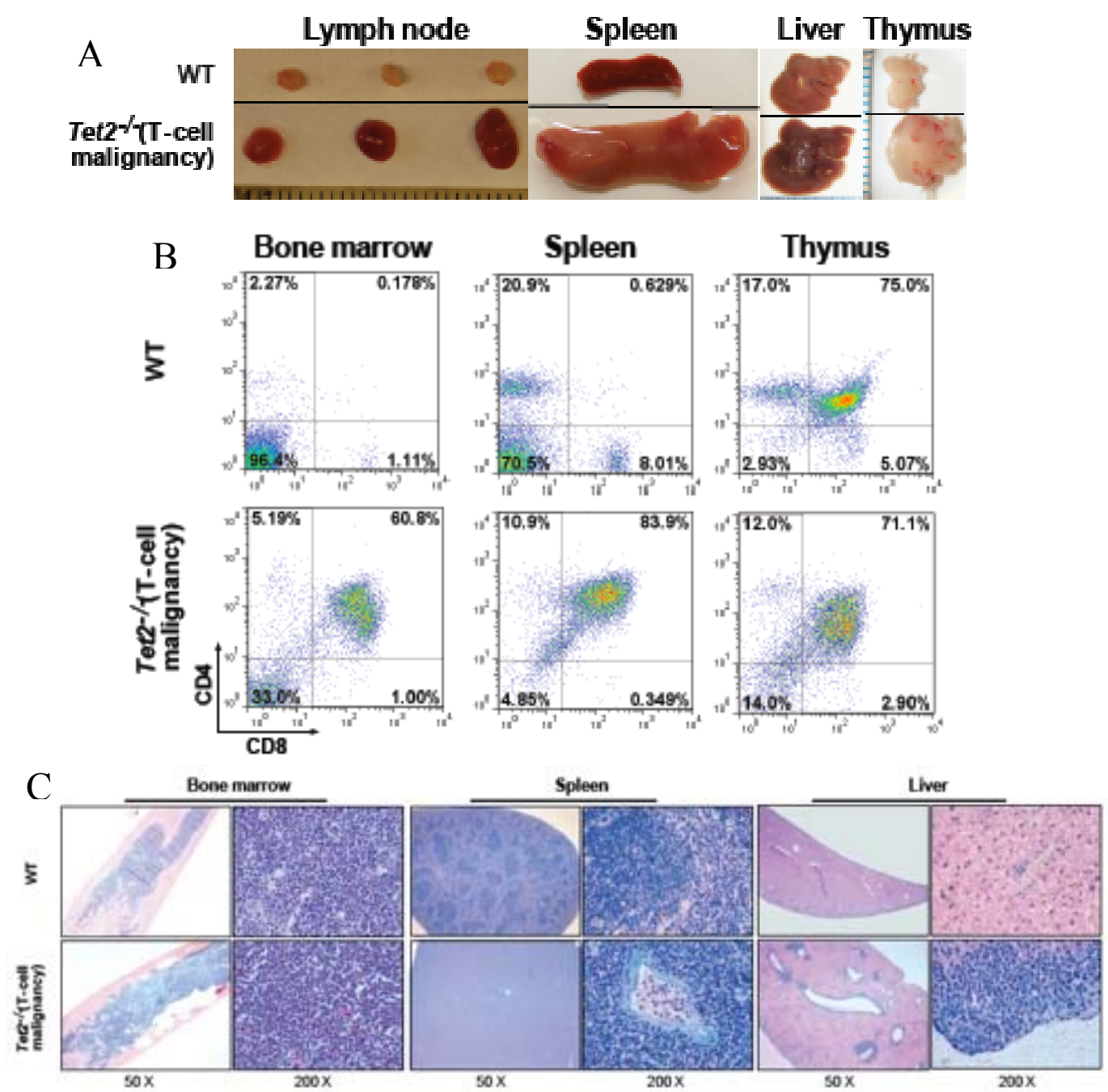

Figure 15 Tet2 $^{-/-}$mice with T-cell malignancy.

(A) The gross morphologies of lymph nodes, spleen, liver, and thymus from a representative Tet $2^{-/-}$mouse with T-cell malignancy. (B) Flow cytometric analysis of the T-cell lineage (CD4/CD8) in BM, spleen and thymus of a representative Tet $2^{-/-}$mouse with T-cell leukemia/lymphoma and an age matched WT mouse. (C) H\&E stained histological sections of femurs, spleen and liver from a representative Tet $2^{-/-}$mouse with T-cell leukemia/lymphoma and an age matched WT mouse. 


\begin{tabular}{|c|c|c|c|c|c|c|c|c|}
\hline \multirow{2}{*}{ ID } & \multirow{2}{*}{$\begin{array}{l}\text { Age, } \\
\text { days }\end{array}$} & \multirow{2}{*}{ Necropsy findings } & \multirow{2}{*}{$\begin{array}{l}\text { Thymus } \\
\text { weight (g) }\end{array}$} & \multicolumn{3}{|c|}{ Blood Counts } & \multirow{2}{*}{ T-Cell Type } & \multirow{2}{*}{ Diagnosis } \\
\hline & & & & $\mathrm{WBC}, \mathrm{K} / \mu \mathrm{L}$ & $L Y, K / \mu L$ & $R B C, M / \mu L$ & & \\
\hline G3-6 & 200 & $\begin{array}{l}\text { Hepatosplenomegaly, } \\
\text { Lymphadenopathy }\end{array}$ & 0.388 & 165.2 & 148.7 & 6.23 & $\mathrm{CD} 3^{+} \mathrm{CD} 4^{+} \mathrm{CD} 8^{+}$ & T cell lymphoma/leukemia \\
\hline $3 G-1$ & 615 & $\begin{array}{l}\text { Hepatosplenomegaly, } \\
\text { Lymphadenopathy }\end{array}$ & 0.201 & 11.7 & 10.1 & 7.48 & $\mathrm{CD}^{+}{ }^{+} \mathrm{CD} 4^{+} \mathrm{CD} 8^{\circ}$ & T cell lymphoma/leukemia \\
\hline G4-17 & 105 & $\begin{array}{l}\text { Hepatosplenomegaly, } \\
\text { Lymphadenopathy }\end{array}$ & 0.347 & & $N / D$ & & $\mathrm{CD}^{+} \mathrm{CD} 4^{+} \mathrm{CD} 8^{+}$ & T cell lymphoma/leukemia \\
\hline G2-105 & 440 & $\begin{array}{l}\text { Hepatosplenomegaly, } \\
\text { Lymphadenopathy }\end{array}$ & 0.300 & 15.5 & 13.3 & 7.59 & $\mathrm{CD}^{+} \mathrm{CD} 4^{+} \mathrm{CD} 8^{-}$ & T cell lymphoma/leukemia \\
\hline G3-49 & 381 & Hepatosplenomegaly & $\begin{array}{c}0.056 \\
\text { (Normal) }\end{array}$ & 18.5 & 11.7 & 5.65 & $\mathrm{CD}^{+} \mathrm{CD} 4^{+} \mathrm{CD} 8$ & T cell lymphoma/leukemia \\
\hline G3-24 & 305 & Hepatosplenomegaly & 0.238 & 9.7 & 5.5 & 8.61 & $\mathrm{CD}^{+} \mathrm{CD} 4{ }^{-} \mathrm{CD} 8^{+}$ & T cell lymphoma/leukemia \\
\hline G3-50 & 328 & Hepatosplenomegaly & $\begin{array}{c}0.069 \\
\text { (Normal) }\end{array}$ & 68.2 & 60.3 & 4.23 & $\mathrm{CD}^{+}{ }^{\mathrm{CD}} 4 \mathrm{CD} 8$ & T cell lymphoma/leukemia \\
\hline
\end{tabular}

Table 2.1 Phenotypic characteristics of T-cell malignancies developed in 7 Tet2 $^{-/-}$ mice. 


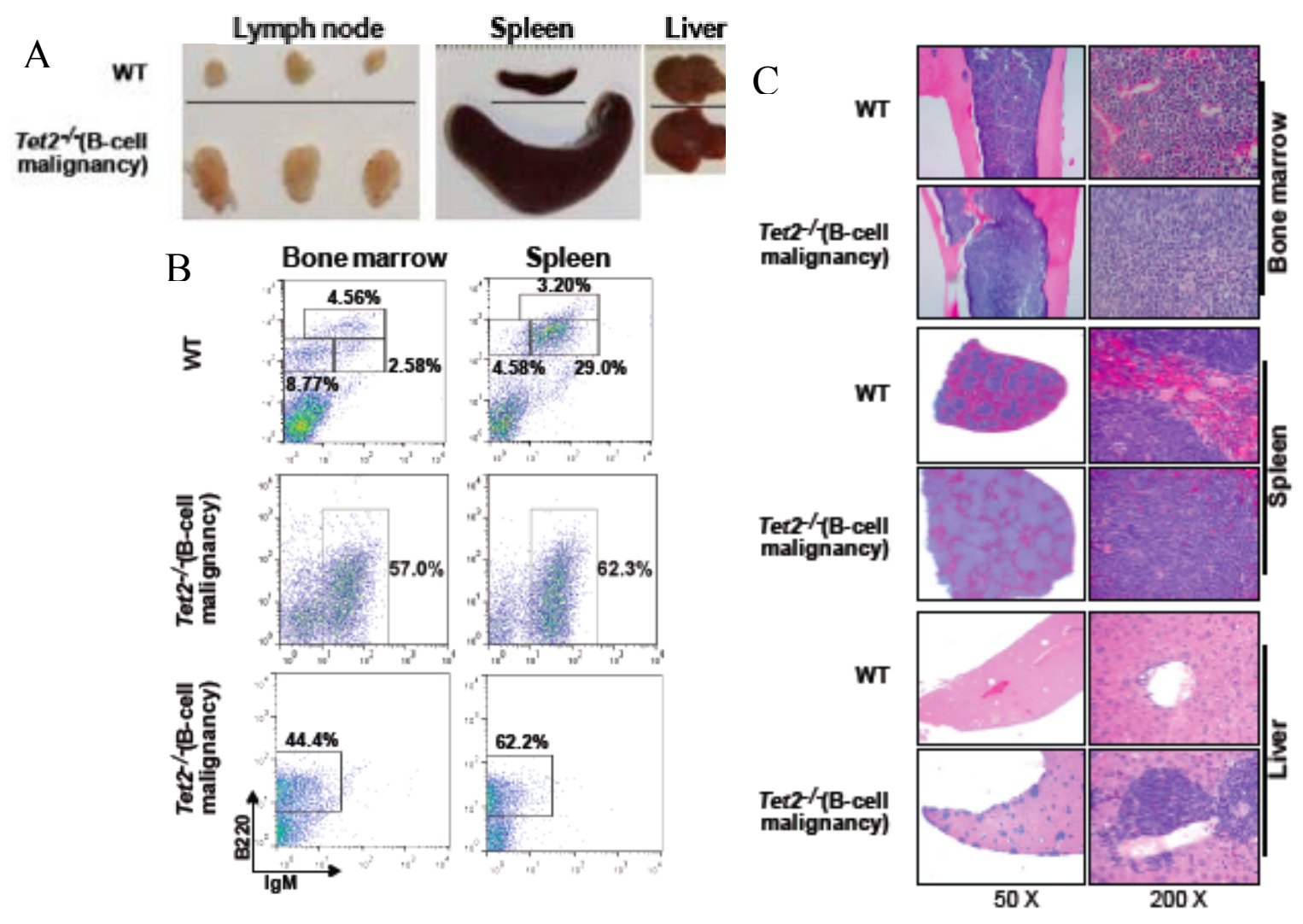

Figure 16 Tet2 $^{-/-}$mice with B-cell malignancy.

(A) The gross morphologies of lymph nodes, spleen and liver from a representative Tet21- mouse with B-cell malignancy. (B) Flow cytometric analysis of the B-cell lineage (B220/IgM) in BM and spleen of representative Tet $2^{-/-}$mice with B-cell leukemia/lymphoma and an age matched WT mouse. The numbers indicate the percent cells in each cell population. (C) H\&E stained histological sections of femurs, spleen and liver from a representative Tet $2^{-/}$mouse with B-cell leukemia/lymphoma and an age matched WT mouse. 


\begin{tabular}{|c|c|c|c|c|c|c|c|c|c|}
\hline \multirow{2}{*}{ ID } & \multirow{2}{*}{ Age, mo } & \multirow{2}{*}{ Necropsy findings } & \multirow{2}{*}{ Histology } & \multirow{2}{*}{ B Cell Type } & \multicolumn{4}{|c|}{ Blood Counts } & \multirow{2}{*}{ Diagnosis } \\
\hline & & & & & WBC, $K / \mu \mathrm{L}$ & $\mathrm{LY}, \mathrm{K} / \mathrm{\mu L}$ & $\mathrm{RBC}, \mathrm{M} / \mu \mathrm{L}$ & $\mathrm{PLT}, \mathrm{K} / \mu \mathrm{L}$ & \\
\hline G3-35 & 18 & $\begin{array}{l}\text { Hepatosplenomegaly, } \\
\text { Lymphadenopathy }\end{array}$ & $\begin{array}{l}\text { Invasion lymph nodes, } \\
\text { intestine, liver }\end{array}$ & $\mathrm{B}_{22} 0^{\circ} \mathrm{ggM}^{+} \mathrm{CD} 19^{+} \mathrm{CD} 43^{+}$ & 12.3 & 8.2 & 8.89 & 451 & B cell lymphoma/leukemia \\
\hline G3-38 & 18 & $\begin{array}{l}\text { Hepatosplenomegaly, } \\
\text { Lymphadenopathy }\end{array}$ & $\begin{array}{l}\text { Invasion of lymph nodes, } \\
\text { intestine, liver }\end{array}$ & $\mathrm{B} 220^{\circ} \mathrm{IgM}{ }^{*} \mathrm{CD} 19^{+} \mathrm{CD} 43^{+}$ & 11.9 & 7.1 & 5.76 & 249 & B cell lymphoma/leukemia \\
\hline G2-8 & 13 & $\begin{array}{l}\text { Hepatosplenomegaly, } \\
\text { Lymphadenopathy }\end{array}$ & $\begin{array}{l}\text { Invasion of BM, intestines, } \\
\text { liver, kidney, lung }\end{array}$ & $\mathrm{B} 220^{1 \%} \mathrm{gMM}^{+} \mathrm{CD} 19^{+} \mathrm{CD} 43^{+}$ & \multicolumn{4}{|c|}{ N.D } & B cell lymphoma/leukemia \\
\hline G5-87 & 8 & $\begin{array}{l}\text { Hepatosplenomegaly. } \\
\text { Lymphadenopathy }\end{array}$ & $\begin{array}{l}\text { Invasion of spleen. liver. } \\
\text { lymph nodes }\end{array}$ & $\begin{array}{c}\mathrm{B} 220^{1 \%} \mathrm{gg} \mathrm{glo}^{1 /-} \\
\mathrm{CD} 19^{+} \mathrm{CD} 43^{+} \mathrm{CD} 5^{+}\end{array}$ & 15.7 & 10.3 & 6.16 & 227 & B cell lymphoma/leukemia \\
\hline G3-322 & 3 & Splenomegaly & Invasion of spleen & 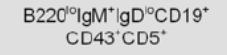 & 15.7 & 123 & 9.99 & 106 & B cell lymphoma/leukemia \\
\hline $\mathrm{G} 2-25$ & 16 & $\begin{array}{l}\text { Hepatosplenomegaly, } \\
\text { Lymphadenopathy }\end{array}$ & $\begin{array}{l}\text { Invasion of spleen, liver, } \\
\text { lymph nodes }\end{array}$ & $\mathrm{B} 220^{10} \mathrm{gM}^{+} \mathrm{CD} 19^{+} \mathrm{CD} 43^{+}$ & 41.9 & 29.8 & 6.01 & 324 & B cell lymphoma/leukemia \\
\hline G3-185 & 9 & $\begin{array}{l}\text { Hepatosplenomegaly. } \\
\text { Lymphadenopathy }\end{array}$ & $\begin{array}{l}\text { Invasion of spleen. liver. } \\
\text { lymph nodes }\end{array}$ & 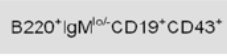 & $\begin{array}{l}\text { Very } \\
\text { High }\end{array}$ & $\begin{array}{l}\text { Very } \\
\text { High }\end{array}$ & 6.45 & 527 & B cell lymphoma/leukemia \\
\hline G5-50 & 11 & $\begin{array}{l}\text { Hepatosplenomegaly. } \\
\text { Lymphadenopathy }\end{array}$ & $\begin{array}{l}\text { Invasion of spleen, liver. } \\
\text { lymph nodes }\end{array}$ & $\begin{array}{l}\mathrm{B}^{2} 20^{+} \operatorname{lgM} \mathrm{M}^{+} \mathrm{CD} 19^{+} \mathrm{CD} 43^{+} \\
\mathrm{CDS}^{+}\end{array}$ & 183.7 & 172.4 & 6.17 & 412 & B cell lymphoma/leukemia \\
\hline G2-7 & 11 & $\begin{array}{l}\text { Hepatosplenomegaly, } \\
\text { Lymphadenopathy }\end{array}$ & $\begin{array}{l}\text { Invasion of BM, intestine, } \\
\text { spleen, liver }\end{array}$ & $\mathrm{B} 220^{+} \mathrm{lgM}{ }^{+} \mathrm{CD} 19^{+} \mathrm{CD} 43^{+}$ & 54.1 & 43.7 & 9.37 & 774 & B cell lymphoma/leukemia \\
\hline
\end{tabular}

Table 2.2 Phenotypic characteristics of B-cell malignancies developed in 9 Tet2 $^{-/-}$ mice. 

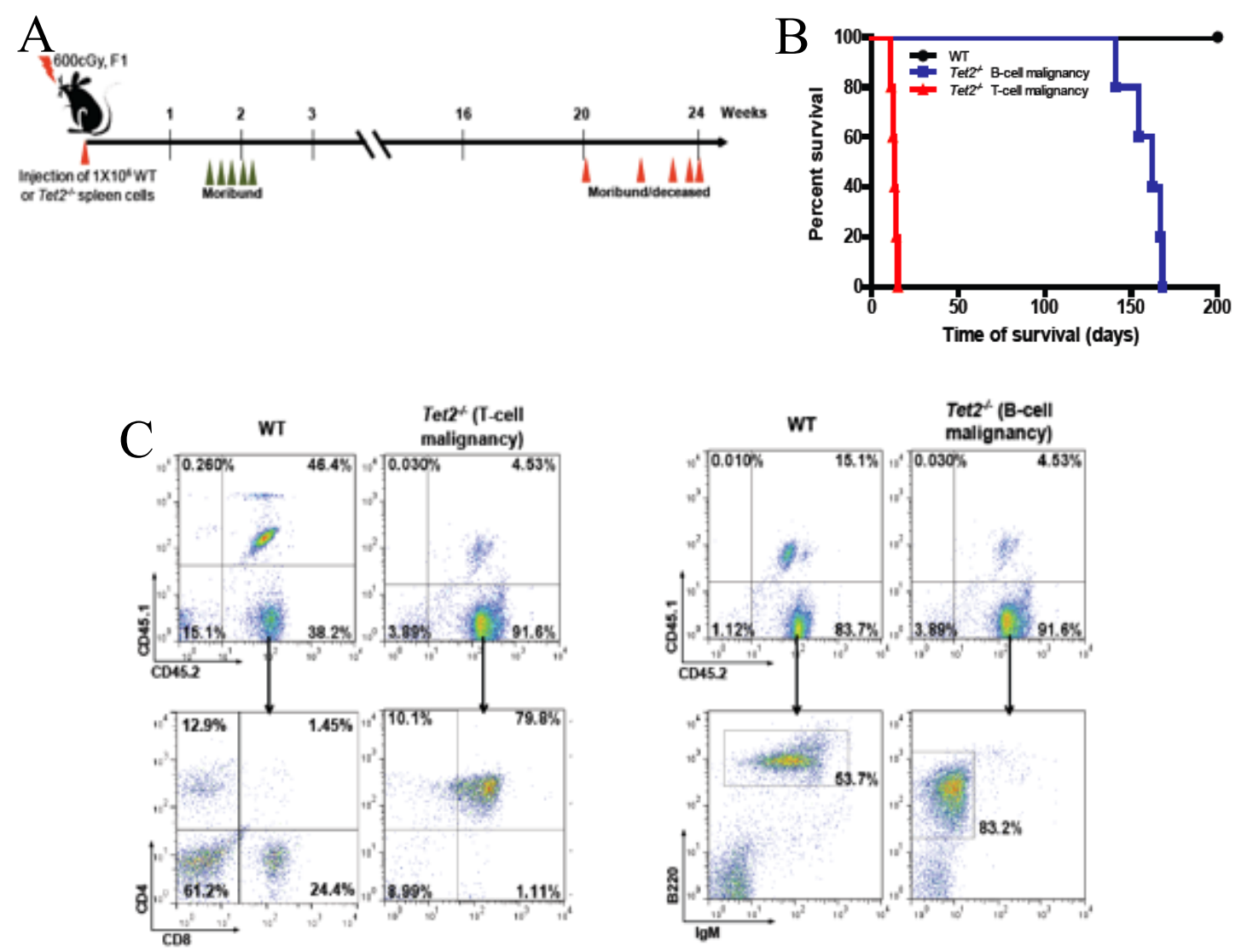

Figure 17 Lymphoid malignancies in Tet $^{-/-}$mice are transplantable to secondary recipients.

(A) Tumor transfer schema. Spleen cells (1x106) from a WT mouse or Tet ${ }^{-/ 2}$ mice with T- or B-cell lymphoma/leukemia were each injected into sub-lethally irradiated (600cGy) CD45.1+/CD45.2+ F1 recipients. (B) Kaplan-Meier survival curve of sub-lethally irradiated recipients ( 5 animals / donor) transplanted with spleen cells from a WT muse or Tet2 ${ }^{-/}$mice with T- or B-cell lymphoma/leukemia. (C) Flow cytometric analyses on the T-cell lineage $(\mathrm{CD} 4 / \mathrm{CD} 8)$ within the donor $(\mathrm{CD} 45.2+)$ cell populations of peripheral blood cells from a representative recipient receiving spleen cells from a WT mouse or a $\mathrm{Tet}^{-/-}$mouse with T-cell lymphoma/leukemia. Flow cytometric analyses on the B-cell lineage $(\mathrm{B} 220 / \mathrm{IgM})$ within the donor $(\mathrm{CD} 45.2+)$ cell populations of peripheral blood cells from a representative recipient receiving spleen cells from a WT mouse or a Tet2 $2^{-1-}$ mouse with B-cell lymphoma/leukemia. Data demonstrate that the recipients receiving spleen cells from Tet ${ }^{-/-}$mice with $\mathrm{T}$ - or B-cell lymphoma/leukemia developed diseases similar to their respective donor mice. 


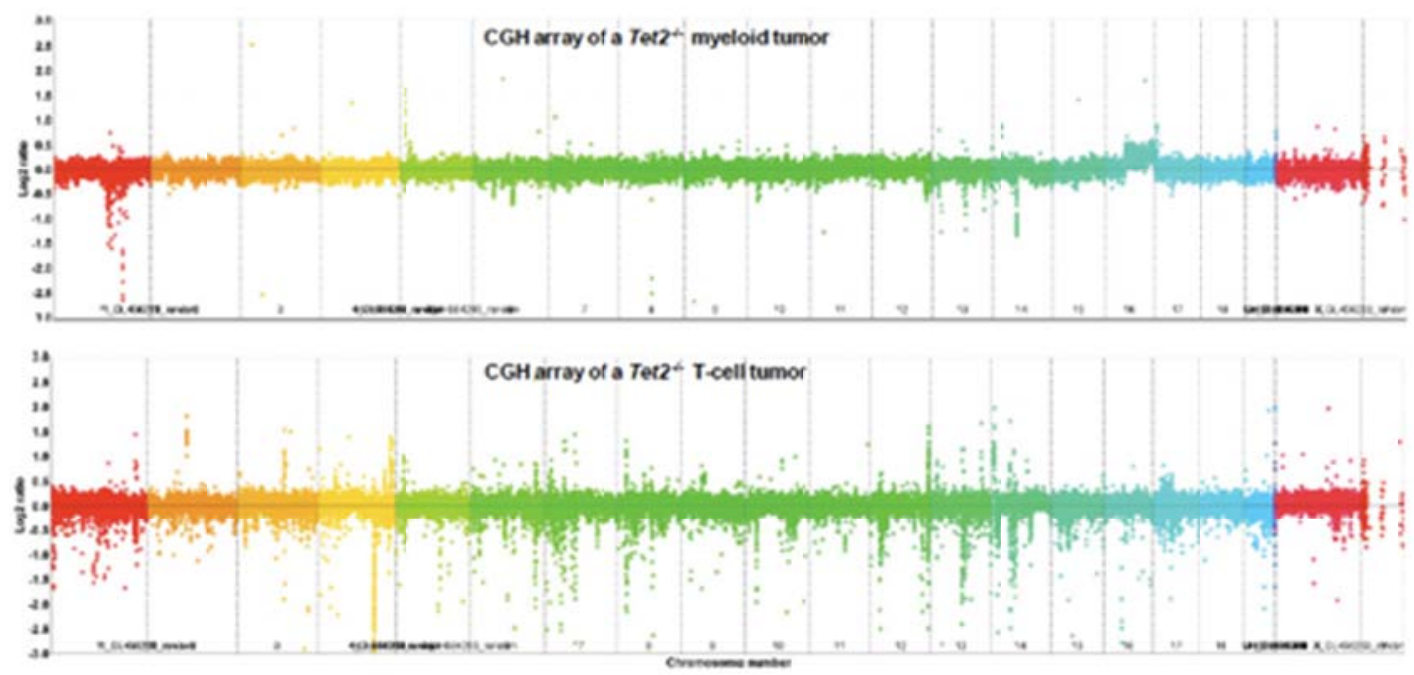

Figure 18 Array-based CGH ideograms of Tet $2^{-/-}$tumors.

DNA was extracted from 10 Tet2 ${ }^{-/}$tumors (4 myeloid, $3 \mathrm{~T}$ - and $3 \mathrm{~B}$-cell malignancies) and processed for hybridization to 244K Whole Mouse Genome Chip (G4122A; Agilent Technologies). Arrays were scanned with an Agilent scanner and analyzed with the Agilent Feature Extraction software. After processing on the Genomic Workbench system 5.0, normalized array-CGH values were used to calculate the median ratio at each individual chromosome for each tumor. Graphical representation of the data used the Visualization and Analysis of Array-CGH. Chromosomes are listed in numerical order from left to right. Red squares above zero on the y-axis represent genomic gains relative to the diploid control. The yellow lines indicate the absence of numerical alterations relative to the diploid control. The reference DNA was obtained from the bone marrow of a wild-type C57BL/6 female mouse. 


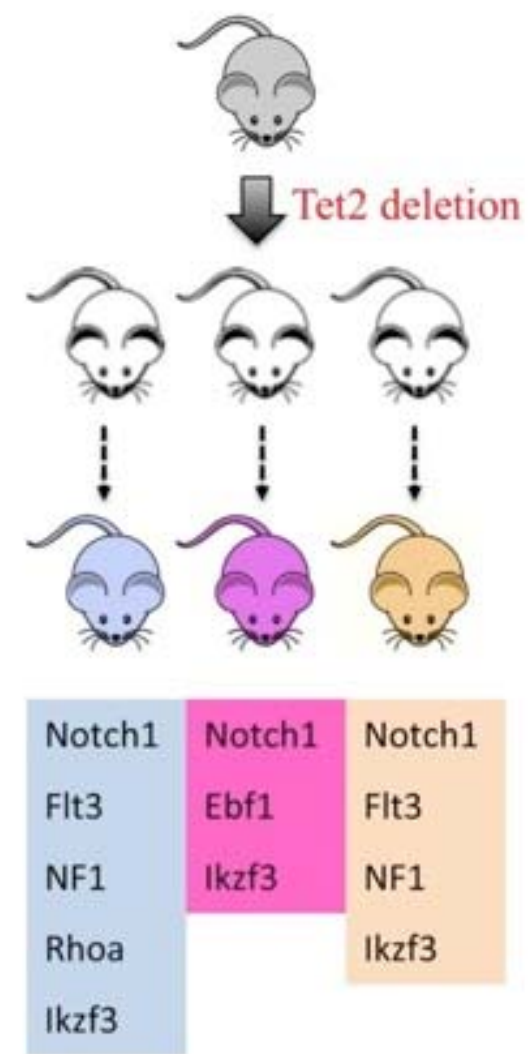

Figure 19 Acquisition of mutations in Tet ${ }^{-/-}$tumors.

Selected recurrent gene mutations in Tet $2^{-/ /}$tumors involving myeloid-, B- or T-cell lineages as identified by whole exome sequencing. 


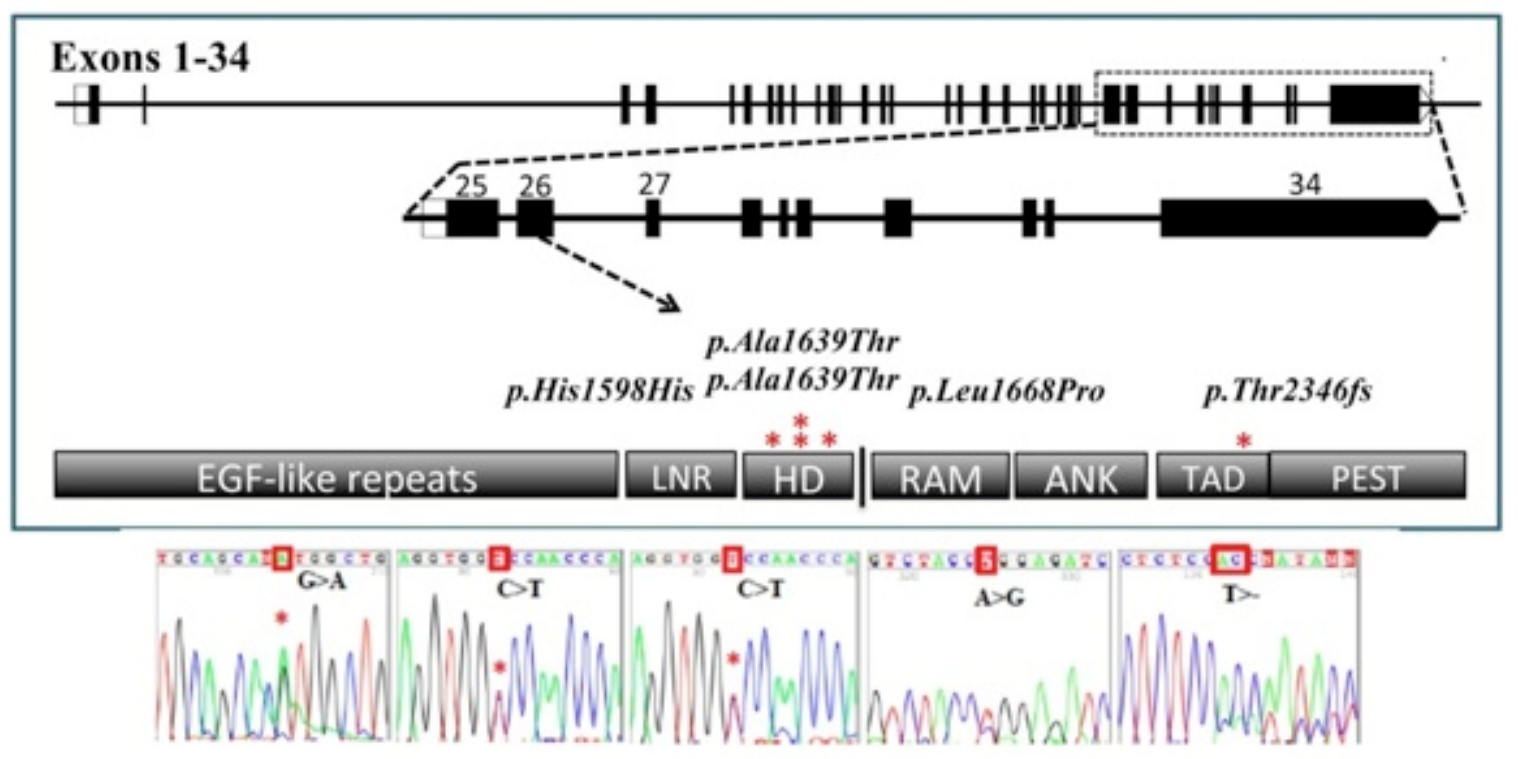

Mutational status of Notch1 gene in T-cell leukemia/lymphoma cases of Tet2\%- mice

\begin{tabular}{|c|c|c|c|c|c|c|}
\hline $\begin{array}{l}\text { Sample } \\
\text { ID }\end{array}$ & $\begin{array}{c}\text { Mutation } \\
\text { Type }\end{array}$ & $\begin{array}{l}\text { Mutation } \\
\text { Location }\end{array}$ & Position & $\begin{array}{c}\text { Allele } \\
\text { Change }\end{array}$ & $\begin{array}{c}\text { Amino Acid } \\
\text { Change }\end{array}$ & Methods \\
\hline 1 & $\begin{array}{l}\text { Missense } \\
\text { Deletion } \\
\text { Deletion }\end{array}$ & $\begin{array}{l}\text { HD Domain } \\
\text { PEST Domain } \\
\text { PEST Domain }\end{array}$ & $\begin{array}{l}\text { Chr2: } 26,466,601 \\
\text { Chr2: } 26,460,090 \\
\text { Chr2: } 26,460,091\end{array}$ & $\begin{array}{l}T>C \\
A>- \\
C>\end{array}$ & $\begin{array}{l}\text { p.Leu1668Pro } \\
\text { p.Thr2346- } \\
\text { p.Thr2346- }\end{array}$ & $\begin{array}{l}\text { Exome Sequencing } \\
\text { PCR/direct sequencing }\end{array}$ \\
\hline 2 & Missense & HD Domain & $\mathrm{Chr} 2: 26,466,586$ & $\subset G$ & p.Arg1673Pro & Exome Sequencing \\
\hline 3 & Missense & HD Domain & Chr2: $26,468,359$ & $\mathrm{C} \mathrm{T}$ & p.Ab1639Thr & PCR/direct sequencing \\
\hline 4 & Salent & HD Domain & Chr2: $26,468,238$ & $\mathrm{C}>\mathrm{T}$ & pHis1598* & PCR/direct sequencing \\
\hline 5 & Missense & HD Domain & Chr2: $26,468,359$ & $\mathrm{C}>\mathrm{T}$ & p.Abl639Thr & PCR/direct sequencing \\
\hline
\end{tabular}

Figure 20 Notch1 mutations were identified from Tet ${ }^{-/}$mice with T-cell malignancy. Sanger sequence traces of 4 Tet $2^{-/-} \mathrm{T}$-cell tumors with heterozygous mutations in Notch1 are shown in the middle panel. The mutational locations are shown as red asterisks in the mouse Notch1 protein schematic representation (upper panel). Notch1 gene mutations identified by exome-sequencing and/or Sanger sequencing in 6 Tet $2^{-/-} \mathrm{T}$-cell tumors are summarized in the lower panel. 


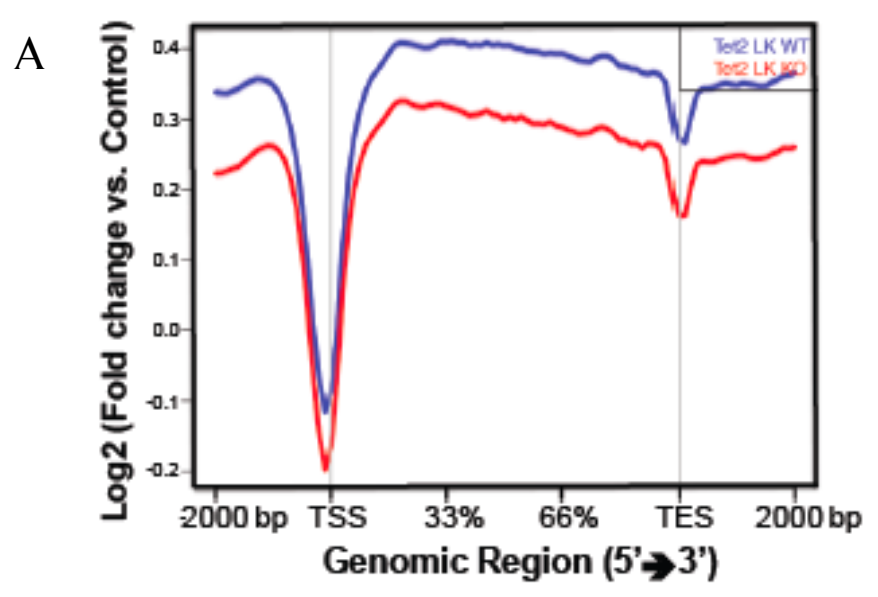

B

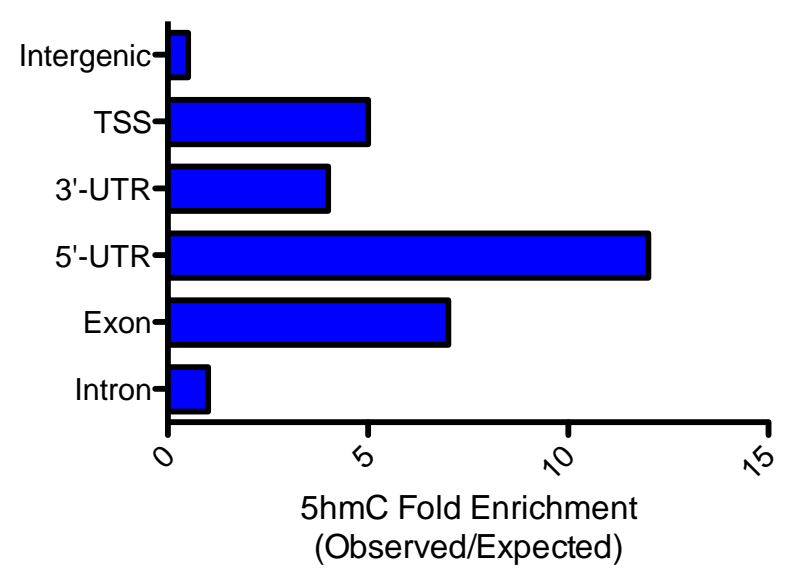

Figure $215 \mathrm{hmC}$ distribution and enriched regions with genomic features.

(A) Distribution of averaged $5 \mathrm{hmC}$ enrichment at all genes in WT and Tet $2^{-/} \mathrm{LK}$ cells. (B) Association of 5hmC-enriched regions with genomic features in LK cells. The percentage of $5 \mathrm{hmC}$-enriched regions overlapping a defined genomic feature was compared with the percentage expected to fall in that particular region by chance based on the genomic coverage of that region. Values are expressed as fold change from expected. 
A

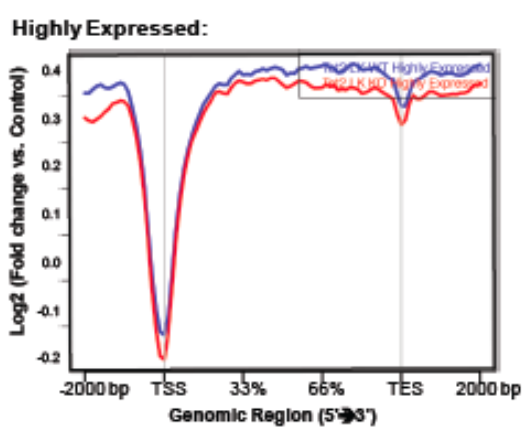

C

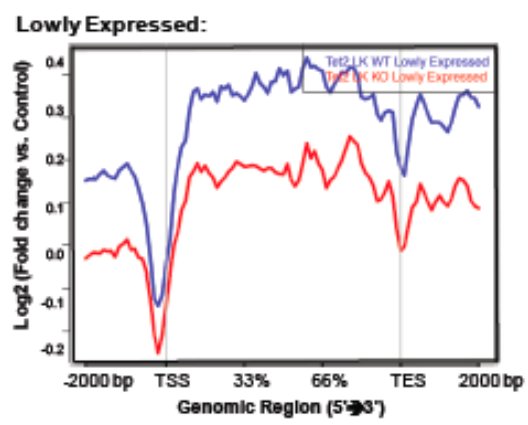

B

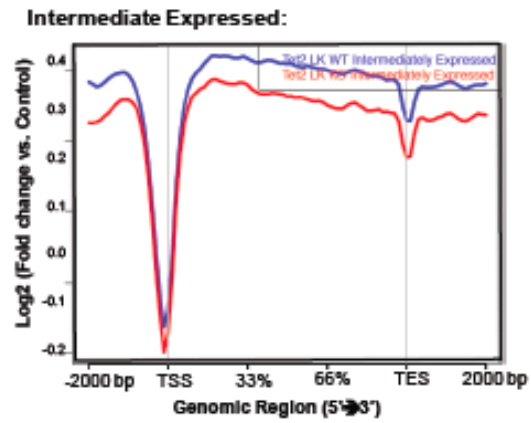

D

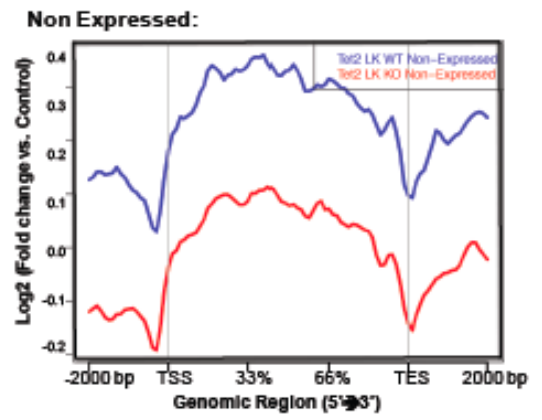

Figure 22 Changes of $5 \mathrm{hmC}$ among the genes with different expression levels. Gene expression values (RPKM) obtained from RNA-Seq were used to divide all the genes into four groups: Highly expressed (top 25\%), Intermediate Expressed (25-50\%), Lowly expressed (50-75\%) and Non Expressed (below 75\%). Distributions of averaged $5 \mathrm{hmC}$ enrichment at all genes of each group in WT and Tet $2^{-/-}$LK cells are shown. 

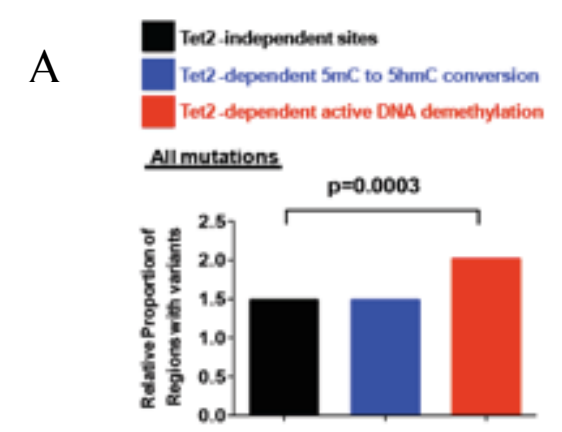

$\mathrm{C} / \mathrm{T}$ and $\mathrm{C} / \mathrm{A}$ mutations
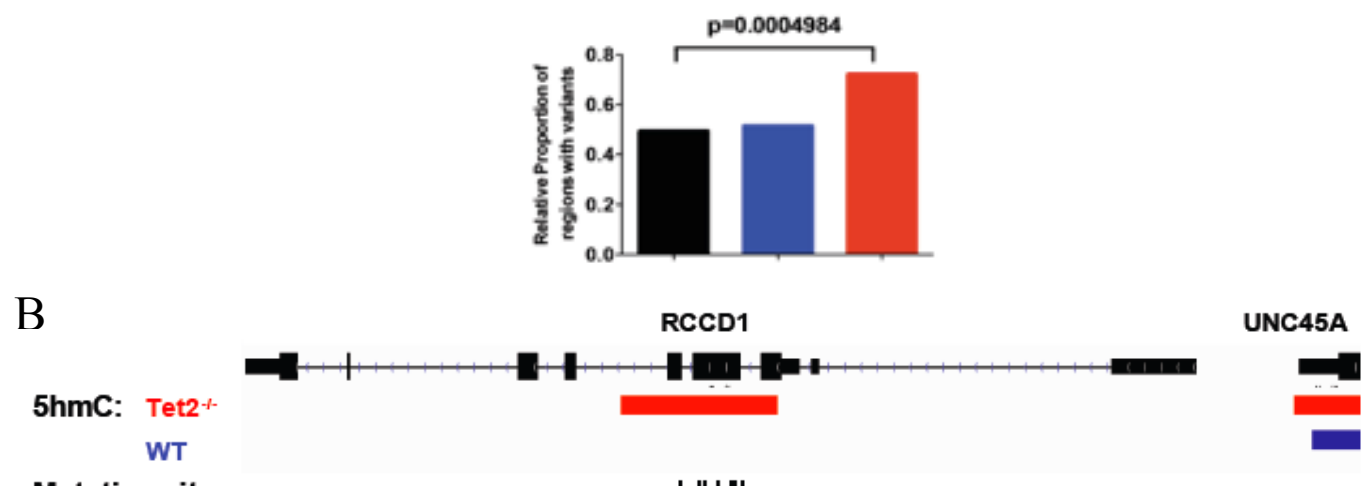

Mutation sites: I I | | |

Figure 23 Increased mutational frequency in loci marked by Tet2-dependent $5 \mathrm{hmC}$. Significantly greater frequencies of overall SNVs/indel (A, upper panel) or C to T (or G to A) mutations (A, lower panel) within the loci with Tet2-dependent active DNA demethylation, but not the regions with Tet2-dependent $5 \mathrm{mC}$ conversion to $5 \mathrm{hmC}$ or Tet2-independent $5 \mathrm{hmC}$ modification. Example of a genomic view showing the overlapping feature of Tet2-dependent active DNA demethylation, with Rccd1 mutations (B). 

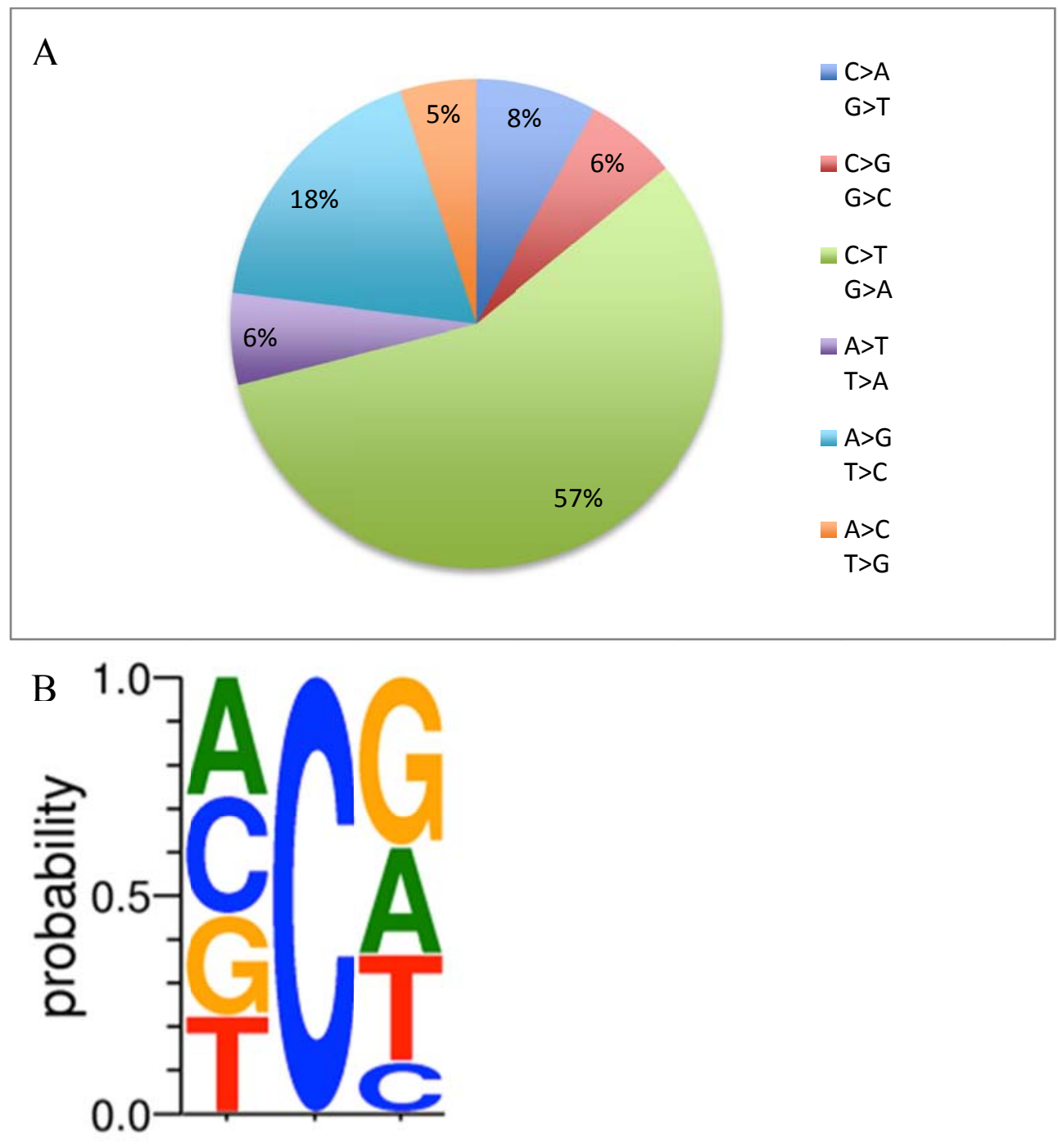

Figure 24 Validated mutational signatures found in Tet ${ }^{-/-}$tumors.

(A) Mutational signatures of Tet2-/- tumors characterized predominantly by $\mathrm{C}>\mathrm{T}$. (B) The mutated "C" favors formation of $\mathrm{NCG}$. 


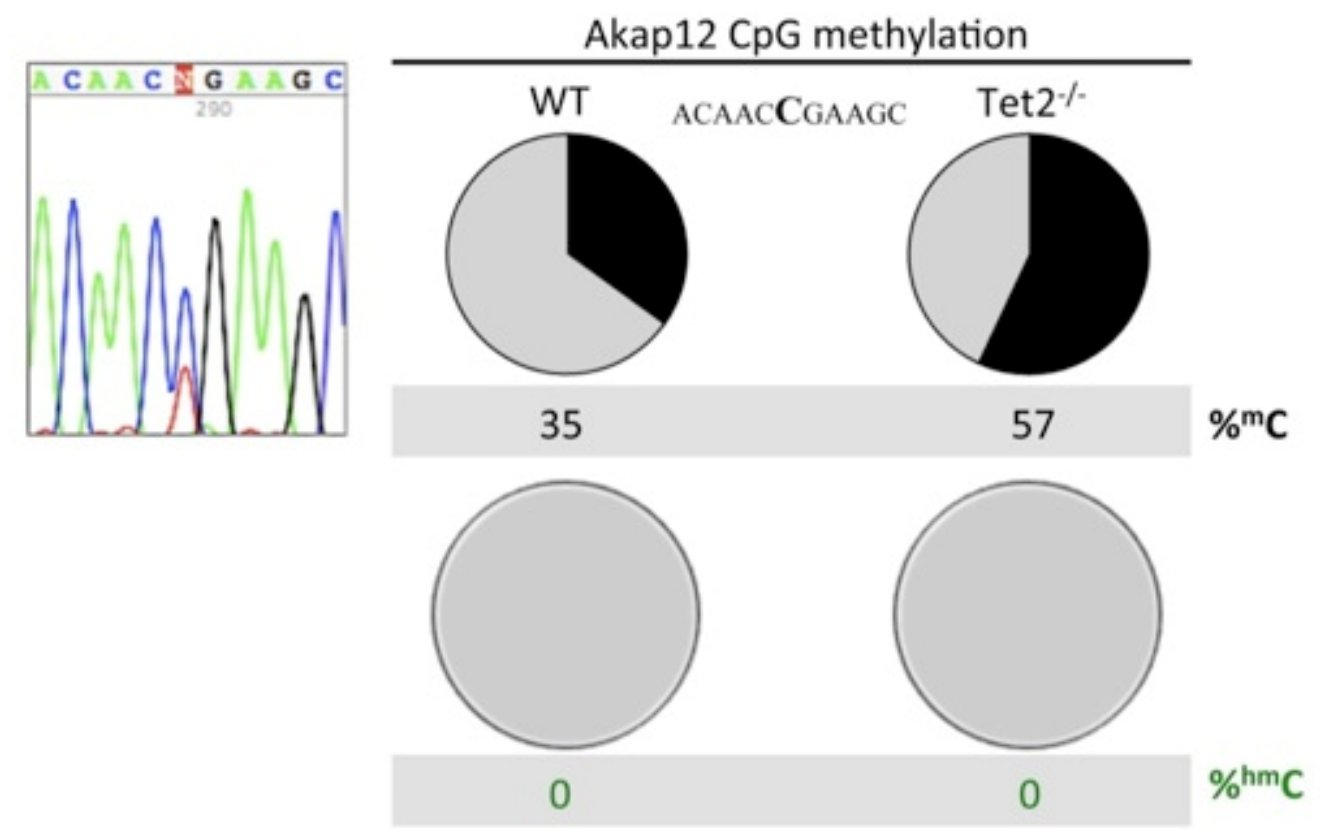

Figure 25 Dynamic changes of $5 \mathrm{mC}$ and $5 \mathrm{hmC}$ surrounding the mutation sites.

Akap12 mutational signature was characterized as CCG. Pie chart depicts the results of bisulfite-Seq and TAB-Seq. 

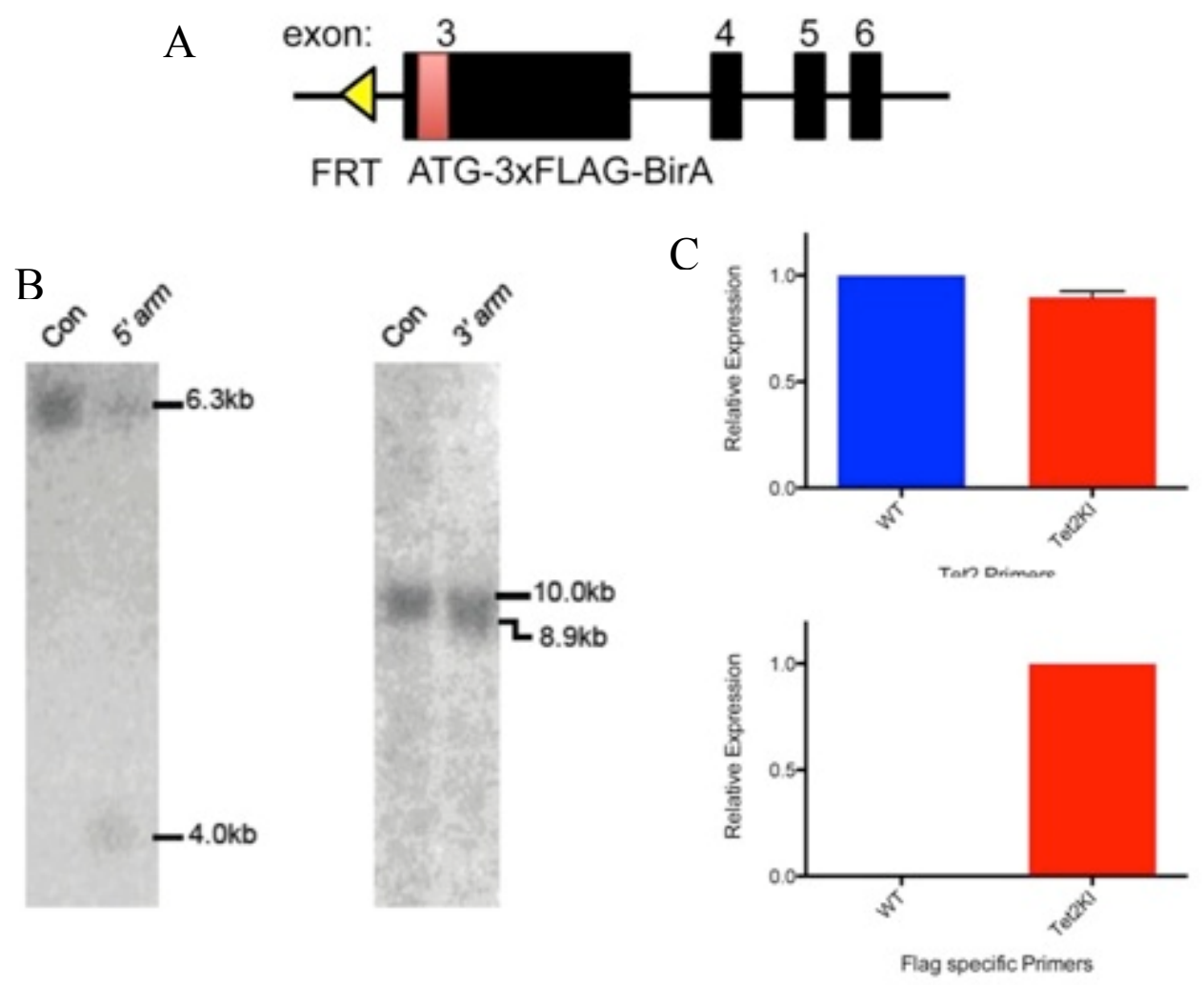

Figure 26 Generation of Flag-V5 tag knock-in ES cells.

(A) Targeting strategy for Tet2:Tag allele ES cells. The targeting vector contained a Neo cassette flanked by two FRT sites, followed by a $0.5 \mathrm{~kb}$ genomic fragment upstream of the Tet 2 start codon and an ATG/3xFlag/V5 sequence. A $2.2 \mathrm{~kb} 5^{\prime}$ and a $4.8 \mathrm{~kb} \mathrm{3'}$ arm genomic fragments were sub-cloned into the vector for gene targeting. Positive ES cells were identified by Southern blot. Square bars indicate exons. E, EcoRI. S, ScaI. (B) Southern blot of ES cell DNA digested with ScaI and hybridized with a genomic fragment external to the 5' arm displayed a WT band of $6.3 \mathrm{~kb}$ and recombinant band of $4.0 \mathrm{~kb}$ (left panel), and ES cell DNA digested with EcoRI and hybridized with a probe external to the 3' arm displayed a WT band of $10.0 \mathrm{~kb}$ and a recombinant band of $8.9 \mathrm{~kb}$ (right panel). (C) Comparable WT Tet2 and Tag-Tet2 transcripts in Tet2:Tag ES cells. Data reported as relative expression units to the WT Tet 2 expression in WT ES cells using $\beta$-actin as internal calibrator. 


\begin{tabular}{cccc}
\hline Protein & Size & No. of Peptide & No. of Peptide (control) \\
\hline TET2 & 220 & 78 & 0 \\
OGT & 110 & 2 & 2 \\
MSH6 & 163 & 2 & 9 \\
TOP2A & 174 & 47 & 32 \\
SIN3A & 15 & 1 & 1 \\
MSH2 & 104 & 1 & 1 \\
BRCA1 & 199 & 4 & 0 \\
RAD51 & 37 & 2 & 0 \\
\hline
\end{tabular}

Table 2.3 Table of the most relevant proteins identified by mass spectrometry in the purification of TET2-associated proteins using Tet2:Tag knock-in ES cells. Spectral counts for each interacting protein are shown. 
A

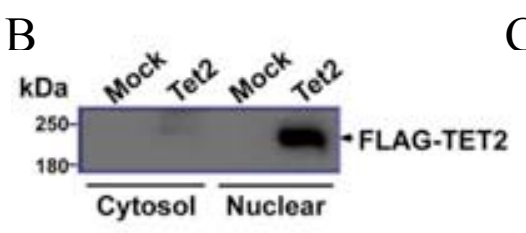

WB: Anti-FLAG

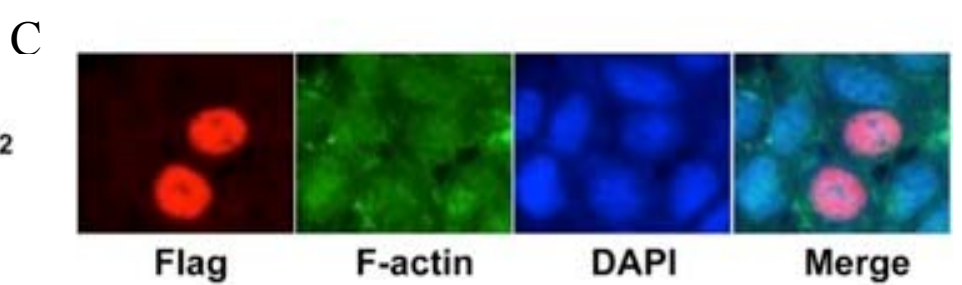

Flag
F-actin
DAPI
Merge

Figure 27 Flag-TET2 is expressed as a $240 \mathrm{kD}$ protein and localized in the nucleus. pcDNA3.1-hTET2 (TET2) or empty vector (Mock) was transfected into 293 cells using Lipo3000 transfection reagent. (A) Schematic map of pcDNA3.1-hTET2 construct. (B) Western blot was performed with cytosol and nuclear fractions using anti-Flag antibody. A $\sim 240 \mathrm{kD}$ band was detected in the nuclear fraction of TET2-transfected 293 cells, but not Mock cells, which agrees with the calculated molecular mass of Flag-TET2 based on its primary structure. (C) Cells were stained with anti-Flag antibody followed by the orange-fluorescent second antibody and green-fluorescent conjugated anti-F-actin antibody. The cells were then stained with DAPI (blue). Merged image artificially expressed in pink indicating co-localization of Flag-TET2 with DAPI, but not F-actin. 

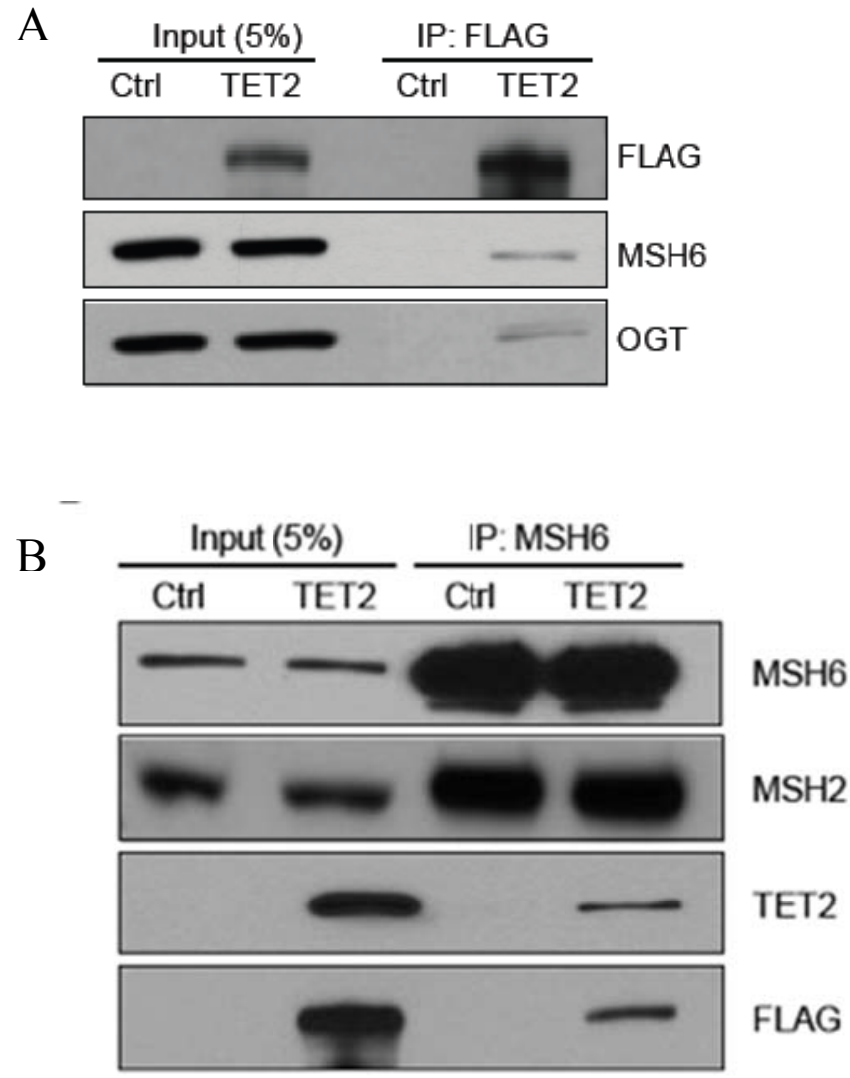

Figure 28 TET2 associates with MSH6.

Reciprocal co-immunoprecipitation and western blots confirmed the interaction of TET2 with MSH6 in HEK293T cells overexpressing Flag-tagged TET2. Non-transfected (ctrl) or Flag-TET2 overexpressing (TET2) HEK293 cell nuclear lysates were immunoprecipitated with anti-Flag (A) or anti-MSH6 (B) antibodies. The presence of Flag-TET2, MSH6, OGT and MSH2 in the precipitates was visualized by western blot using indicated antibodies. Whole cell lysate was used as the input. TET2 shows interaction with OGT in both Tet2:Tag ES cells and Flag-TET2 overexpressing HEK293 cell as previously reported. 

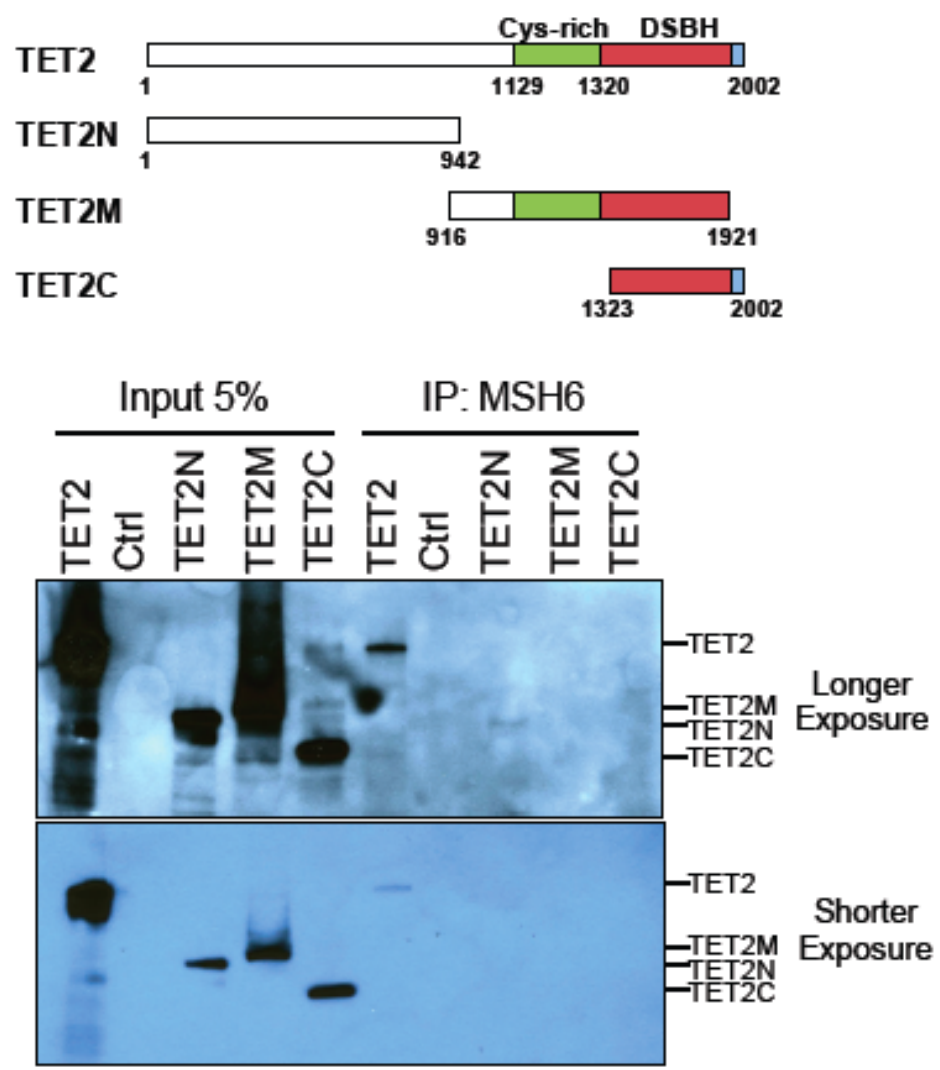

IB: FLAG

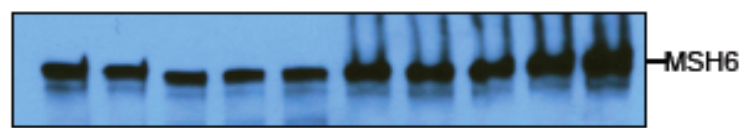

IB: MSH6

Figure 29 MSH6 co-immunoprecipitates with TET2 N-terminal.

MSH6 failed to bind to TET2M and TET2C in HEK293 cells overexpressing each Flagtagged TET2 fragments. Nuclear extracts were immunoprecipitated with anti-MSH6 antibody and probed with anti-FLAG or anti-MSH6 antibodies. 


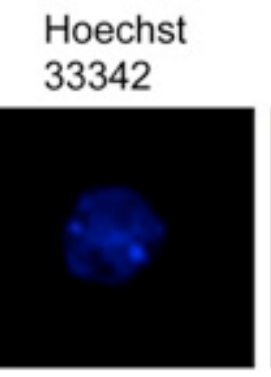

\section{TET2}
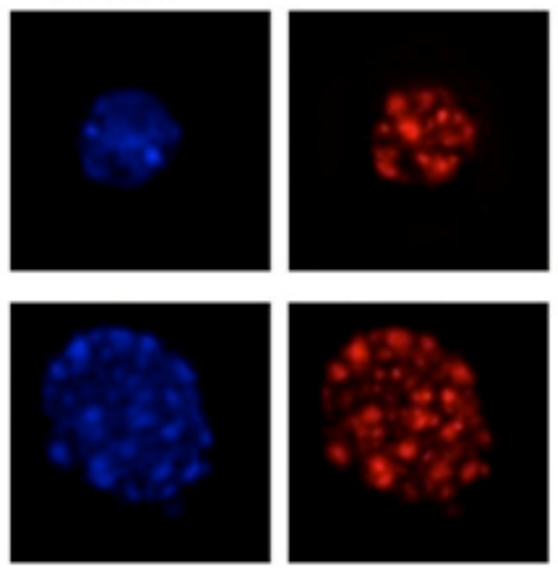

MSH6
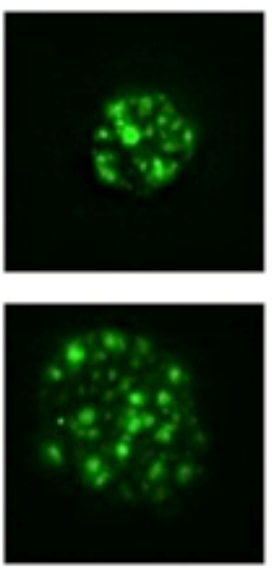

Merge
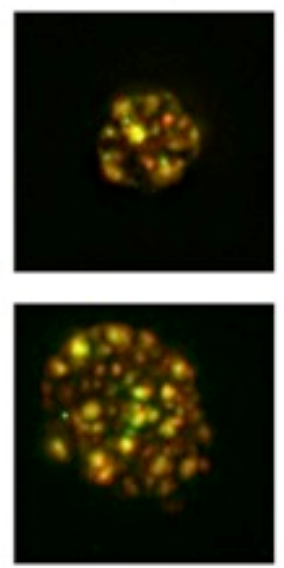

Merge
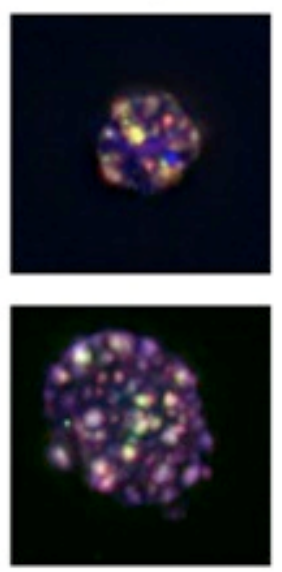

Figure 30 Immunostaining identified TET2 and MSH6 co-localization. MSH6 foci formation and MSH6-TET2 co-localization in HeLa cells. Immunofluorescence was performed to determine nuclear distribution of MSH6 and TET2. Cells were stained with anti-TET2 antibody followed by the red-fluorescent second antibody and anti-MSH6 flowed by green-fluorescent second antibody. The cells were then stained with Hoechst33342 (blue). Merged image artificially expressed in yellow indicating co-localization of TET2 with MSH6 in the nuclear. 


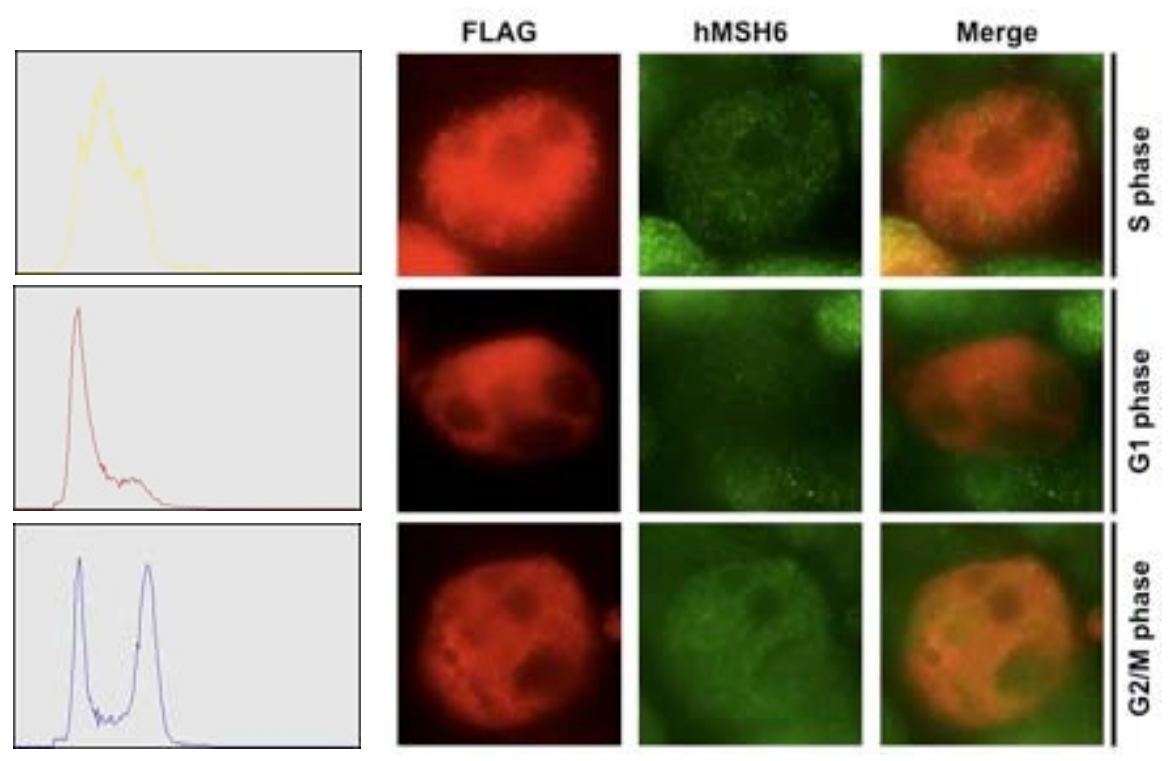

Figure 31 TET2 and MSH6 co-localization at different cell cycle.

HeLa cells were synchronized at G1, S and G2/M phase using double thymidine block. Immunofluorescence was performed to determine co-localization of MSH6 and TET2. Cells were stained with anti-FLAG antibody followed by the red-fluorescent second antibody and anti-MSH6 flowed by green-fluorescent second antibody. Merged image artificially expressed in yellow indicating co-localization of TET2 with MSH6 in the nucleus. 


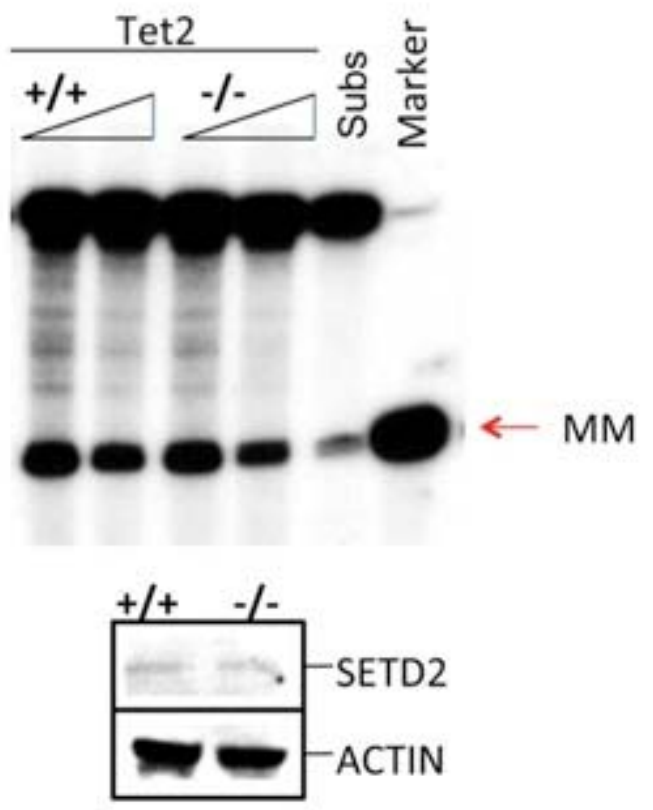

Figure 32 Tet2 is not physically involved in MMR activity in vitro.

In vitro MMR assay using nuclear extracts isolated from WT or Tet2 ${ }^{-/-} \mathrm{BM}$ cells. 


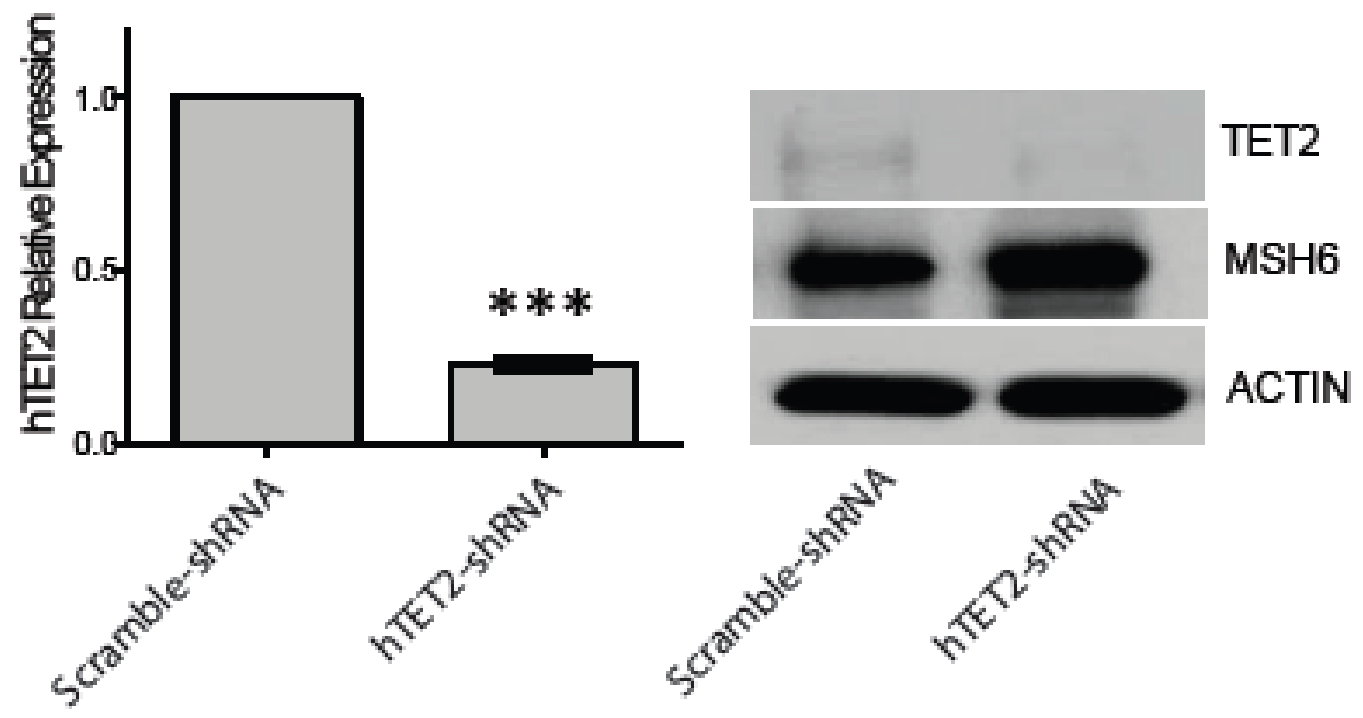

Figure 33 Knockdown of TET2 in HeLa cells using human TET2-specific shRNA. Western blot and qPCR analysis showing the expression of TET2 protein and mRNA in HeLa cells stably transfected with a scrambled shRNA or a TET2-specific shRNAs. 
A

\begin{tabular}{|c|c|c|c|}
\hline Cell line & $\begin{array}{l}\text { Mutation Frequency } \\
\left(\times 10^{-7}\right)\end{array}$ & $\begin{array}{l}\text { Fold change } \\
\text { of Mut. Freq }\end{array}$ & $\begin{array}{c}p \\
\text { value }\end{array}$ \\
\hline $\begin{array}{c}\text { Hela } \\
\text { Scramble shRNA }\end{array}$ & $5.8 \pm 1.7$ & 1 & \multirow{2}{*}{0.029} \\
\hline $\begin{array}{l}\text { Hela } \\
\text { TET2shRNA }\end{array}$ & $137.3 \pm 39.8$ (SD) & 24 & \\
\hline DL-1 & $1370.6 \pm 66.4$ (SD) & 236 & \\
\hline
\end{tabular}

B

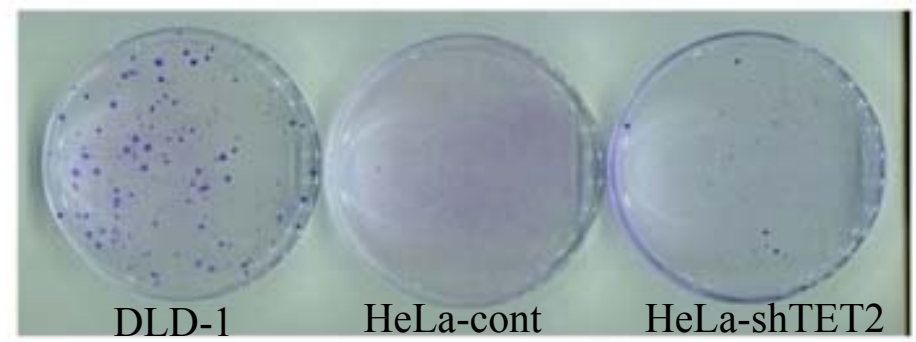

Figure 34 Increased mutational frequency in TET2 knockdown HeLa cells.

(A) HPRT mutability in control- and shTET2-HeLa cells. Data presented as mean $\pm \mathrm{SD}$. Fold increase in mutation frequency was calculated using the mutation frequency of control NIH3T3 cells as a reference, and a t test was used to estimate a p value. (B) Low density 6-TG survival assay indicating resistance of TET2 knockdown HeLa cells. 

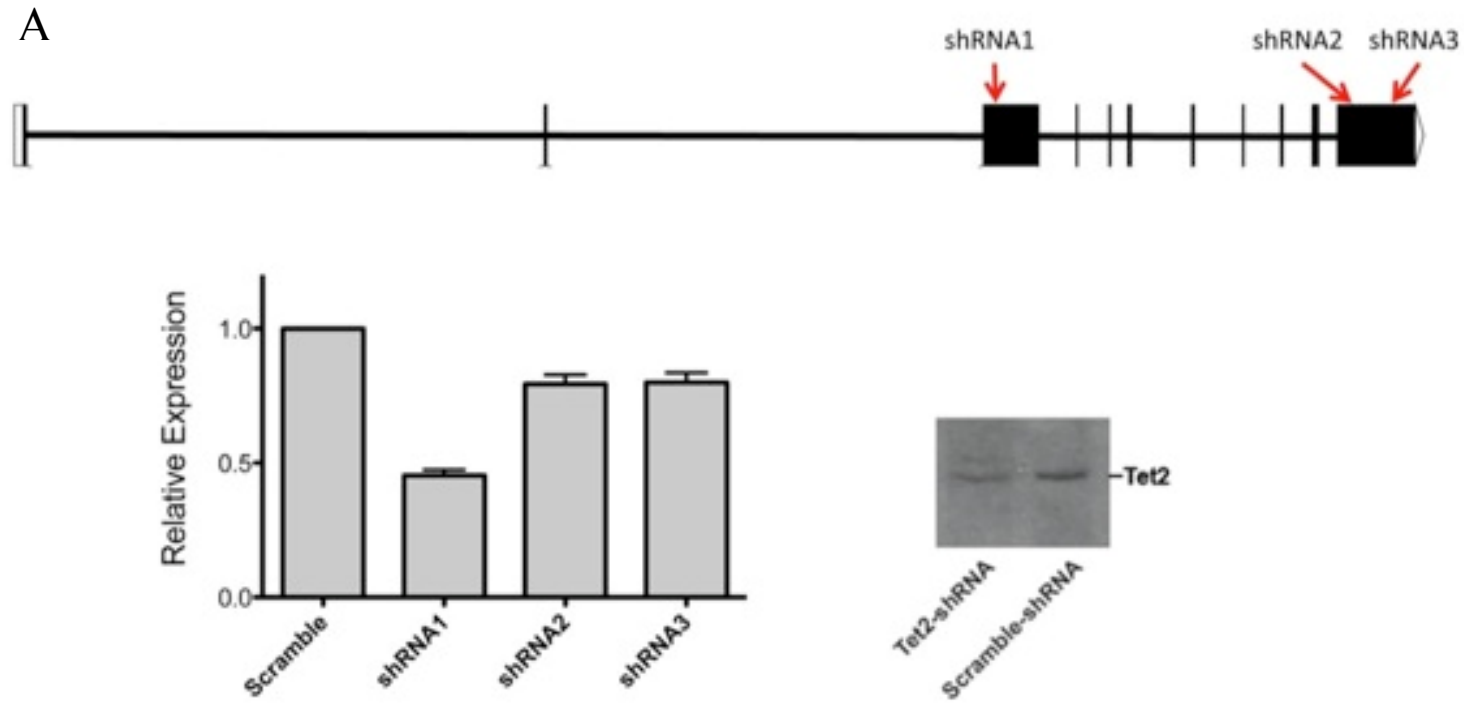

$\mathrm{B}$

\begin{tabular}{|l|l|l|l|}
\hline Cell line & $\begin{array}{l}\text { Mutation } \\
\text { Frequency }\left(\times 10^{-7}\right)\end{array}$ & $\begin{array}{l}\text { Fold change of } \\
\text { Mut.Freq. }\end{array}$ & p value \\
\hline $\begin{array}{l}\text { NIH/3T3 } \\
\text { Scramble shRNAs }\end{array}$ & 9.3 & 1 & 0.027 \\
\hline $\begin{array}{l}\text { NIH/3T3 } \\
\text { Tet2 shRNA1 }\end{array}$ & $142.9 \pm 22.5(\mathrm{SD})$ & 15 & \\
\hline DLD-1 & $1370.6 \pm 66.4(\mathrm{SD})$ & 148 & \\
\hline
\end{tabular}

Figure 35 Increased mutational frequency in shTet2-NIH3T3 cells.

(A) Western blot and qPCR analysis showing the expression of Tet 2 protein and mRNA in NIH3T3 cells stably transfected with a scrambled shRNA or a Tet2-specific shRNAs. (B) HPRT mutability in control- and shTet2-NIH3T3 cells. Data presented as mean \pm SD. Fold increase in mutation frequency was calculated using the mutation frequency of control NIH3T3 cells as a reference, and a t test was used to estimate a p value. 


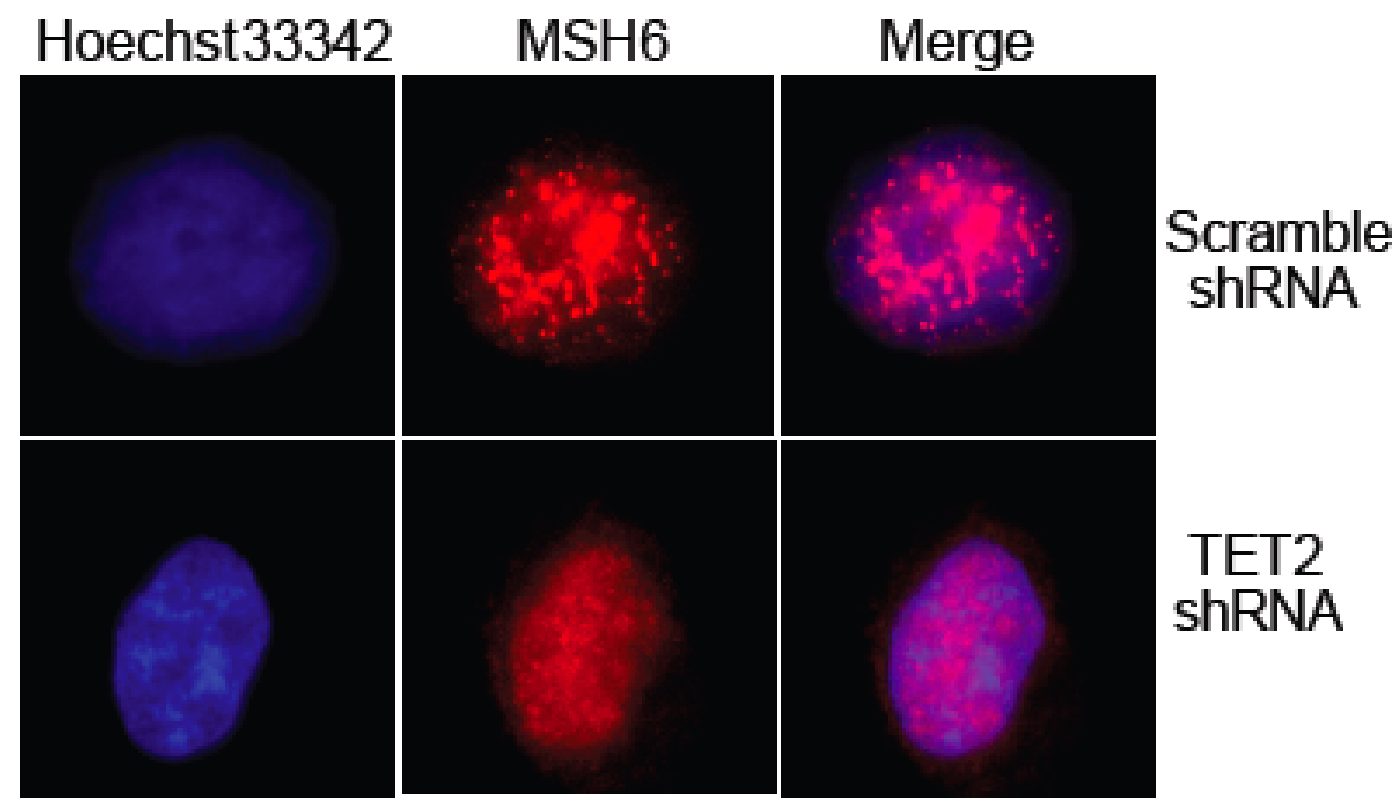

Figure 36 MSH6 foci formation and localization in control- and shTET2- HeLa cells 


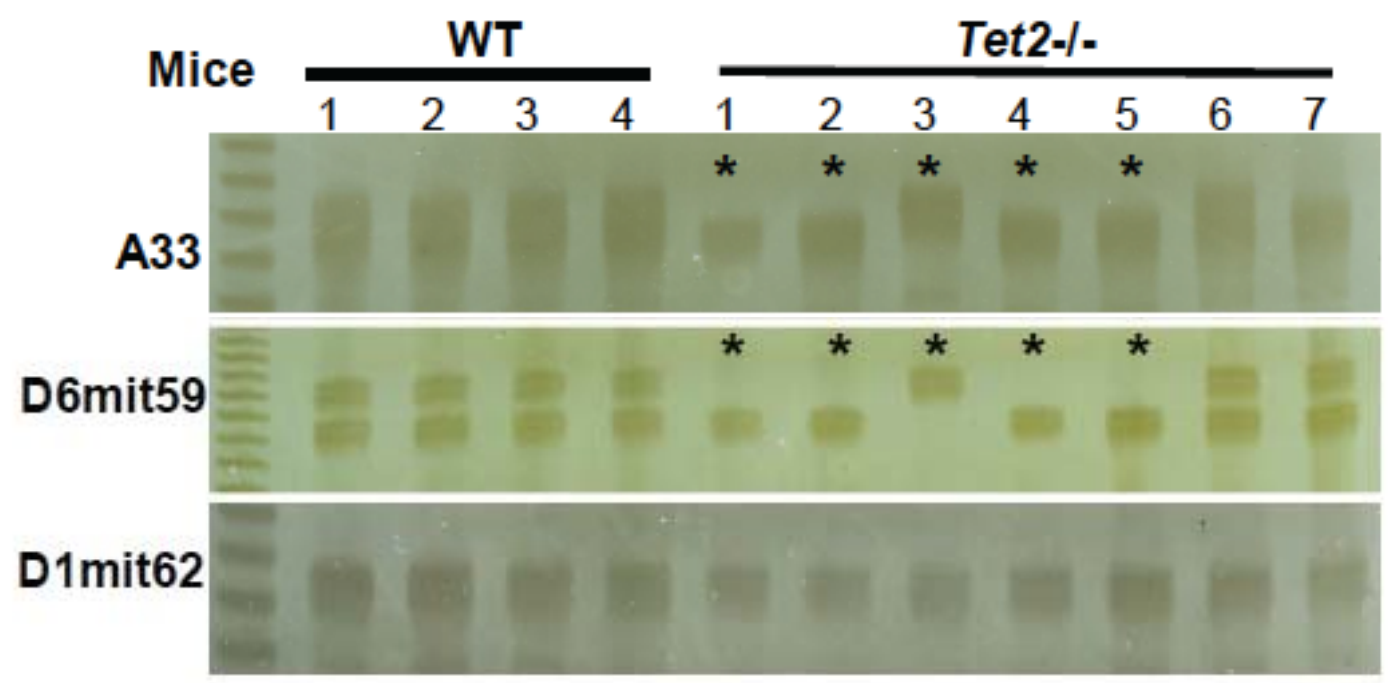

Figure 37 Analysis of PCR product patterns of microsatellite markers in bone marrow cells from WT and Tet $2^{-/-}$mice.

The appearance of novel length alleles of the A33, D6Mit59 loci is indicated (asterisk) for each sample. The D1Mit62 CA-repeat locus was used as a negative control, as this locus is stable. No alterations were found at this stable locus in both WT and Tet ${ }^{-/-}$ samples. 

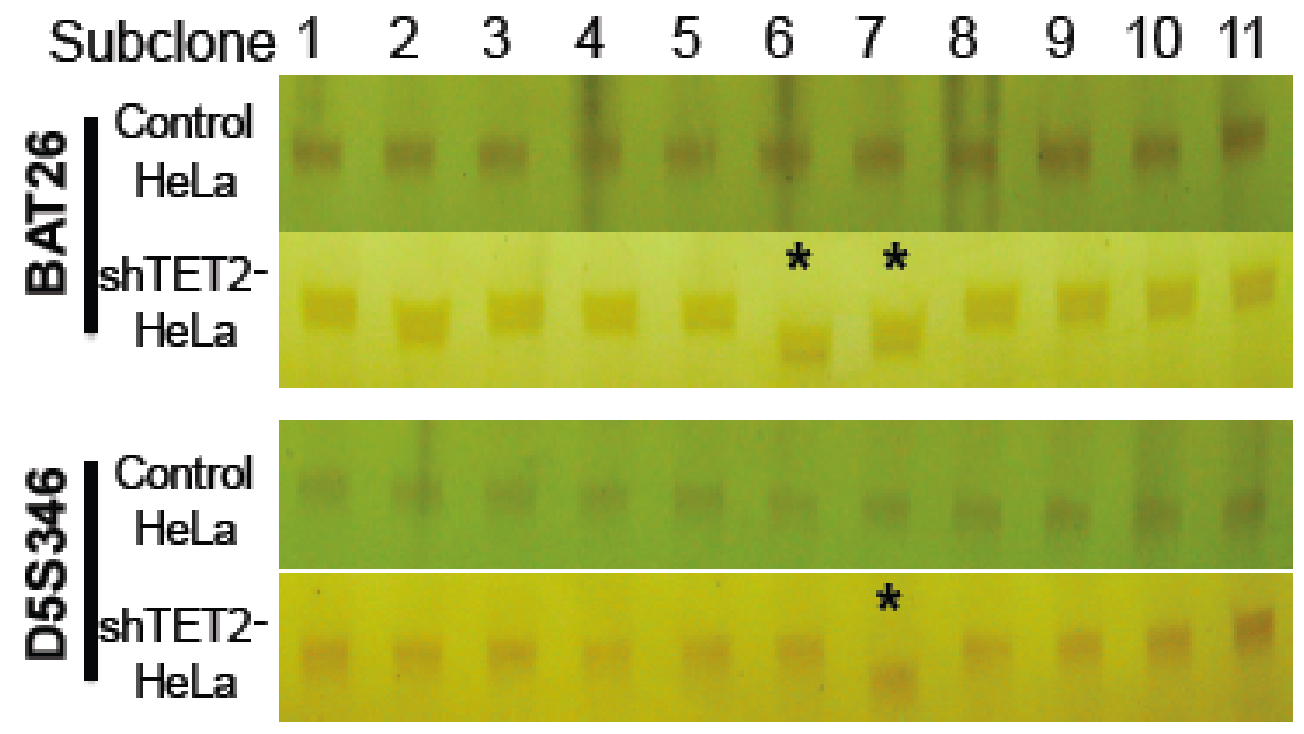

Figure 38 Analysis of PCR product patterns of two microsatellite markers in control- and shTET2-HeLa cells.

The asterisk shows the clone exhibiting new repeat species. 


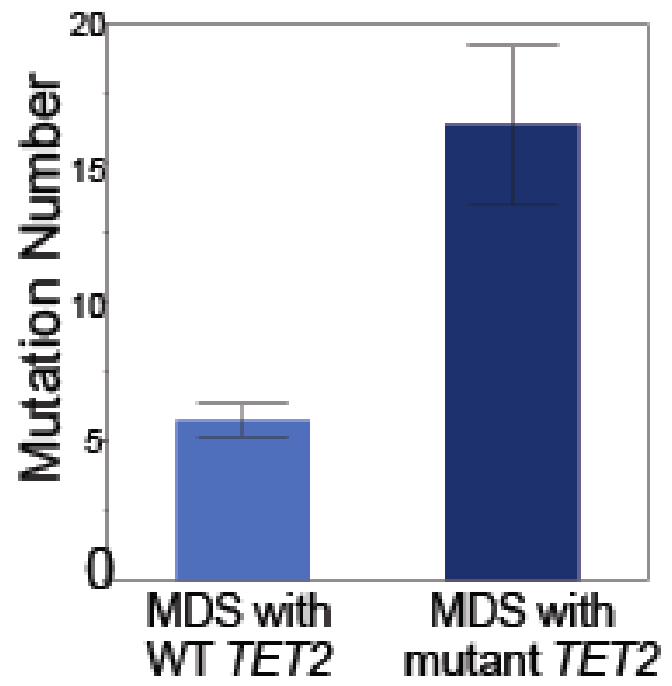

Figure 39 Mutation numbers in MDS patients with or without TET2 mutations. Exome sequencing data from a cohort of human MDS patients were analyzed for the number and type of mutations and were summarized as mean \pm SD in groups with $(n=5)$ or without $(\mathrm{n}=5)$ TET2 mutations. 

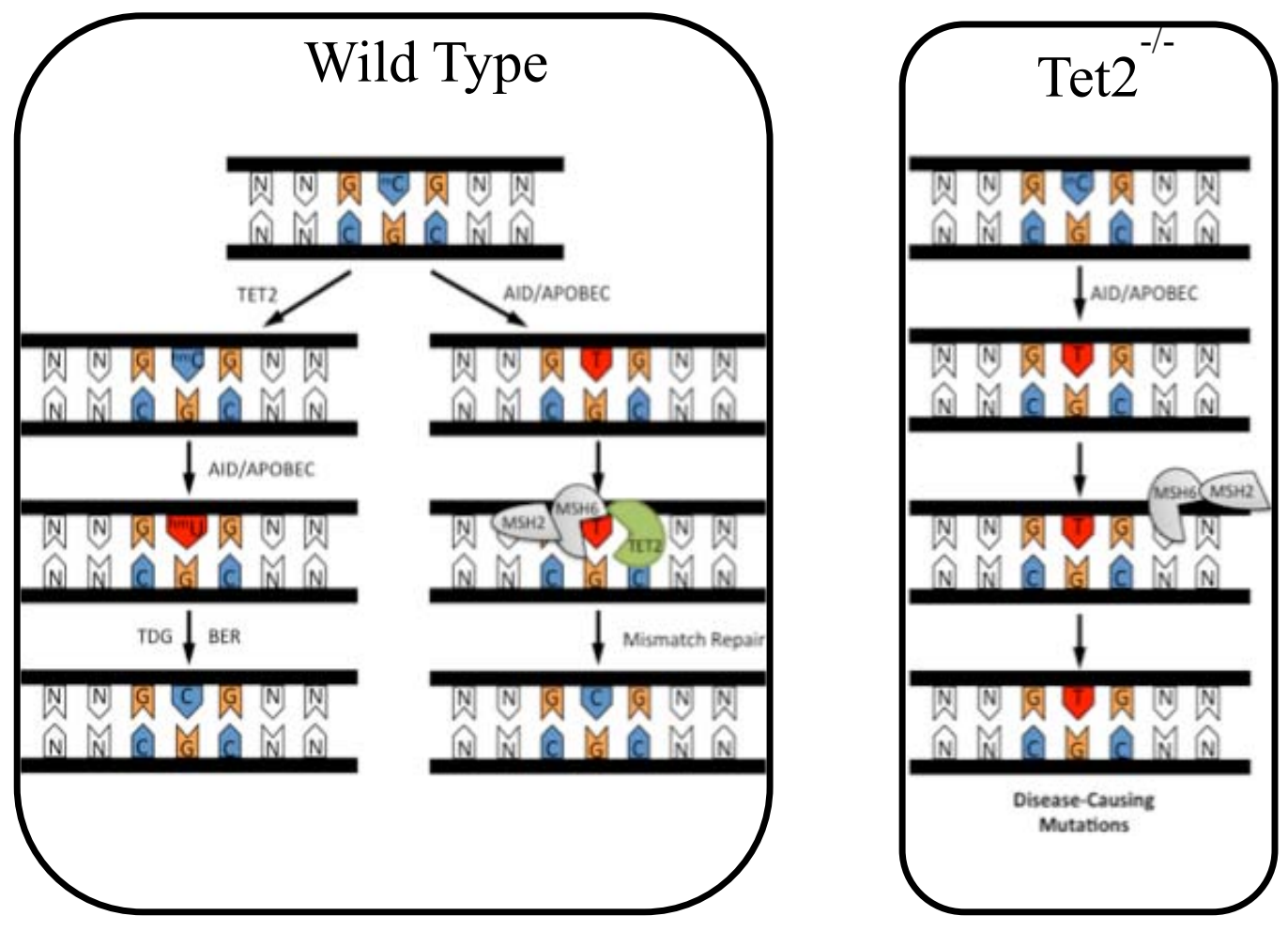

Figure 40 Proposed model for loss of Tet2 induced hematological malignancies.

In wild type individuals, active DNA demethylation can be initiated by TET2-mediated 1) left panel, TET2 catalyzes the hydroxylation of $5 \mathrm{mC}$ to $5 \mathrm{hmC}$, followed by AID/APOBEC mediated conversion from $5 \mathrm{hmC}$ to $5 \mathrm{hmU}$, which can be further recognized by TDG and repaired through BER pathway. 2) right panel, $5 \mathrm{mC}$ is metabolized through deamination to $\mathrm{T}$ to generate $\mathrm{T}: \mathrm{G}$ mismatch, followed mismatch repair mechanism through TET2 recruited MSH2, MSH6 heterodimer complex, which replace $\mathrm{T}$ back to $\mathrm{C}$ during DNA replication. In Tet $2^{-/-}$individuals, the loss oxidative enzymatic activity eliminate Tet2-mediated oxidative pathway; while $5 \mathrm{mC}$ can still be converted to $\mathrm{T}$. The newly generated $\mathrm{T}: \mathrm{G}$ mismatch could not be repaired by $\mathrm{MSH} 2$, MSH6 heterodimer because of the loss of Tet2. This may eventually lead to diseasecausing mutations. 
CHAPTER

TET2 REGULATES ADULT BRAIN NEUROGENESIS 


\subsection{AbStract}

Previous studies that have mapped genome-wide $5 \mathrm{hmC}$, have shown that $5 \mathrm{hmC}$ distributes temporally and spatially during neurodevelopment ${ }^{61,118,119}$. Interestingly, $5 \mathrm{hmC}$ acquisition in these regions (5mC specific) is different than what would be expected. There is no obvious correlation between $5 \mathrm{hmC}$ gain and $5 \mathrm{mC}$ loss in many important neurodevelopment-related genes, therefore one could argue that $5 \mathrm{hmC}$ role in gene regulation may be via a mechanism other than by transient oxidation in the brain ${ }^{118}$. In 2011, a study found Tet1 overexpression in the dentate gyrus (DG) significantly downregulated the methylation levels of Bdnf and Fgflb, highlighting the role of 5hmC in neurogenesis ${ }^{117}$. In addition, several types of neurodevelopment and neurodegenerative disorders have been found closely associated with $5 \mathrm{hmC}$, such as Rett syndrome, Autism spectrum disorder and Alzheimer's disease. Because of the extensive roles of $5 \mathrm{hmC}$ and TETs, several studies have explored TET proteins functions in neurogenesis ${ }^{117,121}$. There is evidence that $\mathrm{Tet}^{-/-}$mice exhibit robust loss $(\sim 45 \%)$ of NSCs in the SGZ compared with WT mice, and neurospheres from Tet ${ }^{-/}$show growth defects. Microarray studies have shown that many genes (Galanin, $\mathrm{Ng} 2$ and $\mathrm{Ngb}$ ) that are involved in NSC proliferation are down-regulated ${ }^{121}$. In addition, Tet $^{-/-}$mice show increased hippocampal long-term repression and memory defects ${ }^{121}$.

Because DNA methylation is critical for postnatal neurodevelopment, 5hmC may also be involved in $5 \mathrm{mC}$ dynamics during aging. I first assessed the abundance of $5 \mathrm{hmC}$ in the subventricular zone of the lateral ventricles and there was a substantial overlap between $5 \mathrm{hmC}+$ and $\mathrm{NeuN}+$ cells in the granule cell layer in the dentate gyrus of the hippocampus, whereas I noted a significant decrease of Tet1 mRNA and increase of Tet2 
mRNA in an age-dependent manner. Also, I observed the down-regulation of $5 \mathrm{hmC}$ abundance at both postnatal day 7 and adult age compared to WT. Furthermore, to explore the function of Tet2 in adult neurogenesis, BrdU incorporation assay and immunofluorescence staining were performed. Interestingly, Tet2 positively regulates neural stem/progenitor cells proliferation and differentiation. As well, luciferase reporter assay indicated that Tet2 regulates the methylation dynamics of NeuroD1 and Gfap promoter regions. Consistent with these observations, mRNA levels of NeuroD1 and Gfap were decreased in Tet2-deficient cells. These results suggest that Tet 2 is positively involved in adult brain neurogenesis through epigenetic regulation.

\subsection{INTRODUCTION}

Adult neurogenesis occurs in two germinal zones of the brain: the subgranular zone (SGZ) in dentate gyrus of the hippocampus and subventricular zone (SVZ) within the walls of the lateral ventricles. Adult neurogenesis can be regulated by many cellular activities including neural stem cells (NSC)/neural progenitor cells (NPC) proliferation and differentiation, fate determination, maturation and localization of newborn neurons $^{115,116}$. Since neurogenesis exists in these two regions, it is possible to postulate that neurogenesis may regulate learning and memory. As well, adult neurogenesis can be regulated by signaling pathways and epigenetic regulators ${ }^{116,138}$.

Ten-eleven translocation (TET) family proteins contain two key components: Fe (II) and 2-oxoglutarate (2-OG) to catalyze oxidation of the methyl group of $5 \mathrm{mC}$ to hydroxymethyl, formyl and carboxyl groups, which generate 5-hydroxymethylcytosine,

5-formylcytosine and 5-carboxylcytosine in an enzymatic activity-dependent manner ${ }^{39,65}$. 
Studies that have mapped genome-wide $5 \mathrm{hmC}$, have shown that $5 \mathrm{hmC}$ distributes temporally and spatially during neurodevelopment ${ }^{61,118,119}$. For example, studies have shown an age-dependent abundance and distribution of $5 \mathrm{hmC}$ in the cerebellum and hippocampus. Interestingly, $5 \mathrm{hmC}$ acquisition in these regions is different than would be expected. There is no strong correlation between $5 \mathrm{hmC}$ acquisition and $5 \mathrm{mC}$ loss in many important neurodevelopment-related genes, therefore one could argue that $5 \mathrm{hmC}$ role in gene regulation may be via a mechanism other than by transient oxidation in the brain ${ }^{118}$. To better understand the role of $5 \mathrm{hmC}$ in the brain, more than 6000 differentially hydroxymethylated regions (DhMRs) at different ages have been identified. These DhMRs were only found in adult brain, from 6-week-old brain, but not in postnatal day 7 (P7) cerebellum, indicating long-term modification of $5 \mathrm{hmC}$ in the brain ${ }^{118,119}$. Although the correlation of $5 \mathrm{hmC}$ abundance and gene transcription is still unclear, the enrichment of $5 \mathrm{hmC}$ and loss of $5 \mathrm{mC}$ at gene bodies coincide with gene transcription activation ${ }^{119}$. In fact, $5 \mathrm{hmC}$ regulation of neurogenesis was reported in 2011. Overexpression of Tet1 in the dentate gyrus (DG) significantly down-regulated the methylation levels of Bdnf and Fgflb, highlighting the role of $5 \mathrm{hmC}$ in neurogenesis ${ }^{117}$. Several types of neurodevelopment and neurodegenerative disorders have been found closely associated with $5 \mathrm{hmC}$, such as Rett syndrome, Autism spectrum disorder and Alzheimer's disease $\mathrm{e}^{119,120,139,140}$.

Because of the extensive roles of $5 \mathrm{hmC}$ and TETs, several studies have explored TET proteins functions in neurogenesis ${ }^{117,121}$. There is evidence that Tet $1^{-/-}$mice exhibits robust loss ( 45\%) of NSCs in the SGZ compared with WT mice, and neurospheres from 
Tet1 ${ }^{-/}$show growth defects. Microarray studies have shown that many genes (Galanin, $\mathrm{Ng} 2$ and $\mathrm{Ngb}$ ) that are down-regulated during NSC proliferation ${ }^{121}$.

The TET2 gene is well-characterized in the hematological system, however, little is known about its biological role in the nervous system. Considering the high abundance of $5 \mathrm{hmC}$ in the mouse adult brain, I tested the assumption of a critical role for Tet 2 in the adult brain and for changes in neural processes, by proposing to examine roles and relationships of Tet2 in the nervous system using a Tet2 knockout mouse model.

To this effect, I answer the following three questions regarding to TET2 in nervous system: 1) Does Tet2 loss alter $5 \mathrm{hmC}$ level in the brain? 2) Does Tet2 regulate the proliferation and differentiation of NSCs? 3) What are the downstream targets of Tet2 in the brain? First, I used Tet $2^{-/}$mouse models to examine the expression and localization of Tet2 at an embryonic stage. Because of the association between $5 \mathrm{hmC}$ and Tet2, I also measured $5 \mathrm{hmC}$ abundance in different brain tissues in the absence of Tet2. During NSC proliferation, DNA methylation can remain with relatively long-lasting effects after several rounds of cell division ${ }^{138}$. As another form of epigenetic mechanism, DNA methylation indeed plays an essential role in regulating adult neurogenesis. Previous studies on Methyl-CpG-binding domain 1 (MBD1) and methyl CpG binding protein 2 (MeCP2) indicated their binding methylated $\mathrm{CpG}$ capacity in the promoters, which subsequently suppressed gene expression. Mice with Mbd1-deficiency showed decreased neurogenesis and impaired cognition through behavior studies. The promoter of fgf 2 was hypomethylated, which led to decreased neuronal differentiation ${ }^{141}$. In another study, when Mecp2 was down-regulated, abnormal maturation and synaptogenesis of granular neurons were present. Also, MeCP2 may influence glia-specific gene expressions like 
GFAP $^{142}$. More recently, a DNA demethylation study of Tet1 showed that Tet1 is involved in neuronal active DNA demethylation and gene expression in mouse dentate gyrus ${ }^{117}$. And, although Tet2 has been shown to be involved in hematopoietic malignancies, the expression of Tet2 is relatively high in the nervous system than hematological system ${ }^{143}$.

Therefore, I used Tet $2^{-/-}$mouse model to investigate whether Tet 2 can regulate adult neurogenesis. The loss of Tet2 increased the proliferation of NSC and decreased the differentiation of NSC. Since DNA methylation is critical in postnatal neurodevelopment and seems to undergo age-dependent changes in the brain, I collected and examined the hippocampus and cerebellum of mice at postnatal day 7 (P7), 6 weeks and 1 year of age. Proliferation and differentiation of NSC/NPC and the underlying molecular mechanisms were examined to uncover the role of Tet 2 in adult neurogenesis.

\subsection{MATERIALS AND METHODS}

\subsubsection{Generation of Tet2 ${ }^{-/-}$mice and LacZ staining}

Tet2: LacZ KI mice were generated as previously described ${ }^{84}$. Briefly, the start codon ATG was replaced by LacZ: GFP: Neo cassette. After crossing with Flipase and/Cre mice, Tet2: LacZ and Tet2: GFP mouse models were obtained. The female mice were euthanized according to The Guide and as required by IACUC protocol. Embryos were collected from the uterus and extra tissues were removed in PBS. Embryos were fixed in whole mount fixative for 40min on ice and rinsed 3 times (3X) in PBS for 15min each. The fixed embryos were then stained by X-gal staining solution at $37^{\circ} \mathrm{C} \mathrm{O} / \mathrm{N}$ in the dark, then rinsed in PBS for imaging. 


\subsubsection{Adult NPCs isolation and culture}

Neural progenitor cells were isolated from 6-week-old male WT and Tet2/- mice. Briefly, the dentate gyrus (DG) was dissected-out from coronal sections. Enzymatic digestion was used to dissociate the cells. Dulbecco's Modified Eagle Medium (DEME) supplemented with $10 \%$ FBS, $2 \mathrm{mM}$ L-Glutamine and $1 \% \mathrm{P} / \mathrm{S}$ was added to each sample. The cells were filtered through $70-\mu \mathrm{m}$ cell strainer and washed with DMEM. The cells were then loaded onto 50\% Percoll for ultracentrifugation at $127 \mathrm{k}$ RPM fro $30 \mathrm{~min}$ at $20^{\circ} \mathrm{C}$. NPCs fraction was cultured in DMEM supplemented with 20ng/ml FGF2, $20 \mathrm{mg} / \mathrm{ml} \mathrm{EGF}$ in a $5 \% \mathrm{CO}_{2}$ cell culture incubator at $37^{\circ} \mathrm{C}$.

\subsubsection{Proliferation and differentiation analyses of cultured adult NPCs}

Neural progenitor cells (between passage 4 to 10) were trypsinized and placed on poly-L-laminin coated chamber slides. Each well contained about 50,000 cells and complete DMEM medium supplemented with growth factors (FGF2 and EGF). 20 hours after plating, the culture medium was supplemented with $5 \mu \mathrm{M}$ BrdU for an additional $8 \mathrm{~h}$. NPCs were fixed with $4 \%$ paraformaldehyde solution (PFA) for 30min at room temperature followed by $1 \mathrm{M}$ hydrochloric acid $(\mathrm{HCl})$ for $30 \mathrm{~min}$ at $37^{\circ} \mathrm{C}$ and then washed by borate buffer for 30min, for immunohistochemistry. For NPCs differentiation, NPCs were cultured with differentiation medium, DMEM with $5 \mu \mathrm{M}$ forskolin, $1 \mu \mathrm{M}$ retinoic acid and $0.5 \%$ FBS. The NPCs were cultured by differentiation medium for 4 days in a $5 \%$ $\mathrm{CO}_{2}$ cell incubator at $37^{\circ} \mathrm{C}$ for immunostaining later. 


\subsubsection{Real-time PCR}

Total RNA was purified from WT and Tet2 KO brain tissue using RNeasy kit (Qiagen). The RNA was reverse transcribed to cDNA. RT-qPCR was performed in $20 \mu 1$ aliquots with $10 \mu \mathrm{l}$ Fast SYBR Green Master Mix, 200nM forward and reverse primers mix and 20ng cDNA. The triplicate reactions were applied to ABI 7500 Fast Real-Time PCR System and quantified using SDS 1.4 software. The relative quantification of Tet2 mRNA was determined by threshold cycle value and normalized to the corresponding value of mouse actin.

\subsubsection{Confocal Microscopy and immunofluorescence analysis}

The protocol has been described in the previous chapter. Briefly, cells were grown in 6-well plates on coverslips. Growth medium was aspirated and cells were fixed with $4 \%$ formaldehyde in PBS for $15 \mathrm{~min}$ at room temperature. Then, the fixative was discarded and the cells were rinsed with PBS 3 times. The cells were incubated by blocking buffer for $60 \mathrm{~min}$ and then incubated with primary antibody overnight at $4^{\circ} \mathrm{C}$. The primary antibody was removed and fluorochrome-conjugated secondary antibody was added to the specimen for $1 \mathrm{~h}$ at room temperature in the dark. Coverslips were mounted by DPAI associated mount reagent and observed by fluorescence microscopy.

\subsubsection{Dot blot}

Genomic DNA was isolated from NSC harvested from WT and Tet $2^{-/-}$hippocampus and denatured by $0.2 \mathrm{~N} \mathrm{NaOH}$. Samples were dotted on nitrocellulose membrane. After cross-linking by ultraviolet, the membrane was blocked in $10 \%$ nonfat milk and $1 \%$ 
bovine serum albumin (BSA). The primary antibody anti- $5 \mathrm{hmC}$ and secondary antibody HRP-conjugated goat anti-mouse were incubated with membrane, respectively. Signals were detected by ECL detection system as described in the previous chapter.

\subsubsection{DNA plasmids and luciferase assay}

NeuroD1 and Gfap promoter regions were amplified by PCR from mouse brain cDNA. The PCR products were cloned into pGL3 and confirmed by Sanger sequencing. Human elongation factor 1a promoter region served as an internal control. $2 \times 10^{6}$ NPCs were trypsinized and mixed with plasmids, and then applied to electroporation. The cells were placed into proliferation medium and differentiation medium for $24 \mathrm{~h}$ and $48 \mathrm{~h}$, respectively. The cells were then lysated and collected for luciferase assay. About $20 \mu 1$ cell lysate was mixed with $100 \mu 1$ Luciferase assay buffer II. F-luc activity was measured by SpectraMax M2E plate reader and the mixture was stopped using Glo Buffer with substrate. After normalization with R-luc, the transfection efficiency was calculated based on a commercial manual (Promega).

\subsubsection{Statistical analysis}

To determine differences between experimental groups, I used the Student's t-test or analysis of variance (ANOVA) followed by Newman-Keuls multiple comparison tests as appropriate. P values $<0.05$ were considered significant. 


\subsection{RESUlTS AND DiscuSSION}

\subsubsection{TET2 is highly expressed in the central nervous system}

Since DNA methylation is critical for postnatal neurodevelopment in an agedependent manner, $5 \mathrm{hmC}$ may also be involved in $5 \mathrm{mC}$ dynamics during aging. To address these issue, I assessed the abundance of $5 \mathrm{hmC}$ in anterior regions of the subventricular zone (SVZa), a region of high neurogenesis, and rostral migratory stream in olfactory bulb (RMS-OB) using $5 \mathrm{hmC}$ specific antibody. This procedure allowed me to discover the most active neurogenesis regions with $5 \mathrm{hmC}$ positive cells, which also helped to define the regions to be studied in the future. Immunohistochemistry of $5 \mathrm{hmC}$ in these regions showed no significant co-localization between $5 \mathrm{hmC}$ positive cells and NeuN positive cells in SVZa (Figure 41). However, in the granule cell layer (GCL), there was a substantial overlap between $5 \mathrm{hmC}+$ and $\mathrm{NeuN}+$ cells, suggesting $5 \mathrm{hmC}$ is required for neurodevelopment. Because TET family proteins catalyze the oxidation of $5 \mathrm{mC}$ to $5 \mathrm{hmC}^{37}$, I speculated that Tets may be required for $5 \mathrm{hmC}$ dynamics during neurodevelopment. A significant decrease of Tet1 mRNA levels was seen during aging from P7 to 6 weeks old, in the cerebellum, whereas an increase in Tet2 mRNA levels occurred during aging (Figure 42). Together, the data suggest that both $5 \mathrm{hmC}$ and Tet2 are required for age-dependent neurodevelopment.

To determine genome-wide Tet2 function and $5 \mathrm{hmC}$ distribution during neurodevelopment and aging, I used a Tet2 knockout mouse model that had been previously generated in Dr. Mingjiang Xu's lab. To examine the localization of Tet2 in vivo, LacZ-GFP-Neo lines was mated with Flipase mice to acquire LacZ-GFP line. The embryos of Tet2: LacZ were collected at embryonic day 13.5 (E13.5) and stained with 
regular $\beta$-gal (Figure 43). Despite some staining variability between embryos, the LacZ expression was observed in both the cerebellum and spinal cord suggesting a potential role for Tet2 in neural cells.

To further confirm the elimination of Tet2 in Tet2 knockout mouse models, I collected the brains of Tet2: GFP. The brain tissue was disrupted and total RNA was purified from it. After reverse transcription, cDNA of Tet2: GFP was applied to RTqPCR to examine relative Tet2 expression. Five primers were designed, which aimed at exon3, 4, 6 and 11 (Figure 44). Clearly, Tet2 was completely lost at ATG region exon3 and exon4. However, there was still low abundance of the last several exons that may be due to the different splicing forms of Tet2.

Although I did not see developmental defects in Tet $2^{-/-}$mice, the role of Tet 2 in adult functioning still needs to be elucidated. Given the high abundance of $5 \mathrm{hmC}$ in mouse brain, it is reasonable to propose a regulatory function for Tet2-mediated $5 \mathrm{mC}$ oxidation in adult neurogenesis. To determine whether Tet 2 deficiency affects $5 \mathrm{hmC}$ dynamics, I compared the abundance of $5 \mathrm{hmC}$ of $\mathrm{WT}$ and $\mathrm{Tet} 2^{-/-}$mice cerebellum. At P7, $5 \mathrm{hmC}$ in $\mathrm{Tet}^{-/-}$samples decreased to half of the amount of $5 \mathrm{hmC}$ in WT samples. In adults, $5 \mathrm{hmC}$ in $\mathrm{Tet}^{-/-}$samples decreased to $3 / 4$ of the amount of $5 \mathrm{hmC}$ in WT samples (Figure 45). This suggests that Tet 2 is required for $5 \mathrm{hmC}$ dynamics in both $\mathrm{P} 7$ and adults.

\subsubsection{Hydroxylation of 5-methylcytosine affects stem cell proliferation and differentiation in dentate gyrus of the hippocampus}

To explore the function of Tet2 in adult neurogenesis, I examined the expression pattern of $5 \mathrm{hmC}$ in the dentate gyrus of adult hippocampus. I isolated adult NPC from 
dentate gyrus of WT and Tet2 $2^{-/}$mice. As shown in (Figure 46), all cultured adult NPCs showed positive Nestin and Sox, which are the markers for progenitor cells. It is feasible to use these cells for molecular and functional analyses because of their homogeneity. I then examined the proliferation of these NPCs by exposing the cells to BrdU for eight hours. It is obvious that Tet $2^{-/}$NPCs exhibited 1.5 fold BrdU incorporation compared to that in WT NPCs.

To determine the effect of Tet2 on NPC differentiation, both WT and Tet2 ${ }^{-/}$DG NPCs were exposed to differentiation medium for three days. Several independent assays were performed to investigate the phenotypes of WT and Tet $2^{-/-}$NPCs differentiation (Figure 47). I first stained the differentiated cells with $\beta$-III tubulin (Tuj1) and glial fibrillary acidic protein (GFAP) (Figure 48). Tuj1 and GFAP are specific cell markers for neurons and astroglia, respectively. In addition to WT NPCs, Tet $2^{-/}$NPCs were also able to differentiate to neurons and astrocytes. Interestingly, $\mathrm{Tet}^{-/-} \mathrm{NPCs}$ showed a $70 \%$ decrease in neuronal cell differentiation and a $50 \%$ decrease in astrocyte differentiation compared with WT NPCs. These data indicate Tet2 negatively regulate NPC proliferation but positively regulate NPC differentiation.

\subsubsection{TET2 regulates the expression of NeuroD and GFAP transcriptionally}

The downstream targets of Tet2 are still unknown. To validate the immunocytochemical results, I tested the assumption that two neural cell markers may be altered by Tet2 deletion: neurogenic differentiation 1 (NeuroD1) and GFAP. NeuroD1 is a pan-neuronal transcriptional activator, which contributes to transcriptional regulation of neurogenesis. GFAP is an astrocyte specific cell marker during development. The 
NeuroD1 and Gfap promoters were cloned upstream of luciferase reporter construct, allowing the detection of transcriptional features of these neural factors. Cells lysates were mixed with luciferase substrate and measured by luminometer. As I expected, the deletion of Tet2 suppressed the Luc activity at $48 \mathrm{~h}$ post-transfection. Little luciferase expression was shown in Tet $2^{-/-}$cell lysate. Furthermore, the relative mRNA expression of NeuroD and Gfap in Tet2 ${ }^{-/}$NSC were much lower than that in WT NSC (Figure 49). Taken together, these data suggest that Tet2 is capable of regulating NeuroD and Gfap expression through promoter suppression.

\subsection{CoNCLuSIONS}

TET family proteins have been well-studied recently, especially their enzymatic function in active DNA demethylation ${ }^{39}$. However, the physiological function of Tet2 in neural systems remains unknown. Although no significant development defects were observed in $\mathrm{Tet}^{-/-}$mice from previous reports ${ }^{84}$, my data indicates a transcriptional regulatory role for Tet 2 in adult neurogenesis.

To determine if the transcription levels of Tets change during postnatal development and aging, I measured Tet1, Tet2 and Tet3 mRNA levels at two different ages, P7 and 6 weeks of age. I observed a remarkable decrease of Tet1 mRNA and increase of Tet2 mRNA during aging, suggesting potential opposite functions of Tet1 and Tet2 during postnatal development. Indeed, I found that Tet2 was expressed in the brain and spinal cord from Tet2:LacZ mouse models. Immunostaining of $5 \mathrm{hmC}$ showed Tet2 regulates $5 \mathrm{hmC}$ abundance preferentially in SGZ rather than SVZ. Finally, I found that overall, $5 \mathrm{hmC}$ abundance was decreased in both $\mathrm{Tet}^{-/-}$proliferating cells and $\mathrm{Tet}^{-/ \text {- }}$ 
differentiating cells, suggesting that the loss of Tet2 impairs the oxidation of $5 \mathrm{mC}$ and subsequently influences NPC proliferation and differentiation. I also examined proliferation and differentiation of WT and Tet $2^{-/}$NPCs in vitro. Loss of Tet2 leads to decreased neuronal differentiation and glial differentiation. I speculated these cellular phenotypes might be induced by the alterations of neural-related transcription factors, which results from the hypermethylation in their promoter regions. Notably, I found two genes NeuroD1 and GFAP mRNAs were reduced and their promoter activities were decrease in $\mathrm{Tet}^{-/-}$cells. Therefore, it is possible that during adult neurogenesis, Tet2 regulates the gene's promoter region and catalyzes the oxidation of $5 \mathrm{mC}$, which allows the transcriptional activation of the genes and balances neuronal and glial cell numbers.

In summary, I characterized Tet2 and $5 \mathrm{hmC}$ in mouse cerebellum and hippocampus during postnatal development and aging. Tet 2 regulates $5 \mathrm{mC}$ oxidation at NeruoD1 and Gfap promoter regions during aging, pointing to a critical role for Tet2 in adult neurogenesis. My study has great potential to improve the understanding of Tet2mediated DNA demethylation in neurodevelopment and neurodegenerative disorders. 

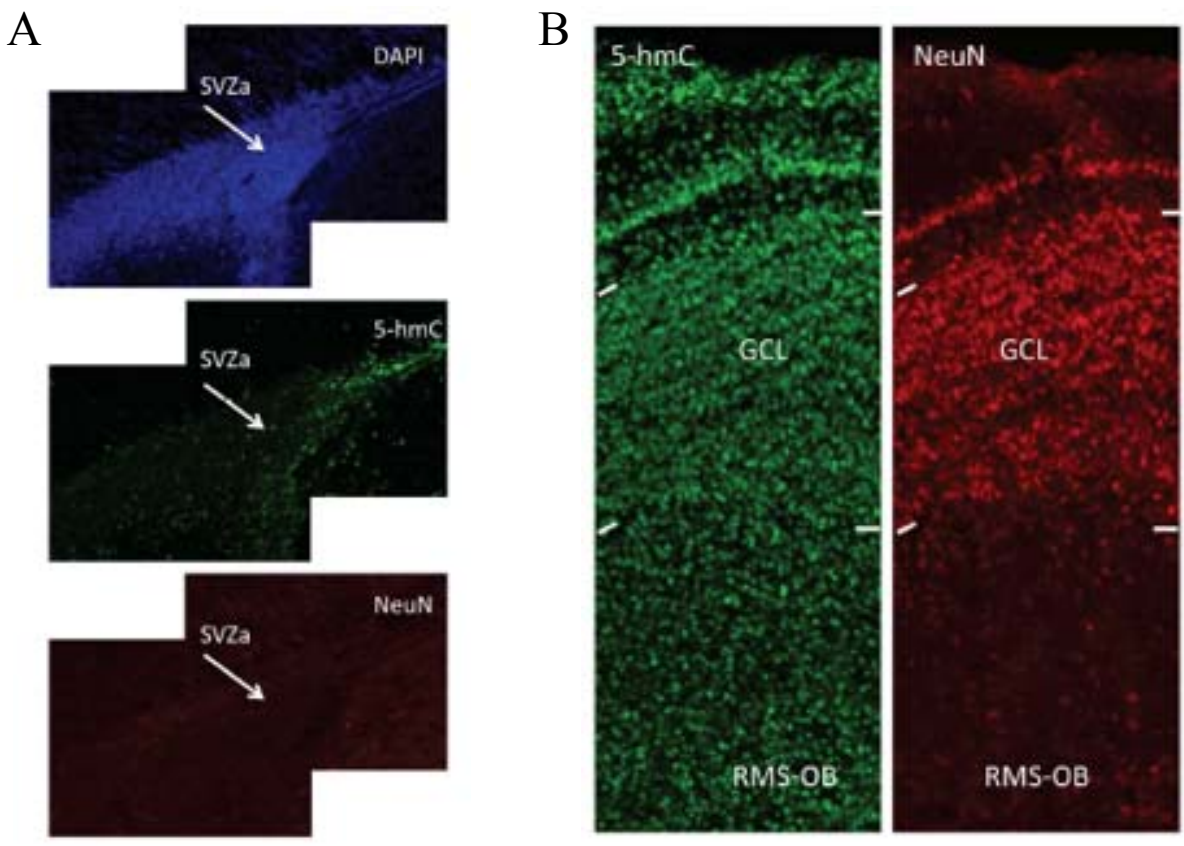

Figure 41 Immunostaining of $5 \mathrm{hmC}$ in two brain regions in mice.

(A) $5 \mathrm{hmC}$ specific immunostaining in 6-week old anterior regions of subventricular zone.

(B) $5 \mathrm{hmC}$ specific immunostaining in 6-week old olfactory bulb. 

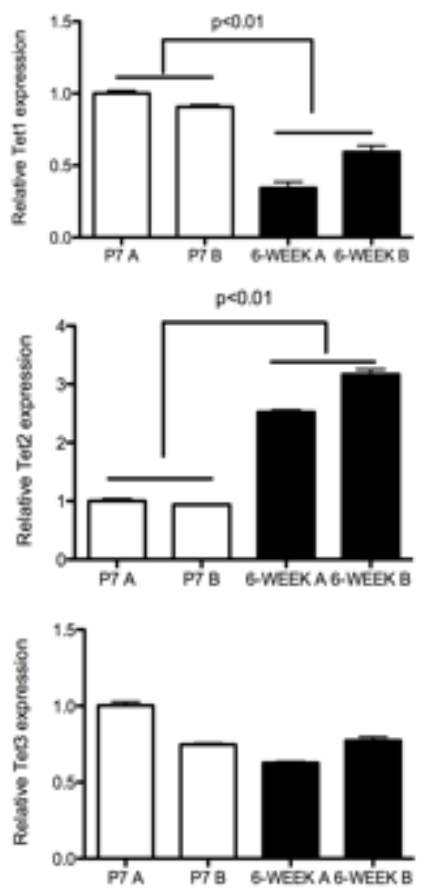

Figure 42 Tet1, Tet2 and Tet3 expression levels in P7 and 6-week old cerebellum.

Quantification of Tet1, Tet 2 and Tet 3 mRNA levels in different individuals (A\&B) $(n=3$, mean \pm SEM.; $* \mathrm{P}<0.05, * * \mathrm{P}<0.01, * * * \mathrm{P}<0.001$, ANOVA) 


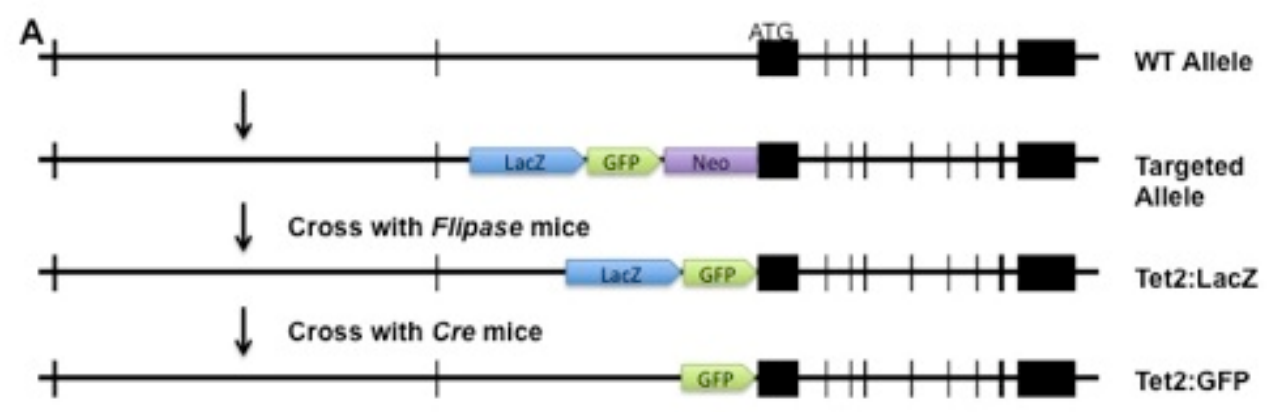

B

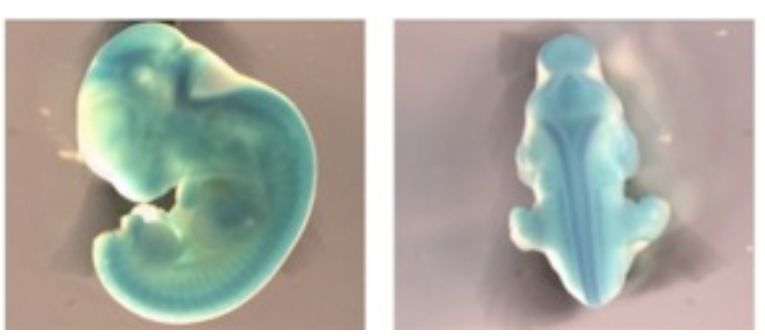

Figure 43 Tet 2 is expressed in the nervous system.

(A) Gene targeting strategy. Exons are filled boxes and LacZ-GFP-Neo cassette was introduced into Tet2 start codon region. (B) LacZ staining of Tet2:LacZ embryos showing Tet 2 expression in the brain and neural tube. 

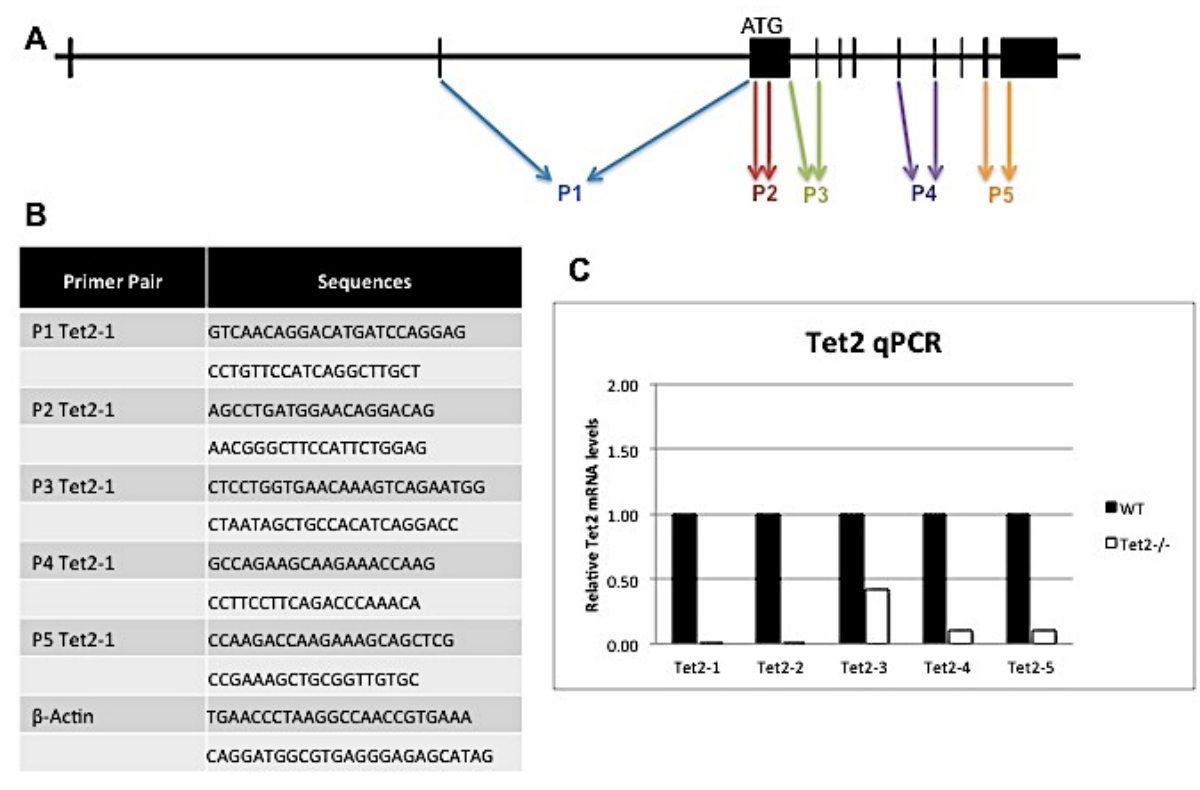

Figure 44 Detection of Tet2 in WT and Tet ${ }^{-/-}$hippocampi.

(A) Schematic of real-time PCR primers used to detect Tet2 mRNA. (B) The sequences of real-time PCR primers. (C) Real-time PCR analysis of Tet2 mRNA levels in the brain. Actin was used for sample normalization. 

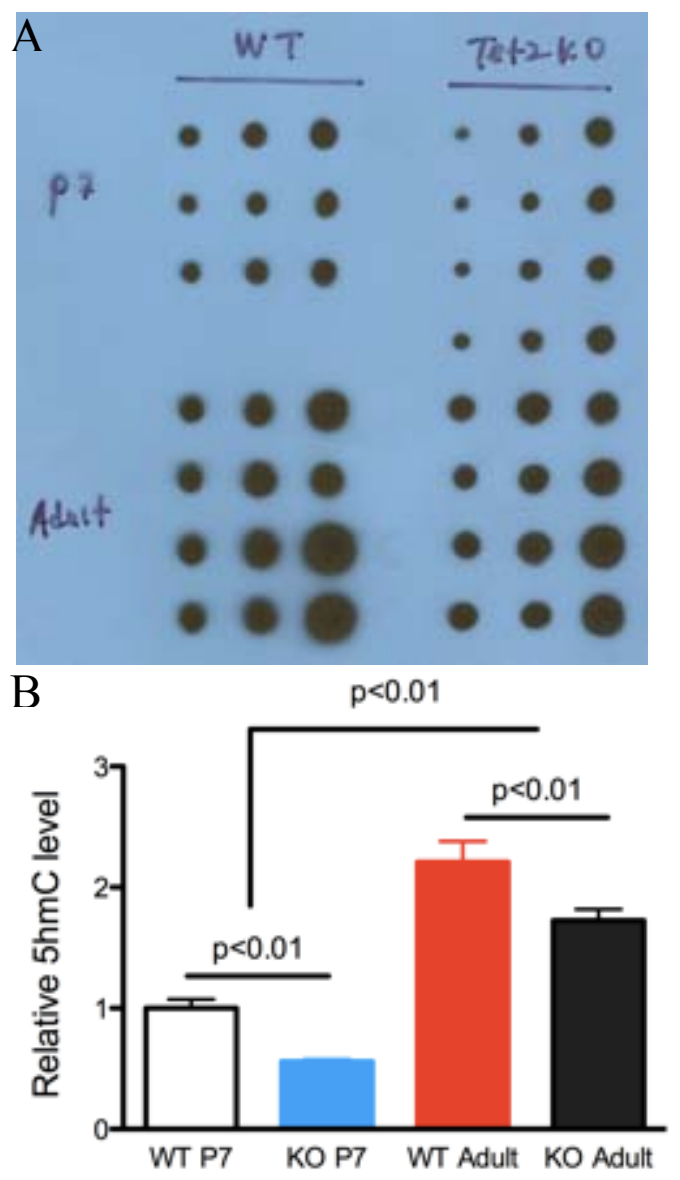

Figure 45 Quantification of $5 \mathrm{hmC}$ in $\mathrm{P7}$ and adult cerebellum.

(A) Measurement of $5 \mathrm{hmC}$ in genomic DNA from P7 and adult cerebellum by dot blot using anti-5hmC antibody. (B) $5 \mathrm{hmC}$ quantification of (A). 

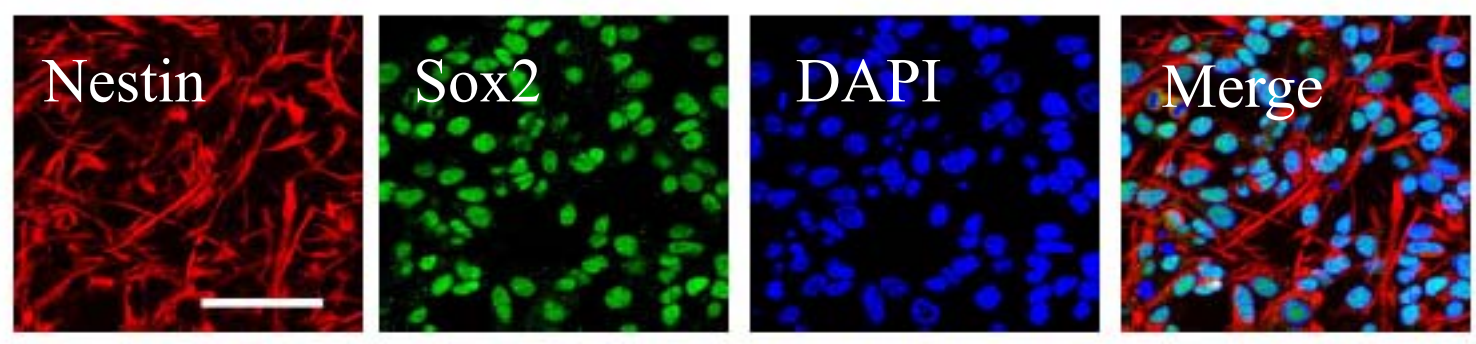

Figure 46 Cultured adult neural progenitor cells expressed representative cell markers. Nestin (cytoplasmic, red) and Sox2 (nuclear, green; DAPI in blue). 

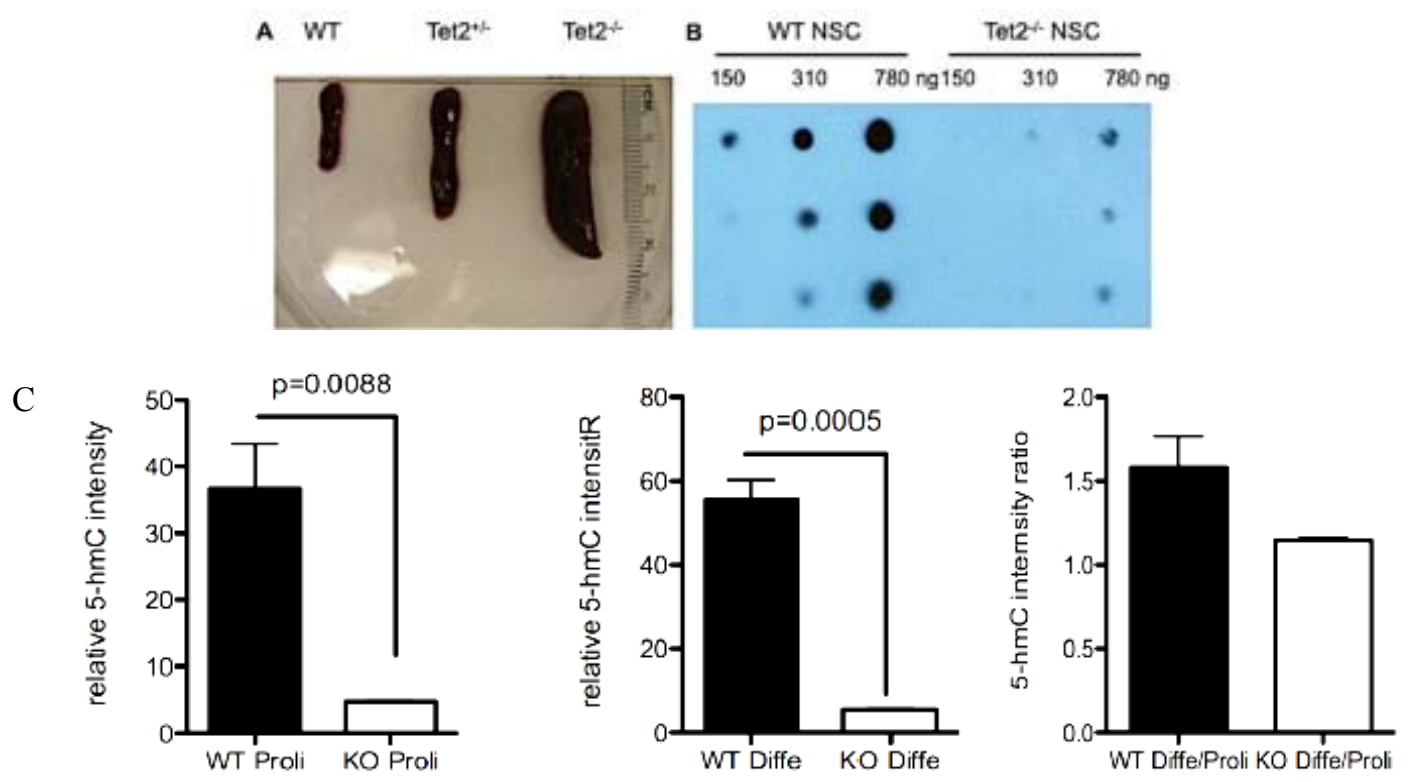

Figure 47 Quantification of $5 \mathrm{hmC}$ in proliferating and differentiating cells from WT and Tet $2^{-1-}$ adult NPCs.

(A) NPCs were harvested from WT and Tet2 ${ }^{-/}$mice with splenomegaly. (B) Detection of $5 \mathrm{hmC}$ in adult NPCs from WT and Tet ${ }^{-/ /}$mice. (C) $5 \mathrm{hmC}$ dynamic changes in proliferating cells and differentiating cells from WT and Tet $2^{-/-}$adult NPCs. 

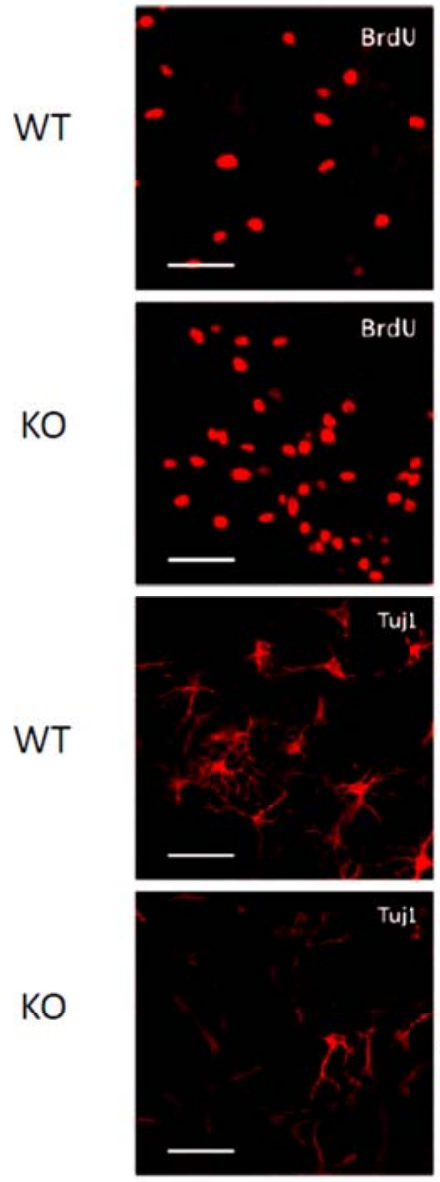
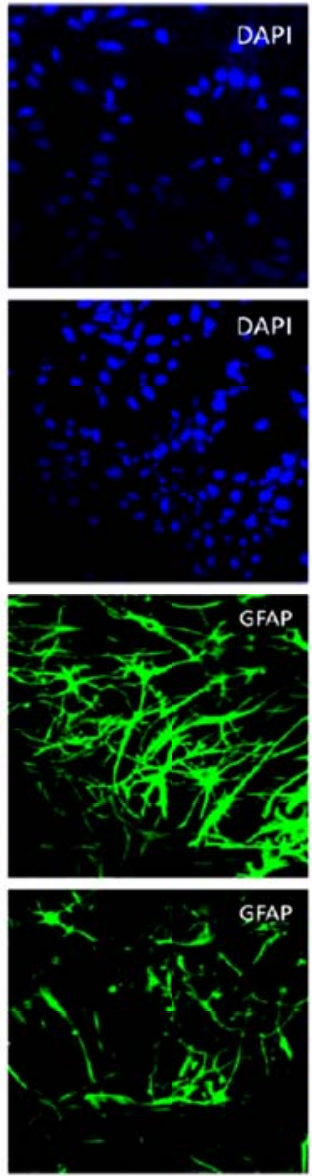
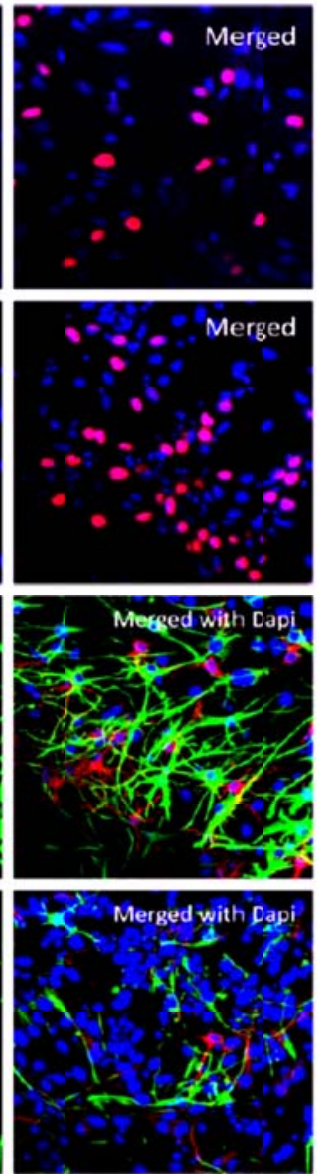
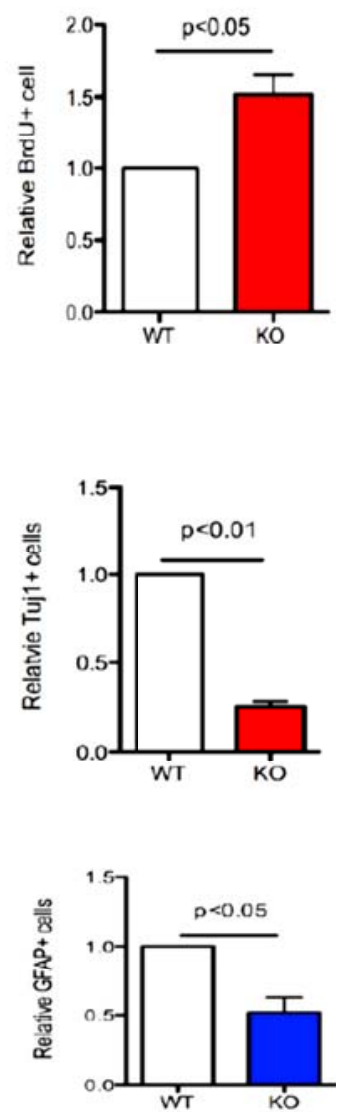

Figure 48 Loss of Tet2 leads to increased adult NPCs proliferation and decreased adult NPCs differentiation.

Immunostaining showing BrdU+ (red) cells in the NPCs. Quantitative analyses of proliferating NPCs suggest that Tet $2^{-/-}$NPCs proliferated more than WT NPCs. Adult NPCs immunostained using cell lineage markers for quantitative cell fate determination. Both WT and Tet2 ${ }^{-/}$were able to differentiate into Tuj $1+$ (red) neurons and GFAP+ (green) astrocytes. Quantitative analyses of differentiating NPCs suggest that Tet $2^{-/-}$ NPCs differentiated fewer neurons and astrocytes than WT NPCs. Data presented as mean \pm SEM; Student's t-test. 


\section{A NeuroD promoter}
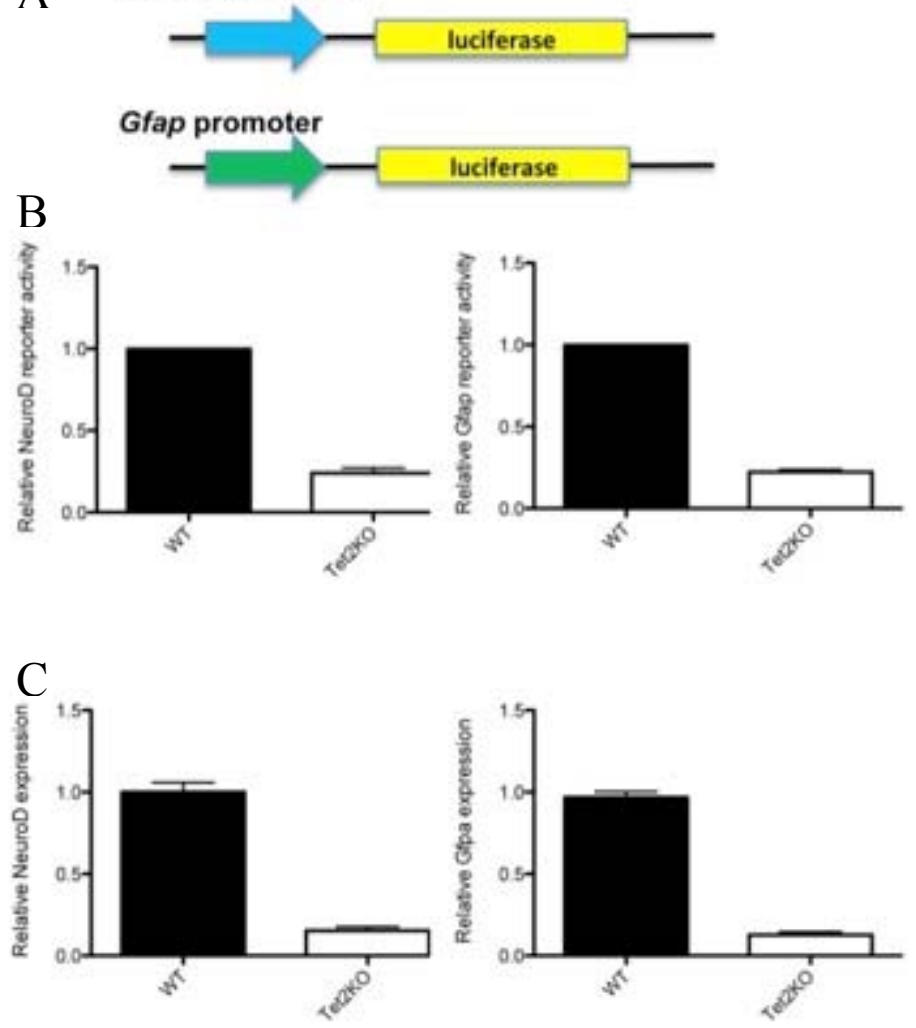

Figure 49 The NeuroD1 and Gfap promoter regions are altered by Tet2.

(A) The NeuroD1 and Gfap promoter regions were cloned into luciferase reporter constructs. (B) Luciferase reporter assay showed decreased NeuroD1 and Gfap promoter activities in Tet $2^{-/-}$differentiating NPCs. Renilla luciferase (R-Luc) plasmid served as a transfection control. Real-time PCR showed that Tet2 ${ }^{-/-}$NPCs had decreased NeuroD1 mRNA levels $(\mathrm{n}=3, \mathrm{p}<0.05)$, and decreased Gfap mRNA levels ( $\mathrm{n}$ $=3, \mathrm{p}<0.05)$ upon differentiation. The relative mRNA levels were in comparison with Gapdh mRNA. 


\section{CHAPTER}

\section{CONCLUSIONS AND FUTURE DIRECTIONS}


Studies using different Tet2 knock-out animal models revealed that Tet2 loss alters the epigenetic landscape with decreased 5hmC and global hypermethylation of the DNA, increases HSC self-renewal and myeloid progenitor expansion with skewed differentiation toward monocytic lineages, leading to the pathogenesis of myeloid malignancies $^{84}$. Identification of critical novel partners of TET2, and unveiling the functional significance of their interactions may provide valuable insights into the mechanisms that underlie critical roles of TET2 in the tumorigenesis of many cancers.

In this dissertation I investigated whether Tet2 loss leads to various types of hematological malignancies other than myeloid malignancies, and what cellular phenotypes Tet $^{-/-}$mice may have. Because clinical studies have reported the haploinsufficient role of TET2 in leukemic patients, it was important to understand if Tet2 loss in mice causes leukemic disease phenotypes as in humans. Using a two-year follow-up investigation, I found that $\mathrm{Tet}^{-/-}$mice also develop lymphoid malignancies, consistent with TET2 mutant patients with lymphoid disorders. Hence, additional genetic lesions is at least in part required for Tet2 loss induced hematological malignancies.

Depending on the methods in genome analysis, diverse $\mathrm{Tet}^{-/}$genome landscapes can be depicted via next-generation exome sequencing and aCGH. These techniques make it possible to sequence all the protein-coding genes and detect chromosome abnormalities. Therefore, it was feasible to propose understanding if Tet2 is required for maintaining genome integrity. By using exome sequencing, several "driver mutations" were identified in Tet2 loss background. Because of the biological instability of $5 \mathrm{mC}$, it is plausible to assume that these mutation sites are close to Tet2-dependent $5 \mathrm{hmC}$ sites. Indeed, significant correlations between mutation sites and Tet2-dependent $5 \mathrm{hmC}$ sites 
were found. Next, if Tet2 regulates genome integrity, relying on its enzymatic activity, mutation sites would be expected to be located only at cytosine. Then, it would be important to understand what are the TET2 protein interactors that participate in Tet2mediated DNA repair mechanism. The present finding that there is a TET2 and MSH6 interaction, strengthen the concept of mutator phenotypes in Tet $2^{-/}$mice and TET2 knockdown cell lines. With these observations, a model was proposed that explains how Tet2 can regulate genome integrity through interacting with MSH6. Chapter II determined that:

- $\sim 8 \%$ of Tet $2^{-/-}$mice develops lymphoid malignancies of both $\mathrm{T}$ - and B-cell origin, although myeloid malignancies dominates.

- Whole-exome sequencing identified recurrent mutations from $T e t 2^{-/-}$tumors of each cell origin, such as Notch1 mutations in the T-cell leukemia/lymphoma.

- Using protein purification and mass spectrometry, I found that TET2 associates with MSH6, a key protein involved in DNA-mismatch repair (MMR).

- Tet2-depleted HeLa, and NIH3T3 cells display elevated spontaneous mutation frequency, characteristic of MMR-deficient cells.

Also, I characterized Tet 2 and $5 \mathrm{hmC}$ in mouse cerebellum and hippocampus during postnatal development and aging. Tet 2 regulates $5 \mathrm{mC}$ oxidation at NeruoD1 and Gfap promoter regions during aging, pointing to a critical role for Tet2 in adult neurogenesis. My study has great potential for improving the understanding of Tet2-mediated DNA demethylation in neurodevelopment and neurodegenerative disorders. Chapter III determined that: 
- Tet2 is highly expressed in adult brain compared to postnatal P7 brain.

- Loss of Tet2 leads to increased adult NPCs proliferation and decreased adult NPCs differentiation.

- Tet2 regulates adult brain neurogenesis through $5 \mathrm{mC}$ oxidation of NeuroD1 and Gfap promoter regions.

Together, the observations presented here reveal that Tet2 is involved in different regulatory mechanisms in different systems. In the hematological system, Tet2 serves as a tumor suppressor gene to protect the genome from being mutated and is also dependent on the interaction with MSH6 during DNA damage repair. In the nervous system, it is also clear that Tet 2 regulates $5 \mathrm{hmC}$ dynamics at its specific downstream loci, and subsequently has an effect on adult neurogenesis. A better understanding of Tet2 regulatory network including TET2-binding protein complex and Tet2-binding DNA sequences may prove to be essential for pharmaceutical research, with the goal, to address Tet2-related diseases.

Future research on Tet2 in the hematological system will be focused on several important aims: 1) providing a detailed characterization of hematological malignancies of Tet $2^{-/-}$mice; 2) determining when mutations occur during cell differentiation; 3) mapping the minimum binding regions between TET2 and MSH6; 4) crossing Tet2 ${ }^{-/-}$and Msh6 $6^{-{ }_{-}}$ mice to elucidate the relationship between TET2 and MSH6. Additional questions to be addressed include whether the association between TET2 and MSH6 is disrupted in Tet2deficient mice; and if genomic instability is a "driver" or a "consequence" of malignant transformation. The latter could be clarified by exome sequencing of premalignant WT, $\mathrm{Tet}^{+/-}$and $\mathrm{Tet} 2^{-/}$hematopoietic stem/progenitor cells. 
For understanding the role of Tet2 in neurogenesis, it makes sense to evaluate Tet2 in the context of spatial learning and memory based on the present findings of impaired neurogenesis in Tet2 mutants, which may greatly influence learning and memory. I can also investigate the epigenetic changes $(5 \mathrm{mC}$ and $5 \mathrm{hmC})$ of Tet2 downstream target genes and examine their transcriptional regulation and involvement in neurogenesis. The definitive role of Tet2 loss-induced adult-neurogenesis-defects should be investigated using Tet2 conditional knockout mice in which tissue/cell-specific elimination would help to better understand the biological functions of Tet2 in the nervous system. 


\section{REFERENCES:}

1 WADDINGTON, C. H. AN INTRODUCTION TO MODERN GENETICS. (G. ALLEN \& UNWIN LTD., 1939).

2 CEDAR, H. \& BERGMAN, Y. EPIGENETICS OF HAEMATOPOIETIC CELL DEVELOPMENT. NATURE REVIEWS. IMMUNOLOGY 11, 478-488, DOI:10.1038/NRI2991 (2011).

3 BRANCO, M. R., FICZ, G. \& REIK, W. UNCOVERING THE ROLE OF 5HYDROXYMETHYLCYTOSINE IN THE EPIGENOME. NATURE REVIEWS. GENETICS 13, 7-13, DOI:10.1038/NRG3080 (2012).

4 ISSA, J. P. THE MYELODYSPLASTIC SYNDROME AS A PROTOTYPICAL EPIGENETIC DISEASE. BLOOD 121, 3811-3817, DOI:10.1182/BLOOD-201302-451757 (2013).

5 BIRD, A. DNA METHYLATION PATTERNS AND EPIGENETIC MEMORY. GENES \& DEVELOPMENT 16, 6-21, DOI:10.1101/GAD.947102 (2002).

6 JENUWEIN, T. \& ALLIS, C. D. TRANSLATING THE HISTONE CODE. SCIENCE 293, 1074-1080, DOI:10.1126/SCIENCE.1063127 (2001).

7 GARDNER, K. E., ALLIS, C. D. \& STRAHL, B. D. OPERATING ON CHROMATIN, A COLORFUL LANGUAGE WHERE CONTEXT MATTERS. JOURNAL OF MOLECULAR BIOLOGY 409, 36-46, DOI:10.1016/J.JMB.2011.01.040 (2011).

8 AMIEL, J., DE PONTUAL, L. \& HENRION-CAUDE, A. MIRNA, DEVELOPMENT AND DISEASE. ADVANCES IN GENETICS 80, 1-36, DOI:10.1016/B978-0-12-404742-6.00001-6 (2012).

9 SONG, J., RECHKOBLIT, O., BESTOR, T. H. \& PATEL, D. J. STRUCTURE OF DNMT1-DNA COMPLEX REVEALS A ROLE FOR AUTOINHIBITION IN MAINTENANCE DNA METHYLATION. SCIENCE 331, 1036-1040, DOI:10.1126/SCIENCE.1195380 (2011). 
10 SUBRAMANIAM, D., THOMBRE, R., DHAR, A. \& ANANT, S. DNA METHYLTRANSFERASES: A NOVEL TARGET FOR PREVENTION AND THERAPY. FRONTIERS IN ONCOLOGY 4, 80, DOI:10.3389/FONC.2014.00080 (2014).

11 OOI, S. K., O'DONNELL, A. H. \& BESTOR, T. H. MAMMALIAN CYTOSINE METHYLATION AT A GLANCE. JOURNAL OF CELL SCIENCE 122, 27872791, DOI:10.1242/JCS.015123 (2009).

12 OKANO, M., BELL, D. W., HABER, D. A. \& LI, E. DNA METHYLTRANSFERASES DNMT3A AND DNMT3B ARE ESSENTIAL FOR DE NOVO METHYLATION AND MAMMALIAN DEVELOPMENT. CELL 99, 247-257 (1999).

13 GOLL, M. G. \& BESTOR, T. H. EUKARYOTIC CYTOSINE METHYLTRANSFERASES. ANNUAL REVIEW OF BIOCHEMISTRY 74, 481514, DOI:10.1146/ANNUREV.BIOCHEM.74.010904.153721 (2005).

14 ZILLER, M. J. ET AL. CHARTING A DYNAMIC DNA METHYLATION LANDSCAPE OF THE HUMAN GENOME. NATURE 500, 477-481, DOI:10.1038/NATURE12433 (2013).

15 ROLLINS, R. A. ET AL. LARGE-SCALE STRUCTURE OF GENOMIC METHYLATION PATTERNS. GENOME RESEARCH 16, 157-163, DOI:10.1101/GR.4362006 (2006).

16 JEONG, M. \& GOODELL, M. A. NEW ANSWERS TO OLD QUESTIONS FROM GENOME-WIDE MAPS OF DNA METHYLATION IN HEMATOPOIETIC CELLS. EXPERIMENTAL HEMATOLOGY 42, 609-617, DOI:10.1016/J.EXPHEM.2014.04.008 (2014).

17 DEATON, A. M. \& BIRD, A. CPG ISLANDS AND THE REGULATION OF TRANSCRIPTION. GENES \& DEVELOPMENT 25, 1010-1022, DOI:10.1101/GAD.2037511 (2011).

18 KELLY, T. K. ET AL. H2A.Z MAINTENANCE DURING MITOSIS REVEALS NUCLEOSOME SHIFTING ON MITOTICALLY SILENCED GENES. MOLECULAR CELL 39, 901-911, DOI:10.1016/J.MOLCEL.2010.08.026 (2010). 
19 JONES, P. A. FUNCTIONS OF DNA METHYLATION: ISLANDS, START SITES, GENE BODIES AND BEYOND. NATURE REVIEWS. GENETICS 13, 484-492, DOI:10.1038/NRG3230 (2012).

20 DOI, A. ET AL. DIFFERENTIAL METHYLATION OF TISSUE- AND CANCER-SPECIFIC CPG ISLAND SHORES DISTINGUISHES HUMAN INDUCED PLURIPOTENT STEM CELLS, EMBRYONIC STEM CELLS AND FIBROBLASTS. NATURE GENETICS 41, 1350-1353, DOI:10.1038/NG.471 (2009).

21 JI, H. ET AL. COMPREHENSIVE METHYLOME MAP OF LINEAGE COMMITMENT FROM HAEMATOPOIETIC PROGENITORS. NATURE 467, 338-342, DOI:10.1038/NATURE09367 (2010).

22 HODGES, E. ET AL. DIRECTIONAL DNA METHYLATION CHANGES AND COMPLEX INTERMEDIATE STATES ACCOMPANY LINEAGE SPECIFICITY IN THE ADULT HEMATOPOIETIC COMPARTMENT. MOLECULAR CELL 44, 17-28, DOI:10.1016/J.MOLCEL.2011.08.026 (2011).

23 BOCK, C. ET AL. DNA METHYLATION DYNAMICS DURING IN VIVO DIFFERENTIATION OF BLOOD AND SKIN STEM CELLS. MOLECULAR CELL 47, 633-647, DOI:10.1016/J.MOLCEL.2012.06.019 (2012).

24 LISTER, R. ET AL. HUMAN DNA METHYLOMES AT BASE RESOLUTION SHOW WIDESPREAD EPIGENOMIC DIFFERENCES. NATURE 462, 315-322, DOI:10.1038/NATURE08514 (2009).

25 COOLEN, M. W. ET AL. CONSOLIDATION OF THE CANCER GENOME INTO DOMAINS OF REPRESSIVE CHROMATIN BY LONG-RANGE EPIGENETIC SILENCING (LRES) REDUCES TRANSCRIPTIONAL PLASTICITY. NATURE CELL BIOLOGY 12, 235-246, DOI:10.1038/NCB2023 (2010).

26 HANSEN, K. D. ET AL. INCREASED METHYLATION VARIATION IN EPIGENETIC DOMAINS ACROSS CANCER TYPES. NATURE GENETICS 43, 768-775, DOI:10.1038/NG.865 (2011). 
27 JEONG, M. ET AL. LARGE CONSERVED DOMAINS OF LOW DNA METHYLATION MAINTAINED BY DNMT3A. NATURE GENETICS 46, 1723, DOI:10.1038/NG.2836 (2014).

28 XIE, W. ET AL. EPIGENOMIC ANALYSIS OF MULTILINEAGE DIFFERENTIATION OF HUMAN EMBRYONIC STEM CELLS. CELL 153, 1134-1148, DOI:10.1016/J.CELL.2013.04.022 (2013).

29 HELLMAN, A. \& CHESS, A. GENE BODY-SPECIFIC METHYLATION ON THE ACTIVE X CHROMOSOME. SCIENCE 315, 1141-1143, DOI:10.1126/SCIENCE.1136352 (2007).

30 SHUKLA, S. ET AL. CTCF-PROMOTED RNA POLYMERASE II PAUSING LINKS DNA METHYLATION TO SPLICING. NATURE 479, 74-79, DOI:10.1038/NATURE10442 (2011).

31 MAUNAKEA, A. K. ET AL. CONSERVED ROLE OF INTRAGENIC DNA METHYLATION IN REGULATING ALTERNATIVE PROMOTERS. NATURE 466, 253-257, DOI:10.1038/NATURE09165 (2010).

32 MAUNAKEA, A. K., CHEPELEV, I., CUI, K. \& ZHAO, K. INTRAGENIC DNA METHYLATION MODULATES ALTERNATIVE SPLICING BY RECRUITING MECP2 TO PROMOTE EXON RECOGNITION. CELL RESEARCH 23, 1256-1269, DOI:10.1038/CR.2013.110 (2013).

33 ANASTASIADOU, C., MALOUSI, A., MAGLAVERAS, N. \& KOUIDOU, S. HUMAN EPIGENOME DATA REVEAL INCREASED CPG METHYLATION IN ALTERNATIVELY SPLICED SITES AND PUTATIVE EXONIC SPLICING ENHANCERS. DNA AND CELL BIOLOGY 30, 267-275, DOI:10.1089/DNA.2010.1094 (2011).

34 MOAREFI, A. H. \& CHEDIN, F. ICF SYNDROME MUTATIONS CAUSE A BROAD SPECTRUM OF BIOCHEMICAL DEFECTS IN DNMT3BMEDIATED DE NOVO DNA METHYLATION. JOURNAL OF MOLECULAR BIOLOGY 409, 758-772, DOI:10.1016/J.JMB.2011.04.050 (2011). 
HEYN, H. ET AL. WHOLE-GENOME BISULFITE DNA SEQUENCING OF A DNMT3B MUTANT PATIENT. EPIGENETICS : OFFICIAL JOURNAL OF THE DNA METHYLATION SOCIETY 7, 542-550, DOI:10.4161/EPI.20523 (2012).

36 RAVAL, A. ET AL. REDUCED RRNA EXPRESSION AND INCREASED RDNA PROMOTER METHYLATION IN CD34+ CELLS OF PATIENTS WITH MYELODYSPLASTIC SYNDROMES. BLOOD 120, 4812-4818, DOI:10.1182/BLOOD-2012-04-423111 (2012).

37 TAHILIANI, M. ET AL. CONVERSION OF 5-METHYLCYTOSINE TO 5HYDROXYMETHYLCYTOSINE IN MAMMALIAN DNA BY MLL PARTNER TET1. SCIENCE 324, 930-935, DOI:10.1126/SCIENCE.1170116 (2009).

38 KRIAUCIONIS, S. \& HEINTZ, N. THE NUCLEAR DNA BASE 5HYDROXYMETHYLCYTOSINE IS PRESENT IN PURKINJE NEURONS AND THE BRAIN. SCIENCE 324, 929-930, DOI:10.1126/SCIENCE.1169786 (2009).

39 HE, Y. F. ET AL. TET-MEDIATED FORMATION OF 5CARBOXYLCYTOSINE AND ITS EXCISION BY TDG IN MAMMALIAN DNA. SCIENCE 333, 1303-1307, DOI:10.1126/SCIENCE.1210944 (2011).

40 WU, S. C. \& ZHANG, Y. ACTIVE DNA DEMETHYLATION: MANY ROADS LEAD TO ROME. NAT REV MOL CELL BIOL 11, 607-620, DOI:10.1038/NRM2950 (2010).

41 ZHU, J. K. ACTIVE DNA DEMETHYLATION MEDIATED BY DNA GLYCOSYLASES. ANNU REV GENET 43, 143-166, DOI:10.1146/ANNUREVGENET-102108-134205 (2009).

42 FENG, S., JACOBSEN, S. E. \& REIK, W. EPIGENETIC REPROGRAMMING IN PLANT AND ANIMAL DEVELOPMENT. SCIENCE 330, 622-627, DOI:10.1126/SCIENCE.1190614 (2010). 
43 GUO, J. U., SU, Y., ZHONG, C., MING, G. L. \& SONG, H. EMERGING ROLES OF TET PROTEINS AND 5-HYDROXYMETHYLCYTOSINES IN ACTIVE DNA DEMETHYLATION AND BEYOND. CELL CYCLE 10, 26622668 (2011).

44 BHATTACHARYA, S. K., RAMCHANDANI, S., CERVONI, N. \& SZYF, M. A MAMMALIAN PROTEIN WITH SPECIFIC DEMETHYLASE ACTIVITY FOR MCPG DNA. NATURE 397, 579-583, DOI:10.1038/17533 (1999).

45 HARDELAND, U., BENTELE, M., JIRICNY, J. \& SCHAR, P. THE VERSATILE THYMINE DNA-GLYCOSYLASE: A COMPARATIVE CHARACTERIZATION OF THE HUMAN, DROSOPHILA AND FISSION YEAST ORTHOLOGS. NUCLEIC ACIDS RES 31, 2261-2271 (2003).

46 RAI, K. ET AL. DNA DEMETHYLATION IN ZEBRAFISH INVOLVES THE COUPLING OF A DEAMINASE, A GLYCOSYLASE, AND GADD45. CELL 135, 1201-1212, DOI:10.1016/J.CELL.2008.11.042 (2008).

47 POPP, C. ET AL. GENOME-WIDE ERASURE OF DNA METHYLATION IN MOUSE PRIMORDIAL GERM CELLS IS AFFECTED BY AID DEFICIENCY. NATURE 463, 1101-1105, DOI:10.1038/NATURE08829 (2010).

HAJKOVA, P. ET AL. GENOME-WIDE REPROGRAMMING IN THE MOUSE GERM LINE ENTAILS THE BASE EXCISION REPAIR PATHWAY. SCIENCE 329, 78-82, DOI:10.1126/SCIENCE.1187945 (2010).

PENN, N. W., SUWALSKI, R., O'RILEY, C., BOJANOWSKI, K. \& YURA, R. THE PRESENCE OF 5-HYDROXYMETHYLCYTOSINE IN ANIMAL DEOXYRIBONUCLEIC ACID. BIOCHEM J 126, 781-790 (1972).

ITO, S. ET AL. ROLE OF TET PROTEINS IN 5MC TO 5HMC CONVERSION, ES-CELL SELF-RENEWAL AND INNER CELL MASS SPECIFICATION. NATURE 466, 1129-1133, DOI:10.1038/NATURE09303 (2010).

51 KOH, K. P. ET AL. TET1 AND TET2 REGULATE 5HYDROXYMETHYLCYTOSINE PRODUCTION AND CELL LINEAGE SPECIFICATION IN MOUSE EMBRYONIC STEM CELLS. CELL STEM CELL 8, 200-213, DOI:10.1016/J.STEM.2011.01.008 (2011). 
YU, M. ET AL. BASE-RESOLUTION ANALYSIS OF 5HYDROXYMETHYLCYTOSINE IN THE MAMMALIAN GENOME. CELL 149, 1368-1380, DOI:10.1016/J.CELL.2012.04.027 (2012).

YU, M. ET AL. TET-ASSISTED BISULFITE SEQUENCING OF 5HYDROXYMETHYLCYTOSINE. NATURE PROTOCOLS 7, 2159-2170, DOI:10.1038/NPROT.2012.137 (2012).

54 TAN, L. ET AL. GENOME-WIDE COMPARISON OF DNA HYDROXYMETHYLATION IN MOUSE EMBRYONIC STEM CELLS AND NEURAL PROGENITOR CELLS BY A NEW COMPARATIVE HMEDIP-SEQ METHOD. NUCLEIC ACIDS RESEARCH 41, E84, DOI:10.1093/NAR/GKT091 (2013).

55 HUANG, Y., PASTOR, W. A., ZEPEDA-MARTINEZ, J. A. \& RAO, A. THE ANTI-CMS TECHNIQUE FOR GENOME-WIDE MAPPING OF 5HYDROXYMETHYLCYTOSINE. NATURE PROTOCOLS 7, 1897-1908, DOI:10.1038/NPROT.2012.103 (2012).

BOOTH, M. J. ET AL. QUANTITATIVE SEQUENCING OF 5METHYLCYTOSINE AND 5-HYDROXYMETHYLCYTOSINE AT SINGLEBASE RESOLUTION. SCIENCE 336, 934-937, DOI:10.1126/SCIENCE.1220671 (2012).

57 GLOBISCH, D. ET AL. TISSUE DISTRIBUTION OF 5HYDROXYMETHYLCYTOSINE AND SEARCH FOR ACTIVE DEMETHYLATION INTERMEDIATES. PLOS ONE 5, E15367, DOI:10.1371/JOURNAL.PONE.0015367 (2010).

58 PASTOR, W. A. ET AL. GENOME-WIDE MAPPING OF 5HYDROXYMETHYLCYTOSINE IN EMBRYONIC STEM CELLS. NATURE 473, 394-397, DOI:10.1038/NATURE10102 (2011).

59 WU, H. ET AL. DUAL FUNCTIONS OF TET1 IN TRANSCRIPTIONAL REGULATION IN MOUSE EMBRYONIC STEM CELLS. NATURE 473, 389393, DOI:10.1038/NATURE09934 (2011). 
60 FICZ, G. ET AL. DYNAMIC REGULATION OF 5HYDROXYMETHYLCYTOSINE IN MOUSE ES CELLS AND DURING DIFFERENTIATION. NATURE 473, 398-402, DOI:10.1038/NATURE10008 (2011).

61 SONG, C. X. ET AL. SELECTIVE CHEMICAL LABELING REVEALS THE GENOME-WIDE DISTRIBUTION OF 5-HYDROXYMETHYLCYTOSINE. NATURE BIOTECHNOLOGY 29, 68-72, DOI:10.1038/NBT.1732 (2011).

62 SZULWACH, K. E. ET AL. INTEGRATING 5HYDROXYMETHYLCYTOSINE INTO THE EPIGENOMIC LANDSCAPE OF HUMAN EMBRYONIC STEM CELLS. PLOS GENETICS 7, E1002154, DOI:10.1371/JOURNAL.PGEN.1002154 (2011).

63 SHEARSTONE, J. R. ET AL. GLOBAL DNA DEMETHYLATION DURING MOUSE ERYTHROPOIESIS IN VIVO. SCIENCE 334, 799-802, DOI:10.1126/SCIENCE.1207306 (2011).

64 MADZO, J. ET AL. HYDROXYMETHYLATION AT GENE REGULATORY REGIONS DIRECTS STEM/EARLY PROGENITOR CELL COMMITMENT DURING ERYTHROPOIESIS. CELL REPORTS 6, 231-244, DOI:10.1016/J.CELREP.2013.11.044 (2014).

65 ITO, S. ET AL. TET PROTEINS CAN CONVERT 5-METHYLCYTOSINE TO 5-FORMYLCYTOSINE AND 5-CARBOXYLCYTOSINE. SCIENCE 333, 1300-1303, DOI:10.1126/SCIENCE.1210597 (2011).

66 IYER, L. M., ANANTHARAMAN, V., WOLF, M. Y. \& ARAVIND, L. COMPARATIVE GENOMICS OF TRANSCRIPTION FACTORS AND CHROMATIN PROTEINS IN PARASITIC PROTISTS AND OTHER EUKARYOTES. INTERNATIONAL JOURNAL FOR PARASITOLOGY 38, 1-31, DOI:10.1016/J.IJPARA.2007.07.018 (2008).

67 YU, Z. ET AL. THE PROTEIN THAT BINDS TO DNA BASE J IN TRYPANOSOMATIDS HAS FEATURES OF A THYMIDINE HYDROXYLASE. NUCLEIC ACIDS RESEARCH 35, 2107-2115, DOI:10.1093/NAR/GKM049 (2007). 
GOMMERS-AMPT, J. H. ET AL. BETA-D-GLUCOSYLHYDROXYMETHYLURACIL: A NOVEL MODIFIED BASE PRESENT IN THE DNA OF THE PARASITIC PROTOZOAN T. BRUCEI. CELL 75, 11291136 (1993). POSSIBLE FUNCTIONS. ANNUAL REVIEW OF MICROBIOLOGY 62, 235-251, DOI:10.1146/ANNUREV.MICRO.62.081307.162750 (2008).

70 IYER, L. M., TAHILIANI, M., RAO, A. \& ARAVIND, L. PREDICTION OF NOVEL FAMILIES OF ENZYMES INVOLVED IN OXIDATIVE AND OTHER COMPLEX MODIFICATIONS OF BASES IN NUCLEIC ACIDS. CELL CYCLE 8, 1698-1710 (2009).

71 PASTOR, W. A., ARAVIND, L. \& RAO, A. TETONIC SHIFT: BIOLOGICAL ROLES OF TET PROTEINS IN DNA DEMETHYLATION AND TRANSCRIPTION. NATURE REVIEWS. MOLECULAR CELL BIOLOGY 14, 341-356, DOI:10.1038/NRM3589 (2013).

72 KO, M. ET AL. MODULATION OF TET2 EXPRESSION AND 5METHYLCYTOSINE OXIDATION BY THE CXXC DOMAIN PROTEIN IDAX. NATURE 497, 122-126, DOI:10.1038/NATURE12052 (2013).

73 XU, Y. ET AL. GENOME-WIDE REGULATION OF 5HMC, 5MC, AND GENE EXPRESSION BY TET1 HYDROXYLASE IN MOUSE EMBRYONIC STEM CELLS. MOLECULAR CELL 42, 451-464, DOI:10.1016/J.MOLCEL.2011.04.005 (2011).

74 XU, Y. ET AL. TET3 CXXC DOMAIN AND DIOXYGENASE ACTIVITY COOPERATIVELY REGULATE KEY GENES FOR XENOPUS EYE AND NEURAL DEVELOPMENT. CELL 151, 1200-1213, DOI:10.1016/J.CELL.2012.11.014 (2012).

75 LOENARZ, C. \& SCHOFIELD, C. J. PHYSIOLOGICAL AND BIOCHEMICAL ASPECTS OF HYDROXYLATIONS AND DEMETHYLATIONS CATALYZED BY HUMAN 2-OXOGLUTARATE OXYGENASES. TRENDS IN BIOCHEMICAL SCIENCES 36, 7-18, DOI:10.1016/J.TIBS.2010.07.002 (2011). 
HU, L. ET AL. CRYSTAL STRUCTURE OF TET2-DNA COMPLEX: INSIGHT INTO TET-MEDIATED 5MC OXIDATION. CELL 155, 1545-1555, DOI:10.1016/J.CELL.2013.11.020 (2013).

77 TROWBRIDGE, J. J., SNOW, J. W., KIM, J. \& ORKIN, S. H. DNA METHYLTRANSFERASE 1 IS ESSENTIAL FOR AND UNIQUELY REGULATES HEMATOPOIETIC STEM AND PROGENITOR CELLS. CELL STEM CELL 5, 442-449, DOI:10.1016/J.STEM.2009.08.016 (2009).

78 BROSKE, A. M. ET AL. DNA METHYLATION PROTECTS HEMATOPOIETIC STEM CELL MULTIPOTENCY FROM MYELOERYTHROID RESTRICTION. NATURE GENETICS 41, 1207-1215, DOI:10.1038/NG.463 (2009).

79 TADOKORO, Y., EMA, H., OKANO, M., LI, E. \& NAKAUCHI, H. DE NOVO DNA METHYLTRANSFERASE IS ESSENTIAL FOR SELF-RENEWAL, BUT NOT FOR DIFFERENTIATION, IN HEMATOPOIETIC STEM CELLS. THE JOURNAL OF EXPERIMENTAL MEDICINE 204, 715-722, DOI:10.1084/JEM.20060750 (2007).

CHALLEN, G. A. ET AL. DNMT3A IS ESSENTIAL FOR HEMATOPOIETIC STEM CELL DIFFERENTIATION. NATURE GENETICS 44, 23-31, DOI:10.1038/NG.1009 (2012).

81 YAN, X. J. ET AL. EXOME SEQUENCING IDENTIFIES SOMATIC MUTATIONS OF DNA METHYLTRANSFERASE GENE DNMT3A IN ACUTE MONOCYTIC LEUKEMIA. NATURE GENETICS 43, 309-315, DOI:10.1038/NG.788 (2011).

ABDEL-WAHAB, O. ET AL. GENETIC CHARACTERIZATION OF TET1, TET2, AND TET3 ALTERATIONS IN MYELOID MALIGNANCIES. BLOOD 114, 144-147, DOI:10.1182/BLOOD-2009-03-210039 (2009).

83 WEISSMANN, S. ET AL. LANDSCAPE OF TET2 MUTATIONS IN ACUTE MYELOID LEUKEMIA. LEUKEMIA 26, 934-942, DOI:10.1038/LEU.2011.326 (2012). 
LI, Z. ET AL. DELETION OF TET2 IN MICE LEADS TO DYSREGULATED HEMATOPOIETIC STEM CELLS AND SUBSEQUENT DEVELOPMENT OF MYELOID MALIGNANCIES. BLOOD 118, 4509-4518, DOI:10.1182/BLOOD2010-12-325241 (2011).

KO, M. ET AL. TEN-ELEVEN-TRANSLOCATION 2 (TET2) NEGATIVELY REGULATES HOMEOSTASIS AND DIFFERENTIATION OF HEMATOPOIETIC STEM CELLS IN MICE. PROCEEDINGS OF THE NATIONAL ACADEMY OF SCIENCES OF THE UNITED STATES OF AMERICA 108, 14566-14571, DOI:10.1073/PNAS.1112317108 (2011).

QUIVORON, C. ET AL. TET2 INACTIVATION RESULTS IN PLEIOTROPIC HEMATOPOIETIC ABNORMALITIES IN MOUSE AND IS A RECURRENT EVENT DURING HUMAN LYMPHOMAGENESIS. CANCER CELL 20, 25-38, DOI:10.1016/J.CCR.2011.06.003 (2011).

87 MORAN-CRUSIO, K. ET AL. TET2 LOSS LEADS TO INCREASED HEMATOPOIETIC STEM CELL SELF-RENEWAL AND MYELOID TRANSFORMATION. CANCER CELL 20, 11-24, DOI:10.1016/J.CCR.2011.06.001 (2011).

TEFFERI, A. ET AL. DETECTION OF MUTANT TET2 IN MYELOID MALIGNANCIES OTHER THAN MYELOPROLIFERATIVE NEOPLASMS: CMML, MDS, MDS/MPN AND AML. LEUKEMIA 23, 1343-1345, DOI:10.1038/LEU.2009.59 (2009).

ITZYKSON, R. ET AL. PROGNOSTIC SCORE INCLUDING GENE MUTATIONS IN CHRONIC MYELOMONOCYTIC LEUKEMIA. JOURNAL OF CLINICAL ONCOLOGY : OFFICIAL JOURNAL OF THE AMERICAN SOCIETY OF CLINICAL ONCOLOGY 31, 2428-2436, DOI:10.1200/JCO.2012.47.3314 (2013).

GROSSMANN, V. ET AL. MOLECULAR PROFILING OF CHRONIC MYELOMONOCYTIC LEUKEMIA REVEALS DIVERSE MUTATIONS IN $>80 \%$ OF PATIENTS WITH TET2 AND EZH2 BEING OF HIGH PROGNOSTIC RELEVANCE. LEUKEMIA 25, 877-879, DOI:10.1038/LEU.2011.10 (2011). 
91 NIBOUREL, O. ET AL. INCIDENCE AND PROGNOSTIC VALUE OF TET2 ALTERATIONS IN DE NOVO ACUTE MYELOID LEUKEMIA ACHIEVING COMPLETE REMISSION. BLOOD 116, 1132-1135, DOI:10.1182/BLOOD2009-07-234484 (2010).

92 KONSTANDIN, N. ET AL. GENOMIC 5-HYDROXYMETHYLCYTOSINE LEVELS CORRELATE WITH TET2 MUTATIONS AND A DISTINCT GLOBAL GENE EXPRESSION PATTERN IN SECONDARY ACUTE MYELOID LEUKEMIA. LEUKEMIA 25, 1649-1652, DOI:10.1038/LEU.2011.134 (2011).

93 FIGUEROA, M. E. ET AL. LEUKEMIC IDH1 AND IDH2 MUTATIONS RESULT IN A HYPERMETHYLATION PHENOTYPE, DISRUPT TET2 FUNCTION, AND IMPAIR HEMATOPOIETIC DIFFERENTIATION. CANCER CELL 18, 553-567, DOI:10.1016/J.CCR.2010.11.015 (2010).

94 LANGEMEIJER, S. M. ET AL. ACQUIRED MUTATIONS IN TET2 ARE COMMON IN MYELODYSPLASTIC SYNDROMES. NATURE GENETICS 41, 838-842, DOI:10.1038/NG.391 (2009).

95 DELHOMMEAU, F. ET AL. MUTATION IN TET2 IN MYELOID CANCERS. THE NEW ENGLAND JOURNAL OF MEDICINE 360, 2289-2301, DOI:10.1056/NEJMOA0810069 (2009).

96 BEJAR, R. ET AL. CLINICAL EFFECT OF POINT MUTATIONS IN MYELODYSPLASTIC SYNDROMES. THE NEW ENGLAND JOURNAL OF MEDICINE 364, 2496-2506, DOI:10.1056/NEJMOA1013343 (2011).

97 LIU, W. J. ET AL. PROGNOSTIC SIGNIFICANCE OF TET METHYLCYTOSINE DIOXYGENASE 2 (TET2) GENE MUTATIONS IN ADULT PATIENTS WITH ACUTE MYELOID LEUKEMIA: A METAANALYSIS. LEUKEMIA \& LYMPHOMA, DOI:10.3109/10428194.2014.893308 (2014).

98 ODEJIDE, O. ET AL. A TARGETED MUTATIONAL LANDSCAPE OF ANGIOIMMUNOBLASTIC T-CELL LYMPHOMA. BLOOD 123, 1293-1296, DOI:10.1182/BLOOD-2013-10-531509 (2014). 
99 SAKATA-YANAGIMOTO, M. ET AL. SOMATIC RHOA MUTATION IN ANGIOIMMUNOBLASTIC T CELL LYMPHOMA. NATURE GENETICS 46, 171-175, DOI:10.1038/NG.2872 (2014).

100 LEMONNIER, F. ET AL. RECURRENT TET2 MUTATIONS IN PERIPHERAL T-CELL LYMPHOMAS CORRELATE WITH TFH-LIKE FEATURES AND ADVERSE CLINICAL PARAMETERS. BLOOD 120, 1466-1469, DOI:10.1182/BLOOD-2012-02-408542 (2012).

101 PAPAEMMANUIL, E. ET AL. CLINICAL AND BIOLOGICAL IMPLICATIONS OF DRIVER MUTATIONS IN MYELODYSPLASTIC SYNDROMES. BLOOD 122, 3616-3627; QUIZ 3699, DOI:10.1182/BLOOD2013-08-518886 (2013).

102 HAFERLACH, T. ET AL. LANDSCAPE OF GENETIC LESIONS IN 944 PATIENTS WITH MYELODYSPLASTIC SYNDROMES. LEUKEMIA 28, 241 247, DOI:10.1038/LEU.2013.336 (2014).

103 BUSQUE, L. ET AL. RECURRENT SOMATIC TET2 MUTATIONS IN NORMAL ELDERLY INDIVIDUALS WITH CLONAL HEMATOPOIESIS. NATURE GENETICS 44, 1179-1181, DOI:10.1038/NG.2413 (2012).

104 MUTO, T. ET AL. CONCURRENT LOSS OF EZH2 AND TET2 COOPERATES IN THE PATHOGENESIS OF MYELODYSPLASTIC DISORDERS. THE JOURNAL OF EXPERIMENTAL MEDICINE 210, 26272639, DOI:10.1084/JEM.20131144 (2013).

105 ABDEL-WAHAB, O. ET AL. DELETION OF ASXL1 RESULTS IN MYELODYSPLASIA AND SEVERE DEVELOPMENTAL DEFECTS IN VIVO. THE JOURNAL OF EXPERIMENTAL MEDICINE 210, 2641-2659, DOI:10.1084/JEM.20131141 (2013).

106 YOSHIDA, K. ET AL. FREQUENT PATHWAY MUTATIONS OF SPLICING MACHINERY IN MYELODYSPLASIA. NATURE 478, 64-69, DOI:10.1038/NATURE10496 (2011). 
107 SIMON, J. A. \& KINGSTON, R. E. OCCUPYING CHROMATIN: POLYCOMB MECHANISMS FOR GETTING TO GENOMIC TARGETS, STOPPING TRANSCRIPTIONAL TRAFFIC, AND STAYING PUT. MOLECULAR CELL 49, 808-824, DOI:10.1016/J.MOLCEL.2013.02.013 (2013).

108 SESHAGIRI, S. ET AL. RECURRENT R-SPONDIN FUSIONS IN COLON CANCER. NATURE 488, 660-664, DOI:10.1038/NATURE11282 (2012).

109 SATO, Y. ET AL. INTEGRATED MOLECULAR ANALYSIS OF CLEARCELL RENAL CELL CARCINOMA. NATURE GENETICS 45, 860-867, DOI:10.1038/NG.2699 (2013).

110 NICKERSON, M. L. ET AL. SOMATIC ALTERATIONS CONTRIBUTING TO METASTASIS OF A CASTRATION-RESISTANT PROSTATE CANCER. HUMAN MUTATION 34, 1231-1241, DOI:10.1002/HUMU.22346 (2013).

111 YAO, B. \& JIN, P. UNLOCKING EPIGENETIC CODES IN NEUROGENESIS. GENES \& DEVELOPMENT 28, 1253-1271, DOI:10.1101/GAD.241547.114 (2014).

112 LI, X. \& JIN, P. ROLES OF SMALL REGULATORY RNAS IN DETERMINING NEURONAL IDENTITY. NATURE REVIEWS. NEUROSCIENCE 11, 329-338, DOI:10.1038/NRN2739 (2010).

113 KRIEGSTEIN, A. \& ALVAREZ-BUYLLA, A. THE GLIAL NATURE OF EMBRYONIC AND ADULT NEURAL STEM CELLS. ANNUAL REVIEW OF NEUROSCIENCE 32, 149-184, DOI:10.1146/ANNUREV.NEURO.051508.135600 (2009).

114 NOCTOR, S. C., MARTINEZ-CERDENO, V., IVIC, L. \& KRIEGSTEIN, A. R. CORTICAL NEURONS ARISE IN SYMMETRIC AND ASYMMETRIC DIVISION ZONES AND MIGRATE THROUGH SPECIFIC PHASES. NATURE NEUROSCIENCE 7, 136-144, DOI:10.1038/NN1172 (2004).

115 MING, G. L. \& SONG, H. ADULT NEUROGENESIS IN THE MAMMALIAN BRAIN: SIGNIFICANT ANSWERS AND SIGNIFICANT QUESTIONS. NEURON 70, 687-702, DOI:10.1016/J.NEURON.2011.05.001 (2011). 
116 SUH, H., DENG, W. \& GAGE, F. H. SIGNALING IN ADULT NEUROGENESIS. ANNUAL REVIEW OF CELL AND DEVELOPMENTAL BIOLOGY 25, 253-275, DOI:10.1146/ANNUREV.CELLBIO.042308.113256 (2009).

117 GUO, J. U., SU, Y., ZHONG, C., MING, G. L. \& SONG, H. HYDROXYLATION OF 5-METHYLCYTOSINE BY TET1 PROMOTES ACTIVE DNA DEMETHYLATION IN THE ADULT BRAIN. CELL 145, 423434, DOI:10.1016/J.CELL.2011.03.022 (2011).

118 SZULWACH, K. E. ET AL. 5-HMC-MEDIATED EPIGENETIC DYNAMICS DURING POSTNATAL NEURODEVELOPMENT AND AGING. NATURE NEUROSCIENCE 14, 1607-1616, DOI:10.1038/NN.2959 (2011).

119 MELLEN, M., AYATA, P., DEWELL, S., KRIAUCIONIS, S. \& HEINTZ, N. MECP2 BINDS TO 5HMC ENRICHED WITHIN ACTIVE GENES AND ACCESSIBLE CHROMATIN IN THE NERVOUS SYSTEM. CELL 151, 14171430, DOI:10.1016/J.CELL.2012.11.022 (2012).

120 CHENG, Y., BERNSTEIN, A., CHEN, D. \& JIN, P. 5HYDROXYMETHYLCYTOSINE: A NEW PLAYER IN BRAIN DISORDERS? EXPERIMENTAL NEUROLOGY, DOI:10.1016/J.EXPNEUROL.2014.05.008 (2014).

121 ZHANG, R. R. ET AL. TET1 REGULATES ADULT HIPPOCAMPAL NEUROGENESIS AND COGNITION. CELL STEM CELL 13, 237-245, DOI:10.1016/J.STEM.2013.05.006 (2013).

122 MAKISHIMA, H. ET AL. SOMATIC SETBP1 MUTATIONS IN MYELOID MALIGNANCIES. NATURE GENETICS 45, 942-946, DOI:10.1038/NG.2696 (2013).

123 SOLARY, E., BERNARD, O. A., TEFFERI, A., FUKS, F. \& VAINCHENKER, W. THE TEN-ELEVEN TRANSLOCATION-2 (TET2) GENE IN HEMATOPOIESIS AND HEMATOPOIETIC DISEASES. LEUKEMIA 28, 485496, DOI:10.1038/LEU.2013.337 (2014). 
124 SHEN, L. ET AL. GENOME-WIDE ANALYSIS REVEALS TET- AND TDGDEPENDENT 5-METHYLCYTOSINE OXIDATION DYNAMICS. CELL 153, 692-706, DOI:10.1016/J.CELL.2013.04.002 (2013).

125 YILDIRIM, O. ET AL. MBD3/NURD COMPLEX REGULATES EXPRESSION OF 5-HYDROXYMETHYLCYTOSINE MARKED GENES IN EMBRYONIC STEM CELLS. CELL 147, 1498-1510, DOI:10.1016/J.CELL.2011.11.054 (2011).

126 CHEN, Q., CHEN, Y., BIAN, C., FUJIKI, R. \& YU, X. TET2 PROMOTES HISTONE O-GLCNACYLATION DURING GENE TRANSCRIPTION. NATURE 493, 561-564, DOI:10.1038/NATURE11742 (2013).

127 GUILHAMON, P. ET AL. META-ANALYSIS OF IDH-MUTANT CANCERS IDENTIFIES EBF1 AS AN INTERACTION PARTNER FOR TET2. NATURE COMMUNICATIONS 4, 2166, DOI:10.1038/NCOMMS3166 (2013).

128 COSTA, Y. ET AL. NANOG-DEPENDENT FUNCTION OF TET1 AND TET2 IN ESTABLISHMENT OF PLURIPOTENCY. NATURE 495, 370-374, DOI:10.1038/NATURE11925 (2013).

129 LI, F. ET AL. THE HISTONE MARK H3K36ME3 REGULATES HUMAN DNA MISMATCH REPAIR THROUGH ITS INTERACTION WITH MUTSALPHA. CELL 153, 590-600, DOI:10.1016/J.CELL.2013.03.025 (2013).

130 AIFANTIS, I., RAETZ, E. \& BUONAMICI, S. MOLECULAR PATHOGENESIS OF T-CELL LEUKAEMIA AND LYMPHOMA. NATURE REVIEWS. IMMUNOLOGY 8, 380-390, DOI:10.1038/NRI2304 (2008).

131 WENG, A. P. ET AL. ACTIVATING MUTATIONS OF NOTCH1 IN HUMAN T CELL ACUTE LYMPHOBLASTIC LEUKEMIA. SCIENCE 306, 269-271, DOI:10.1126/SCIENCE.1102160 (2004).

132 MARSISCHKY, G. T., FILOSI, N., KANE, M. F. \& KOLODNER, R. REDUNDANCY OF SACCHAROMYCES CEREVISIAE MSH3 AND MSH6 IN MSH2-DEPENDENT MISMATCH REPAIR. GENES \& DEVELOPMENT 10, 407-420 (1996). 
133 CASORELLI, I., BOSSA, C. \& BIGNAMI, M. DNA DAMAGE AND REPAIR IN HUMAN CANCER: MOLECULAR MECHANISMS AND CONTRIBUTION TO THERAPY-RELATED LEUKEMIAS. INTERNATIONAL JOURNAL OF ENVIRONMENTAL RESEARCH AND PUBLIC HEALTH 9, 2636-2657, DOI:10.3390/IJERPH9082636 (2012).

134 CHAN, S. M. \& MAJETI, R. ROLE OF DNMT3A, TET2, AND IDH1/2 MUTATIONS IN PRE-LEUKEMIC STEM CELLS IN ACUTE MYELOID LEUKEMIA. INTERNATIONAL JOURNAL OF HEMATOLOGY 98, 648-657, DOI:10.1007/S12185-013-1407-8 (2013).

135 KUNKEL, T. A. \& ERIE, D. A. DNA MISMATCH REPAIR. ANNUAL REVIEW OF BIOCHEMISTRY 74, 681-710, DOI:10.1146/ANNUREV.BIOCHEM.74.082803.133243 (2005).

136 LI, G. M. MECHANISMS AND FUNCTIONS OF DNA MISMATCH REPAIR. CELL RESEARCH 18, 85-98, DOI:10.1038/CR.2007.115 (2008).

137 RIDEOUT, W. M., 3RD, COETZEE, G. A., OLUMI, A. F. \& JONES, P. A. 5METHYLCYTOSINE AS AN ENDOGENOUS MUTAGEN IN THE HUMAN LDL RECEPTOR AND P53 GENES. SCIENCE 249, 1288-1290 (1990).

138 MA, D. K. ET AL. EPIGENETIC CHOREOGRAPHERS OF NEUROGENESIS IN THE ADULT MAMMALIAN BRAIN. NATURE NEUROSCIENCE 13, 13381344, DOI:10.1038/NN.2672 (2010).

139 COPPIETERS, N. ET AL. GLOBAL CHANGES IN DNA METHYLATION AND HYDROXYMETHYLATION IN ALZHEIMER'S DISEASE HUMAN BRAIN. NEUROBIOLOGY OF AGING 35, 1334-1344, DOI:10.1016/J.NEUROBIOLAGING.2013.11.031 (2014).

140 ZHUBI, A. ET AL. INCREASED BINDING OF MECP2 TO THE GAD1 AND RELN PROMOTERS MAY BE MEDIATED BY AN ENRICHMENT OF 5HMC IN AUTISM SPECTRUM DISORDER (ASD) CEREBELLUM. TRANSLATIONAL PSYCHIATRY 4, E349, DOI:10.1038/TP.2013.123 (2014).

141 LI, X. ET AL. EPIGENETIC REGULATION OF THE STEM CELL MITOGEN FGF-2 BY MBD1 IN ADULT NEURAL STEM/PROGENITOR CELLS. J BIOL CHEM 283, 27644-27652, DOI:10.1074/JBC.M804899200 (2008). 
142 CHEN, W. G. ET AL. DEREPRESSION OF BDNF TRANSCRIPTION INVOLVES CALCIUM-DEPENDENT PHOSPHORYLATION OF MECP2. SCIENCE 302, 885-889, DOI:10.1126/SCIENCE.1086446 (2003).

143 SZWAGIERCZAK, A., BULTMANN, S., SCHMIDT, C. S., SPADA, F. \& LEONHARDT, H. SENSITIVE ENZYMATIC QUANTIFICATION OF 5HYDROXYMETHYLCYTOSINE IN GENOMIC DNA. NUCLEIC ACIDS RES 38, E181, DOI:10.1093/NAR/GKQ684 (2010). 
VITA

FENG PAN

Born, Haerbin, China

2000-2004

B.S., Biological Sciences

Jilin University

Changchun, China

2004-2007

M.S., Biochemistry and Molecular biology

Jilin University

Changchun, China

\section{PUBLICATIONS AND PRESENTATIONS}

Pan F, et al. TET2 protects genome stability through interacting with MSH6. Under revision.

Pan F, Xu M. Novel role of Tet2 in DNA-mismatch repair through interaction with MSH6, which is critical for Tet2 loss-mediated hematologic malignancies. Tenth international workshop on molecular aspects of myeloid stem cell development and leukemia. May, 2014.

Wang J, Li Z, He Y, Pan F, Chen S, et al. Loss of Asxl1 leads to myelodysplastic syndrome-like disease in mice. Blood. 2014 Jan 23;123(4):541-53.

Pan F, Xu M. Tet2 plays an important role in controlling genomic instability via NONO complex. Cancer Research Day at Indiana University School of Medicine. May, 2013.

Pan F, Weeks O, Xu M. Role of Tet2 in T Cell Lymphomagenesis. 15 ${ }^{\text {th }}$ Annual Biology Research Symposium at Florida International University. Feb, 2013.

Sheng Y, Jiang D, Li S, Zeng Z, Peng W, Pan F, Sun Y, Zhang J. RNAzyme-DNAzyme. 9th Ordinary General assembly and Congress of CSBMB, 2005.

Teng L, Meng Q, Pan F, Li R, et al. Preparation and identification of specific polyclonal antibody of IFN- $\alpha 2$ b. Chinese Journal of Immunology.2005,21(3):215. 